\title{
Reproductive options for couples at risk of Huntingsdon's disease
}

Citation for published version (APA):

van Rij, M. C. (2013). Reproductive options for couples at risk of Huntingsdon's disease. [Doctoral Thesis, Maastricht University]. Maastricht University. https://doi.org/10.26481/dis.20130613mr

Document status and date:

Published: 01/01/2013

DOI:

10.26481/dis.20130613mr

Document Version:

Publisher's PDF, also known as Version of record

\section{Please check the document version of this publication:}

- A submitted manuscript is the version of the article upon submission and before peer-review. There can be important differences between the submitted version and the official published version of record.

People interested in the research are advised to contact the author for the final version of the publication, or visit the DOI to the publisher's website.

- The final author version and the galley proof are versions of the publication after peer review.

- The final published version features the final layout of the paper including the volume, issue and page numbers.

Link to publication

\footnotetext{
General rights rights.

- You may freely distribute the URL identifying the publication in the public portal. please follow below link for the End User Agreement:

www.umlib.nl/taverne-license

Take down policy

If you believe that this document breaches copyright please contact us at:

repository@maastrichtuniversity.nl

providing details and we will investigate your claim.
}

Copyright and moral rights for the publications made accessible in the public portal are retained by the authors and/or other copyright owners and it is a condition of accessing publications that users recognise and abide by the legal requirements associated with these

- Users may download and print one copy of any publication from the public portal for the purpose of private study or research.

- You may not further distribute the material or use it for any profit-making activity or commercial gain

If the publication is distributed under the terms of Article $25 \mathrm{fa}$ of the Dutch Copyright Act, indicated by the "Taverne" license above, 


\section{Reproductive options for couples at risk of \\ Huntington's disease}




\section{$\sqrt{2}$ MIX \\ FSC responslble sources \\ FSC ${ }^{\star} 112051$}

ISBN

978-94-6191-696-9

Copyright

Cover art \& photography Ivon Drummen

Lay-out \& coverdesign Maartje van Rij

Printing

Ipskamp Drukkers

Publication of this thesis was supported by the department of clinical genetics and neurology in the LUMC, the Vereniging van Huntington and TOPAZ. 


\title{
Reproductive options for couples at risk of Huntington's disease
}

\author{
PROEFSCHRIFT
}

\author{
ter verkrijging van de graad \\ van doctor aan de Universiteit Maastricht, \\ op gezag van de Rector Magnificus, \\ Prof. dr. L.L.G. Soete \\ volgens het besluit van het \\ College van Decanen, \\ in het openbaar te verdedigen op \\ donderdag \\ 13 juni 2013 om 16.00 uur
}

door

Maartje Cornelia van Rij 


\section{Promotores}

Prof. dr. C.E.M. de Die-Smulders

Prof. dr. R.A.C. Roos, LUMC

Prof. dr. J.P.M. Geraedts

\section{Copromotor}

Dr. E.K. Bijlsma, LUMC

\section{Beoordelingscommissie}

Prof. dr. M. Spaanderman, voorzitter

Dr. C.G. Faber

Prof. dr. V.V.A.Knoers, UMCU

Prof. dr. H.A.M. Middelkoop, LUMC

Prof. dr. Y. Temel 


\section{Contents}

Chapter 1 Introduction

Chapter 2 Prenatal testing for Huntington's disease in The Netherlands from 1998 to 2008

Chapter 3 Preimplantation genetic diagnosis for Huntington's disease: the experience of three European centres

Chapter 4 The uptake and outcome of prenatal and preimplantation genetic diagnosis for Huntington's disease in the Netherlands (1998-2008)

Chapter 5 Profiles and motives for PGD: a prospective cohort study of couples referred for PGD in the Netherlands

Chapter 6 Evaluation of exclusion prenatal and exclusion preimplantation genetic diagnosis for Huntington's disease in the Netherlands

Chapter 7 Discussion

Summary

Samenvatting

Co-authors and affiliations

List of publications

Dankwoord 

Chapter 1

Introduction 



\section{GENERAL INTRODUCTION}

Huntington's disease (HD) is a severe late-onset autosomal dominant neurodegenerative disorder ${ }^{1}$. HD was first described by George Huntington in $1872^{2}$. After more than a century the HD gene was localised ${ }^{3}$ and it took another decade until the HD causing genetic defect in the HTT gene was identified in $1993^{4}$. Much has been learned about the disease's pathogenesis since then. Despite all efforts, experimental studies have not yet resulted in preventive or delaying interventions, let alone the discovery of a cure ${ }^{5-7}$.

HD was the first autosomal dominant late-onset disease for which presymptomatic testing became available, enabling at-risk individuals to decide "whether or not to know their genetic status" 8,9 . International guidelines were developed to provide a structured predictive testing programme ${ }^{10}$ which was used as a model for testing programmes for other late onset inherited diseases ${ }^{9}$.

The incurability and moral issues such as the disclosure of information to children and other relatives, as well as consequences for future offspring are of importance in decisions regarding presymptomatic testing ${ }^{11-14}$.

Prenatal diagnosis and preimplantation genetic diagnosis are reproductive options for at-risk couples who want to prevent the birth of a child with a mutation causing HD. Direct mutation testing as well as the more controversial exclusion testing are the methods applied. Reproductive options for $50 \%$ atrisk individuals or carriers of an HD causing mutation vary between countries, due to differences in legislation and ethical, moral or religious considerations.

\section{Clinical and genetic perspectives of Huntington's disease}

\section{Clinical presentation}

The main symptoms and signs of Huntington's disease (HD) consist of motor, cognitive and psychiatric disturbances. $\mathrm{HD}$ is characterized by late onset between the ages of 30 and 50 years, with a range of 2 to 85 years ${ }^{15}$. Preclinically, patients may have subtle and otherwise undetected changes in motor skills, cognition and personality ${ }^{16}$. Progression leads to an increased dependency. Death occurs on average 17-20 years after diagnosis, most 
frequently due to pneumonia, the second most frequent cause of death is suicide ${ }^{17,18}$.

The characteristic choreatic movements are present in over $90 \%$ of individuals during waking hours. These involuntary movements primarily occur in the distal extremities and gradually spread to more proximal and axial muscles, until all muscles are involved. Walking instability and dysarthria may make a patient appear to be drunk. Dysphagia may result in choking or asphyxia ${ }^{15}$.

Psychiatric signs occur in $33 \%$ to $76 \%$ of patients ${ }^{19}$, usually with a considerable impact on functioning and on family members ${ }^{20}$. Depression, the most common sign, may be of pathological rather than psychological origin ${ }^{21}$. Suicide is quite common, especially in the period around the genetic test and when independence diminishes ${ }^{17,18,22,23}$. Anxiety, personality changes, obsessions and compulsions can disturb the patient's life, and can also lead to irritability and aggression. Irritability, varying from disputation to physical aggression, is often the very first $\operatorname{sign}^{19}$. Affective and schizophrenic psychosis may be observed $^{15,24}$, whereas hypersexual behaviour may be present in the early stages of the disease.

Cognitive decline, which can occur long before the first motor symptoms ${ }^{25-27}$, is characterized by loss of executive functions, problems with mental adjustment, and memory loss. All psychomotor processes become severely retarded ${ }^{1}$. Language is relatively preserved.

Unintended weight loss occurs, possibly as a result of decreased appetite, difficulties in handling food and dysphagia. Additionally, hypothalamic neuronal loss ${ }^{28,29}$ and a relatively higher number of CAG-repeats seem to be associated with weight loss ${ }^{30,31}$. Sleep and circadian rhythm disturbances are now under investigation ${ }^{32,33}$.

\section{Genetics and inheritance}

Huntington's disease is caused by an autosomal dominantly inherited mutation in the Huntingtin (HTT) gene. This gene is located on the short arm of chromosome $4 \mathrm{p} 16.3$ and codes for the protein huntingtin ${ }^{4}$. Exon 1 of the normal or 'wild-type' gene contains a CAG repeat coding for a polyglutamine stretch in the protein, ranging from 6 to 26 trinucleotides. HD is associated with 36 CAG repeats or more. Definite clinical manifestation will occur if the number of repeats exceeds 39 . Incomplete penetrance or late onset occurs from 36 to 39 repeats. A repeat length between 27 and 35, the so-called intermediate allele, is generally not associated with symptoms of HD, but (like 
any repeat size larger then 26) may be unstable when passed on to offspring. If changes in the repeat size do occur during meiosis, they most frequently lead to elongation, although shortening does occur occasionally. This may result in expansions within the incomplete penetrance or, incidentally, into the full penetrance range ${ }^{34,35}$. This phenomenon is called anticipation and is mainly observed in the paternal line of inheritance ${ }^{36}$. Juvenile Huntington's disease (JHD), with an onset before the age of 20 years, mostly occurs with a CAG repeat length of over $55^{20}$.

The length of the repeat determines about $70 \%$ of the variance in age at onset and is not associated with a specific form of presentation ${ }^{37-39}$. Relatively more progressive cognitive and motor deterioration appears to be associated with a longer CAG repeat ${ }^{40,41}$. The progression of behavioural symptoms seems not to be related to repeat size ${ }^{42}$. The existence of a modifying effect of the CAG repeat length of the normal HTT allele on disease severity remains under debate ${ }^{41,43,44}$.

\section{Epidemiology}

The prevalence of HD varies from 5 to 10 per 100,000 in the Caucasian population. In Japan, a prevalence of about one-tenth of the Caucasian population is described ${ }^{1}$. HD also appears less frequent in China, Finland, and among black Africans. The prevalence of HD exceeds 15 per 100,000 in some populations, mostly of western European origin ${ }^{1}$. The true prevalence of HD may be higher ${ }^{45,46}$. Intermediate HTT alleles are found in approximately $1 \%-6 \%$ of individuals in some populations ${ }^{34,47,48}$.

\section{Pathogenesis and therapy}

The wild-type Huntingtin protein is involved in synaptic function, and is expressed in the post-embryonic period. It may have an anti-apoptotic effect and play a protective role against the toxic mutant, huntingtin ${ }^{49}$. The role of the mutation has been studied in many cells and organisms, mice models being the most commonly used. Neuronal intranuclear and intracytoplasmic inclusions are found in many areas of the brain, but the exact mechanism is still not clear. They might be pathogenic in themselves, or only as a side-product. The overall pathology, brain atrophy, particularly in the striatum with extensive neuronal loss, is well known ${ }^{50,51}$. Significant atrophic changes in the brain have even been detected prior to any clinical manifestation of $\mathrm{HD}^{27,52}$. 


\section{Reproductive options for couples at risk of transmitting HD to offspring}

The autosomal dominant inheritance of HD implies a 50\% risk for each child of an HD patient or asymptomatic carrier of a CAG repeat expansion to inherit the abnormal HD gene. At-risk individuals or HD mutation carriers historically have a variety of reproductive options. They can accept or take the risk of transmitting HD to their offspring, or they can decide not to have children. Otherwise, transmission of HD can be avoided by using donor gametes or by adopting a child. Sperm donation is relatively easy to apply, either assisted by a fertility clinic or by the use of self-fertilisation kits. The number of available sperm donors has recently decreased, however, perhaps as a result of new regulations involving decreased privacy for sperm donors ${ }^{53}$. In the Netherlands, oocyte donation used to be limited to couples who had found their own donors, but since the introduction of an oocyte bank in the Utrecht University Medical Centre (April 2012), this form of donation may become more widely available in the near future. Adoption through official Dutch adoption institutions is limited to couples with a normal life expectancy, and is therefore no option for couples at risk of HD.

The discovery of the HTT gene created reproductive options for couples at risk to prevent HD in their own biological children. The reproductive options depend on the willingness of the at-risk person to find out his or her HD carrier status. The two most likely options, both requiring medical assistance, are prenatal diagnosis and preimplantation genetic diagnosis. The selection most frequently involves the direct detection of the CAG expansion. However, if the at-risk person does not want to know his/her genetic status, the HD risk may be excluded indirectly by an exclusion test.

\section{Prenatal diagnosis}

In prenatal diagnosis (PND), placental DNA material identical to the foetal DNA is tested for HD. The DNA is obtained by a chorionic villus (placental) biopsy, at around 11-12 weeks of gestational age. Amniocentesis can be carried out from 15 weeks of pregnancy by collecting amniotic fluid. In both cases DNA will be isolated and the result is available after 2 to 3 weeks. A chorionic villus biopsy involves a miscarriage risk, depending on the method and the hospital, of about $1 \%$, while about $0.5 \%$ of amniocenteses result in miscarriages ${ }^{54-56}$. After an unfavourable test result, the couple are expected to terminate the pregnancy, in accordance with what has been discussed during pre-test counselling. 


\section{Preimplantation genetic diagnosis}

Preimplantation genetic diagnosis (PGD) starts with IVF treatment to stimulate the ovaries to grow at least 4 follicles ${ }^{57,58}$. After about 14 days, the oocytes are collected by aspiration of the follicles. Fertilisation of the oocytes takes place via intracytoplasmic sperm injection, in order to avoid contamination with adhesive spermatozoa. After 5 days some of the fertilised oocytes will have developed into embryos consisting of about 8 cells. From each embryo one cell is biopted, representing the DNA of the future child. This blastomere will be used for DNA analyses and will be either directly tested for CAG expansion or indirectly using an exclusion test. A day later, the PGD test result enables the non-HD embryos to be distinguished from the HD expansion carrier embryos in order to select an HD-free embryo for transfer. A disadvantage of PGD is the limited success rate (about 20\% take-home baby rate) per started cycle ${ }^{59}$. What should also be considered are the invasiveness of the PGD procedure and the risk of complications of the IVF treatment to the mother, as well as possible/unknown risks for the future child ${ }^{60}$.

The major advantage, however, is the chance to avoid a pregnancy termination, which can also be considered a fairly invasive procedure.

\section{Single cell DNA analyses used in PGD}

PGD requires a preparation time of some weeks, when both HTT-alleles of both partners are tested for the CAG repeat length. To improve reliability, marker testing was added to the PGD test, requiring family members from both sides of the family to participate. This way the segregation of flanking markers can help to identify the embryos free from $\mathrm{HD}^{58,61,62}$.

\section{Exclusion-testing PND or PGD}

For at-risk individuals who do not want to be informed of their HD status, exclusion testing may be an option. Marker testing using DNA of the future or would-be parents is used to distinguish the HD alleles derived from different grandparents, without information being disclosed about the CAG repeats (Figure 1). In the exclusion test the origin of the HD alleles in a blastomere or foetal DNA is identified. An embryo or foetus which has inherited one of the $\mathrm{HD}$ alleles from an affected grandparent has an HD risk of $50 \%$, identical to the at-risk parent. In this case, the embryo will be discarded or the pregnancy will be terminated. Detection of the HD alleles of the healthy grandparent is associated with a low HD risk, which makes the embryo eligible for transfer or 
allows the pregnancy to be continued. Internationally, the use of exclusion testing is rather controversial, since $50 \%$ of the discarded embryos or terminated pregnancies will in fact not be at risk of developing HD.

In the Netherlands, prenatal exclusion testing has been available since 1987. Exclusion PGD is not allowed in the Netherlands for two reasons. First, the discarded embryos have a $50 \%$ chance of being free from HD. Second, $50 \%$ of women using exclusion PGD are in fact 'unnecessarily' exposed to the side effects and risks involved with IVF/ICSI and embryo biopsy needed for PGD, because the at-risk partner is not actually carrying a mutation causing HD.

Figure 1. Exclusion testing illustrating HTT alleles related to the $50 \%$ HD risk

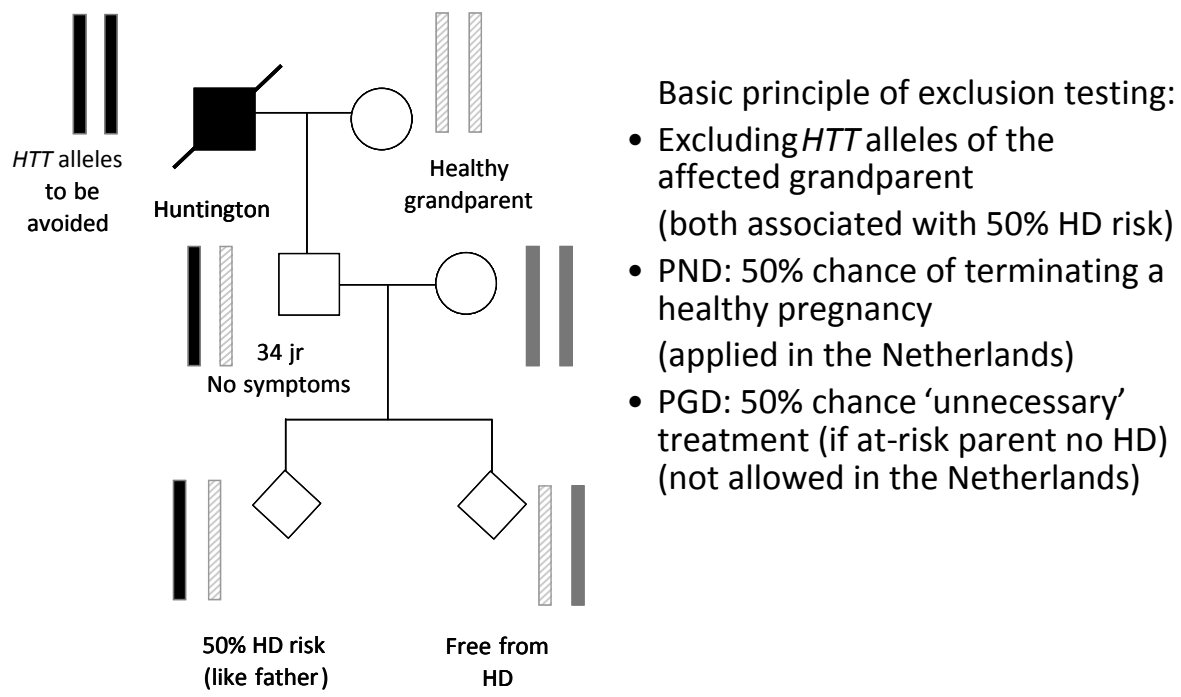

\section{Setting}

In the Netherlands, Leiden University Medical Centre (LUMC) is historically the centre of HD expertise in the fields of Neurology, Pathology, Psychology, Molecular Genetics, and Clinical Genetics. The Laboratory for Diagnostic Genome Analyses LUMC is the national diagnostics centre for DNA analyses for HD. Since the first marker analyses became available in 1983, it has been possible to offer HD families predictive testing. For carriers of the HD causing 
mutation and persons at 50\% risk, prenatal diagnosis for HD has been available in the Netherlands since $1987^{63}$.

In 1995, the Maastricht University Medical Centre (MUMC+) started preimplantation genetic diagnosis (PGD). The MUMC+ is still the only licensed centre for PGD in the Netherlands. PGD for HD has been available since 1998 and in 1999 the first PGD cycle for HD was performed. Initially, it was decided by the Maastricht PGD centre to offer only direct testing ${ }^{64}$. Since 2006, PGD exclusion testing for HD has been prohibited by law ${ }^{65}$. Couples requesting exclusion testing can be referred to the PGD centre in Brussels. More recently, transport IVF/PGD has been established with the University Medical centres in Utrecht, Groningen and Amsterdam. All PGD analyses are centrally performed in Maastricht. Furthermore, Maastricht is one of the main centres in the Netherlands offering PND for HD by direct or exclusion testing.

There is a long tradition of clinical collaboration in the field of HD between the University Medical centres in Leiden and Maastricht. The research underlying this thesis began in Maastricht in 2009 and was continued from 2011 in Leiden and Maastricht.

This thesis represents the first combined scientific output and provides the unique opportunity of displaying results and expertise from both centres.

\section{Aims of this thesis}

We aimed to study the reproductive behaviour of couples at risk of transmitting HD to their offspring in the Netherlands. The specific aims were:

- To study the use of PND for HD over the years and to study the development of its use since the first application of PND for HD and the introduction of PGD (chapters 2 and 4).

- To find factors contributing to a couple's opting for PGD in the Netherlands. To study the effect of age of onset, disease severity, and other characteristics of the disease on a couple's decision to opt for PGD and to actually start PGD (chapters 4 and 5).

- To study the use of PND and PGD for HD in the Netherlands, to define differences between couples opting for PND or PGD and to find factors contributing to a shift from one option to the other (chapter 4).

- To compare the use of PGD for HD in PGD centres in three western European countries. To study differences in requests for exclusion and 
direct testing PGD and differences in legislation between Belgium, France and the Netherlands (chapter 3).

- To explore the motives and experiences of Dutch couples opting for exclusion testing for HD using PND and or PGD, and to reflect on their choices (chapter 6).

\section{References}

1. Bates G, Harper P, Jones L (eds): Huntington's Disease. Oxford University Press, New York, 2002.

2. Huntington G: On chorea. The Medical and Surgical Reporter: A Weekly Journal (Philadelphia: SW Butler) 1872; 26 317-321.

3. Gusella JF, Wexler NS, Conneally PM et al: A polymorphic DNA marker genetically linked to Huntington's disease. Nature 1983; 306: 234-238.

4. Huntington's Disease Collaborative Research Group: A novel gene containing a trinucleotide repeat that is expanded and unstable on Huntington's disease chromosomes. Cell 1993; 72: 971-983.

5. Yamamoto A, Lucas JJ, Hen R: Reversal of neuropathology and motor dysfunction in a conditional model of Huntington's disease. Cell 2000; 101: 57-66.

6. Ross CA, Tabrizi SJ: Huntington's disease: from molecular pathogenesis to clinical treatment. The Lancet Neurology 2011; 10: 83-98.

7. Novak MJ, Tabrizi SJ: Huntington's disease: clinical presentation and treatment. International Review of Neurobiology 2011; 98: 297-323.

8. Macleod R, Tibben A, Frontali $M$ et al: Recommendations for the Predictive Genetic Test in Huntington's Disease. Clinical Genetics 2013; 83(3):221-31.

9. Maat-Kievit A: Predictive testing for Huntington disease. Doctoral thesis, Leiden University, 2001.

10. IHA-WFN: International Huntington Association and the World Federation of Neurology Research Group on Huntington's Chorea. Guidelines for the molecular genetics predictive test in Huntington's disease. Journal of Medical Genetics 1994; 31: 555-559.

11. Hayden MR: Predictive testing for Huntington's disease: the calm after the storm. Lancet 2000; 356: 1944-1945.

12. Richards M: Predictive testing for Huntington's disease. Lancet 2001; 357: 883.

13. Quaid KA, Morris M: Reluctance to undergo predictive testing: the case of Huntington disease. American Journal of Medical Genetics 1993; 45: 41-45.

14. Tibben A, Frets PG, van de Kamp JJ et al: Presymptomatic DNA-testing for Huntington disease: pretest attitudes and expectations of applicants and their partners in the Dutch program. American Journal of Medical Genetics 1993; 48: 10-16. 
15. Roos RA: Huntington's disease: a clinical review. Orphanet Journal of Rare Diseases 2010; 5: 40.

16. Walker FO: Huntington's disease. Lancet 2007; 369: 218-228.

17. Paulsen JS, Nehl C, Hoth KF et al: Depression and stages of Huntington's disease. The Journal of Neuropsychiatry and Clinical Neurosciences 2005; 17: 496-502.

18. Marshall J, White $\mathrm{K}$, Weaver $\mathrm{M}$ et al: Specific psychiatric manifestations among preclinical Huntington disease mutation carriers. Archives of neurology 2007; 64: 116121.

19. van Duijn E, Kingma EM, van der Mast RC: Psychopathology in verified Huntington's disease gene carriers. The Journal of neuropsychiatry and clinical neurosciences 2007; 19: 441-448.

20. Wheelock VL, Tempkin T, Marder $\mathrm{K}$ et al: Predictors of nursing home placement in Huntington disease. Neurology 2003; 60: 998-1001.

21. Slaughter JR, Martens MP, Slaughter KA: Depression and Huntington's disease: prevalence, clinical manifestations, etiology, and treatment. CNS spectrums 2001; 6: 306-326.

22. Baliko L, Csala B, Czopf J: Suicide in Hungarian Huntington's disease patients. Neuroepidemiology 2004; 23: 258-260.

23 Paulsen JS, Hoth KF, Nehl C, Stierman L: Critical periods of suicide risk in Huntington's disease. The American journal of psychiatry 2005; 162: 725-731.

24. Rosenblatt A: Neuropsychiatry of Huntington's disease. Dialogues in clinical neuroscience 2007; 9: 191-197.

25. Witjes-Ane MN, Vegter-van der Vlis $M$, van Vugt JP et al: Cognitive and motor functioning in gene carriers for Huntington's disease: a baseline study. The Journal of neuropsychiatry and clinical neurosciences 2003; 15: 7-16.

26. Paulsen JS, Langbehn DR, Stout JC et al: Detection of Huntington's disease decades before diagnosis: the Predict-HD study. Journal of neurology, neurosurgery, and psychiatry 2008; 79: 874-880.

27. Tabrizi SJ, Langbehn DR, Leavitt BR et al: Biological and clinical manifestations of Huntington's disease in the longitudinal TRACK-HD study: cross-sectional analysis of baseline data. Lancet neurology 2009; 8: 791-801.

28. Kremer HP, Roos RA, Dingjan GM, Bots GT, Bruyn GW, Hofman MA: The hypothalamic lateral tuberal nucleus and the characteristics of neuronal loss in Huntington's disease. Neuroscience letters 1991; 132: 101-104.

29. Aziz NA, Swaab DF, Pijl H, Roos RA: Hypothalamic dysfunction and neuroendocrine and metabolic alterations in Huntington's disease: clinical consequences and therapeutic implications. Reviews in the neurosciences 2007; 18: 223-251.

30. Aziz NA, Pijl H, Frolich M, van der Graaf AW, Roelfsema F, Roos RA: Leptin secretion rate increases with higher CAG repeat number in Huntington's disease patients. Clinical endocrinology 2010; 73: 206-211.

31. Aziz NA, van der Burg JM, Landwehrmeyer GB, Brundin P, Stijnen T, Roos RA: Weight loss in Huntington disease increases with higher CAG repeat number. Neurology 2008; 71: 1506-1513. 
32. Morton AJ, Wood NI, Hastings MH, Hurelbrink C, Barker RA, Maywood ES: Disintegration of the sleep-wake cycle and circadian timing in Huntington's disease. The Journal of neuroscience : the official journal of the Society for Neuroscience 2005; 25: 157-163.

33. Arnulf I, Nielsen J, Lohmann E et al: Rapid eye movement sleep disturbances in Huntington disease. Archives of neurology 2008; 65: 482-488.

34. Semaka A, Collins JA, Hayden MR: Unstable familial transmissions of Huntington disease alleles with 27-35 CAG repeats (intermediate alleles). American journal of medical genetics Part B, Neuropsychiatric genetics : the official publication of the International Society of Psychiatric Genetics 2010; 153B: 314-320.

35. Semaka A, Creighton S, Warby S, Hayden MR: Predictive testing for Huntington disease: interpretation and significance of intermediate alleles. Clinical genetics 2006; 70: 283294.

36. Trottier Y, Biancalana V, Mandel JL: Instability of CAG repeats in Huntington's disease: relation to parental transmission and age of onset. Journal of medical genetics 1994; 31: 377-382.

37. Langbehn DR, Brinkman RR, Falush D, Paulsen JS, Hayden MR: A new model for prediction of the age of onset and penetrance for Huntington's disease based on CAG length. Clinical genetics 2004; 65: 267-277.

38. Langbehn DR, Hayden MR, Paulsen JS: CAG-repeat length and the age of onset in Huntington disease (HD): a review and validation study of statistical approaches. American journal of medical genetics Part B, Neuropsychiatric genetics : the official publication of the International Society of Psychiatric Genetics 2010; 153B: 397-408.

39. Wexler NS, Lorimer J, Porter J et al: Venezuelan kindreds reveal that genetic and environmental factors modulate Huntington's disease age of onset. Proceedings of the National Academy of Sciences of the United States of America 2004; 101: 3498-3503.

40. Rosenblatt $\mathrm{A}$, Liang $\mathrm{KY}$, Zhou $\mathrm{H}$ et al: The association of CAG repeat length with clinical progression in Huntington disease. Neurology 2006; 66: 1016-1020.

41. Lee JM, Ramos EM, Lee JH et al: CAG repeat expansion in Huntington disease determines age at onset in a fully dominant fashion. Neurology 2012; 78: 690-695.

42. Ravina B, Romer M, Constantinescu $R$ et al: The relationship between CAG repeat length and clinical progression in Huntington's disease. Movement disorders : official journal of the Movement Disorder Society 2008; 23: 1223-1227.

43. Aziz NA, Jurgens CK, Landwehrmeyer GB et al: Normal and mutant HTT interact to affect clinical severity and progression in Huntington disease. Neurology 2009; 73: 1280-1285.

44. Aziz NA, Roos RA, Gusella JF, Lee JM, Macdonald ME: CAG repeat expansion in Huntington disease determines age at onset in a fully dominant fashion. Neurology 2012; 79: 952-953.

45. Rawlins M: Huntington's disease out of the closet? Lancet 2010; 376: 1372-1373.

46. Spinney L: Uncovering the true prevalence of Huntington's disease. Lancet neurology 2010; 9: 760-761. 
47. Maat-Kievit $\mathrm{A}$, Losekoot $\mathrm{M}$, van den Boer-van den Berg $\mathrm{H}$ et al: New problems in testing for Huntington's disease: the issue of intermediate and reduced penetrance alleles. Journal of medical genetics 2001; 38: E12.

48. Sequeiros J, Ramos EM, Cerqueira J et al: Large normal and reduced penetrance alleles in Huntington disease: instability in families and frequency at the laboratory, at the clinic and in the population. Clinical genetics 2010; 78: 381-387.

49. Rubinsztein DC: Lessons from animal models of Huntington's disease. Trends in genetics: TIG 2002; 18: 202-209.

50. Imarisio S, Carmichael J, Korolchuk V et al: Huntington's disease: from pathology and genetics to potential therapies. The Biochemical journal 2008; 412: 191-209.

51. Vonsattel JP: Huntington disease models and human neuropathology: similarities and differences. Acta neuropathologica 2008; 115: 55-69.

52. Henley SM, Wild EJ, Hobbs NZ et al: Whole-brain atrophy as a measure of progression in premanifest and early Huntington's disease. Movement disorders: official journal of the Movement Disorder Society 2009; 24: 932-936.

53. Wet donorgegevens kunstmatige bevruchting BWBR0013642, 2002.

54. Alfirevic Z, Tabor A: Pregnancy loss rates after midtrimester amniocentesis. Obstetrics and gynecology 2007; 109: 1203-1204; author reply 1204.

55. Wapner RJ, Evans MI, Platt LD: Pregnancy loss rates after midtrimester amniocentesis. Obstetrics and gynecology 2007; 109: 780; author reply 780-781.

56. Smith L: Pregnancy loss rates after midtrimester amniocentesis. Obstetrics and gynecology 2007; 109: 452; author reply 452-453.

57. Edwards RG, Steptoe PC: Induction of follicular growth, ovulation and luteinization in the human ovary. Journal of reproduction and fertility Supplement 1975: 121-163.

58. Sermon K, Goossens V, Seneca $S$ et al: Preimplantation diagnosis for Huntington's disease (HD): clinical application and analysis of the HD expansion in affected embryos. Prenatal diagnosis 1998; 18: 1427-1436.

59. Goossens V, Traeger-Synodinos J, Coonen E et al: ESHRE PGD Consortium data collection XI: cycles from January to December 2008 with pregnancy follow-up to October 2009. Human reproduction (Oxford, England) 2012; 27: 1887-1911.

60. Dupont C, Sifer C: A Review of Outcome Data concerning Children Born following Assisted Reproductive Technologies. ISRN obstetrics and gynecology 2012; Article ID: 405382.

61. Moutou C, Gardes N, Viville S: New tools for preimplantation genetic diagnosis of Huntington's disease and their clinical applications. Euopean Journal of Human Genetetics 2004; 12: 1007-1014.

62. Sermon $\mathrm{K}$, de Rijcke $\mathrm{M}$, Lissens $\mathrm{W}$ et al: Preimplantation genetic diagnosis for Huntington's disease with exclusion testing. Euopean Journal of Human Genetetics 2002; 10: 591-598.

63. Maat-Kievit A, Vegter-van der Vlis $M$, Zoeteweij $M$ et al: Experience in prenatal testing for Huntington's disease in The Netherlands: procedures, results and guidelines (19871997). Prenatal diagnosis 1999; 19: 450-457. 
64. Braude PR, de Wert GM, Evers-Kiebooms G, Pettigrew RA, Geraedts JP: Non-disclosure preimplantation genetic diagnosis for Huntington's disease: practical and ethical dilemmas. Prenatal diagnosis 1998; 18: 1422-1426.

65. Bussemaker M: Regeling preïmplantatie genetische diagnostiek van de staatssecretaris van Volksgezondheid, Welzijn en Sport (Regulations of the State Secretary of Health on the rules concerning PGD). Staatscourant Koninkrijk der Nederlanden 2009; Nr. 42 edn, Vol 42, pp 1-12. 


\section{Chapter 2}

\section{Prenatal testing for Huntington's disease in The Netherlands from 1998 to 2008}

M.C. van Rij

P.A.M. de Koning Gans

C.M. Aalfs

M. Elting

P.F. Ippel

J.A. Maat-Kievit

S. Vermeer

C.C. Verschuuren-Bemelmans

M.J. van Belzen

R.D.M. Belfroid

M. Losekoot

J.P.M. Geraedts

R.A.C. Roos
A. Tibben
C.E.M. de Die-Smulders
E.K. Bijlsma 


\section{Abstract}

This study aims to give an overview of the number of prenatal tests for Huntington's disease (HD), test results, and pregnancy outcomes in the Netherlands between 1998 and 2008 and to compare them with available data from the period 1987-1997.

A total of 126 couples underwent prenatal diagnosis (PND) on 216 foetuses: $185(86 \%)$ direct tests and 31 (14\%) exclusion tests. In 9\% of direct tests the risk for the foetus was $25 \%$. Four at-risk parents $(4 \%)$ carried intermediate alleles. Ninety-one foetuses had CAG expansions $\geq 36$ or $50 \%$ risk haplotypes: $75(82 \%)$ were terminated for HD, 12 (13\%) were carried to term, four pregnancies were miscarried, terminated for other reasons or lost to follow-up. Unaffected pregnancies (122 foetuses), resulted in the birth of 112 children. The estimated uptake of PND was $22 \%$ of CAG expansion carriers ( $\geq 36$ repeats) at reproductive age.

PND was used by two new subgroups: carriers of intermediate alleles, and $50 \%$ at-risk persons opting for a direct prenatal test of the foetus. A significant number of HD expansion or $50 \%$ risk pregnancies were continued. Speculations were made on causative factors contributing to these continuations. Further research on these couples' motives is needed. 


\section{Introduction}

Huntington's disease (HD) is an incurable, autosomal dominantly inherited, neurodegenerative disorder. The disease is characterized by progressive chorea, cognitive impairment and psychiatric disturbances ${ }^{1}$. Onset of symptoms is usually between the ages of 35 and 44 years, and life expectancy at diagnosis is around 20 years. The HD gene was localised on chromosome 4 in 1983 , enabling predictive linkage testing within families ${ }^{2}$. A decade later the HD causing genetic defect, an expanded trinucleotide (CAG) repeat in the HTT gene, was discovered ${ }^{3}$, creating the possibility of performing individual presymptomatic testing (PT) in persons at risk. A CAG repeat size of up to 26 trinucleotides is considered to be normal. Intermediate alleles range from 27 to 35 repeats and are generally not associated with HD symptoms, but the CAG repeat can increase if the allele is transmitted to offspring. Alleles with 36 to 39 CAG repeats are associated with a reduced penetrance and alleles with a repeat size $\geq 40$ are invariably associated with HD.

Preventing transmission of HD to offspring can be facilitated by prenatal testing (PND) of foetal DNA obtained through chorionic villus sampling or amniocentesis. The most frequently applied method is direct testing of the repeat size with a view of terminating the pregnancy if the foetus shows a CAG repeat size associated with $\mathrm{HD}$ (>35 repeats). If the at-risk parent prefers not to have his/her HD expansion status defined, exclusion testing can be performed by linkage analysis. The presence of one of the chromosome 4 haplotypes of the affected grandparent in the foetus is associated with a $50 \%$ risk of developing HD, equal to the at-risk parent ${ }^{4}$. If the foetus carries this so-called '50\% risk haplotype' the pregnancy is expected to be terminated. If, on the other hand, a couple objects to terminating a 50\% risk pregnancy, an exclusiondefinitive test may be used to determine the actual HD status of the foetus and at-risk parent ${ }^{5}$. Preimplantation genetic diagnosis (PGD) may be an alternative for couples who are reluctant to terminate the pregnancy (TOP) for late onset disorders such as HD or a 50\% HD risk. By selecting IVF embryos without the CAG repeat expansion or the $50 \%$ risk haplotype (exclusion PGD), transmission of HD to offspring can be avoided ${ }^{6-8}$.

This study aims to evaluate the number of prenatal tests, test results, and pregnancy outcomes in relation to repeat size of the at-risk parent in the Netherlands between 1998 and 2008 and compare these data with the preceding decade ${ }^{5}$. 


\section{Materials and Methods}

DNA analysis for HD in the Netherlands is centrally performed in the Laboratory for Diagnostic Genome Analysis in Leiden (LDGA). The results of all prenatal tests from 1998 to 2008 were retrospectively collected from the LDGA and, if applicable, the date of PT and CAG repeat size of the at-risk parent. Eight Dutch university departments of clinical genetics offer genetic counselling around pre- and postnatal testing for HD. Additional clinical information was collected in these centres in cooperation with the clinical geneticists involved. These data included information on gender and age of at-risk parents, reproductive history, and prenatal tests during the study period, including test results and pregnancy outcomes. All results were compared with those obtained in the Netherlands from 1987 to $1997^{5}$.

To estimate the uptake of couples applying for PND, our study population was compared with the number of HD carriers of reproductive age (arbitrarily set at females $\leq 40$ years, and males $\leq 50$ years) undergoing PT in an 11-year period starting in October 1996.

\section{Results}

A total of 126 at-risk couples opted for PND in the period 1998-2008. More than half of the at-risk parents (52\%) were female (Table 1). The majority, $71 \%$ $(89 / 126)$ of at-risk parents, had undergone PT for HD before their first prenatal test. Four individuals had PT at the same time as their first PND with the intention of having their carrier status defined independently of the PND result. For two of these couples, the first PND (and PT) had taken place prior to the study period. Significantly more females than males had performed a PT prior to or simultaneously with their first PND (83\% of females versus $63 \%$ of males, $p=0.01)$. Thirty-three at-risk partners $(26 \%)$, preponderantly males $(M / F$ ratio 22/11), preferred not to know their HD expansion carrier status. None of the at-risk individuals had been diagnosed as clinically affected.

Fifteen per cent of couples $(n=19)$ had had one or more untested children before their first PND. In most cases, the HD diagnosis of a family member was not known before the pregnancy. Thirteen couples had a total of 21 prenatal tests prior to the study period.

In the study period, PND was performed in two pregnancies achieved by PGD to confirm the PGD result. The prior risk of showing HD after PGD is $<1 \%{ }^{9}$, therefore these PND tests were excluded from the analysis. 
Table 1. Characteristics and reproductive history of couples undergoing prenatal diagnosis in the period 1998-2008

\begin{tabular}{lcc}
\hline Characteristics & $n=126$ & $S D$ \\
\hline Gender at-risk partner/carrier CAG expansion: & $n(\%)$ & $60(48 \%)$ \\
$\quad$ Male & $66(52 \%)$ \\
$\quad$ Female & & \\
At-risk parent undergoing PT prior to/or at same time as first PND: & $38(63 \%)$ \\
$\quad$ Male & $55(83 \%)$ \\
$\quad$ Female & \\
At-risk parents not wishing to know their HD-status: & $22(37 \%)$ \\
$\quad$ Male & $11(17 \%)$ \\
$\quad$ Female & mean (n) \\
& $30.3(36)$ & 4.9 \\
Age men at PT (if prior to first PND) & $26.3(53)$ & 5.1 \\
Age women at PT (if prior to first PND) & $33.0(120)$ & 9.8 \\
Male age at first PND & \\
Female age at first PND & & \\
& $30.0(126)$ & 4.5 \\
Untested children prior to first PND & $n($ couples) \\
Pregnancies with PND prior to study period & $25(19)$ & \\
\hline
\end{tabular}

PND, prenatal diagnosis; PT, presymptomatic test

1 Including couples ( $\mathrm{n}=13$ ) who had their first PND before 1998

Prenatal tests results and pregnancy outcomes

A total of 216 prenatal tests were performed in 214 pregnancies in 126 couples (including 2 dichorionic twin pregnancies) (Table 2). Direct tests were performed in $86 \%$ of PND ( $n=185)$. In the remaining $14 \%$, exclusion testing was performed $(n=31)$. For 168 direct tests $(91 \%)$ the prior HD risk was 50\%, 17 (9\%) had a $25 \%$ prior risk for the foetus. Four at-risk parents whose carrier statuses were defined (after exclusion-definitive or direct PND testing for 25\% HD) subsequently used direct PND. PND in 91 foetuses showed a CAG expansion $\geq 36$ or a $50 \%$ risk allele (after exclusion testing). The majority of these pregnancies $(82 \%, 75 / 91)$ were terminated, two ended in spontaneous 
abortion, one was terminated for congenital anomalies, and one was lost to follow-up. In all, $13 \%$ (12/91) of the foetuses with a CAG expansion or $50 \%$ risk allele were carried to term. These continued pregnancies will be described in more detail later. PND had ruled out or excluded the transmission of HD in $89 \%$ of the live born children (112/126). Two pregnancies at 50\% prior risk were continued without obtaining the PND result. A total of 125 pregnancies (including one twin pregnancy), resulted in the birth of one or more liveborn children in 100 couples.

The intermediate alleles in 8 foetuses (Table 2), were identical to the at-risk parents' shortest CAG repeat in four cases, whereas in two cases the intermediate alleles originated from the healthy spouse. On one occasion, the intermediate allele was identical to the at-risk parent's longest allele consisting of 28 CAG repeats (simultaneously tested). The origin of one intermediate allele (27 repeats) remains unknown, since the parents were not tested.

\section{Disclosure of HD carrier status of at-risk parents}

An overview of all individuals with their carrier status as well as the number of prenatal tests is given in Table 3. In the group of 91 persons with a known HD status at the time of their first PND there were 77 carriers of a full penetrance allele (85\%), $10(11 \%)$ had a reduced penetrance allele and four (4\%) an intermediate allele. In the latter group two males had received this 'grey' PT result unexpectedly ${ }^{10}$. They were only prepared to receive a 'positive' or 'negative' result', and decided to undergo PND to avoid any chance of having a child affected with HD. A third male belonged to a family with one documented expansion of an intermediate allele into the full penetrance range after paternal transmission, which may be associated with an increased expansion risk for other family members. No information was available on the female intermediate allele carrier opting for PND. Two others had PT performed simultaneously with their PND, both showing intermediate alleles. The HD status of $27 \%(9 / 33)$ of at-risk individuals who initially did not want to know their status was defined as the result of one or more exclusion-definitive or direct PND tests ( 6 were confirmed by PT). Five at-risk individuals directly or indirectly proved to carry a repeat expansion associated with HD, while four atrisk individuals proved to be free of HD. One of these couples had previously terminated two pregnancies because of a 50\% HD risk (retrospectively unaffected) (Table 3). 


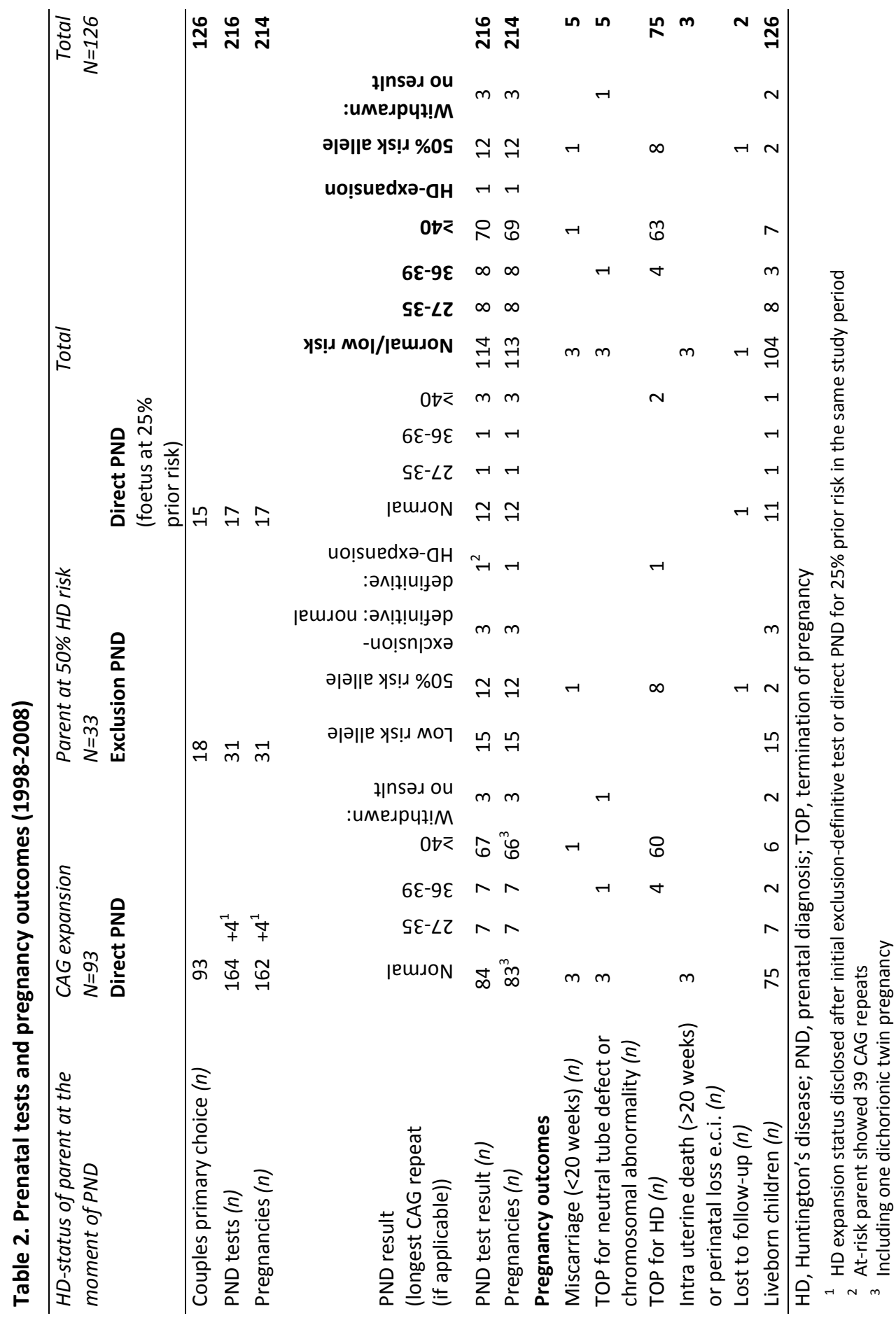


Table 3. Disclosure of HD status of all at-risk parents undergoing prenatal testing (1998-2008)

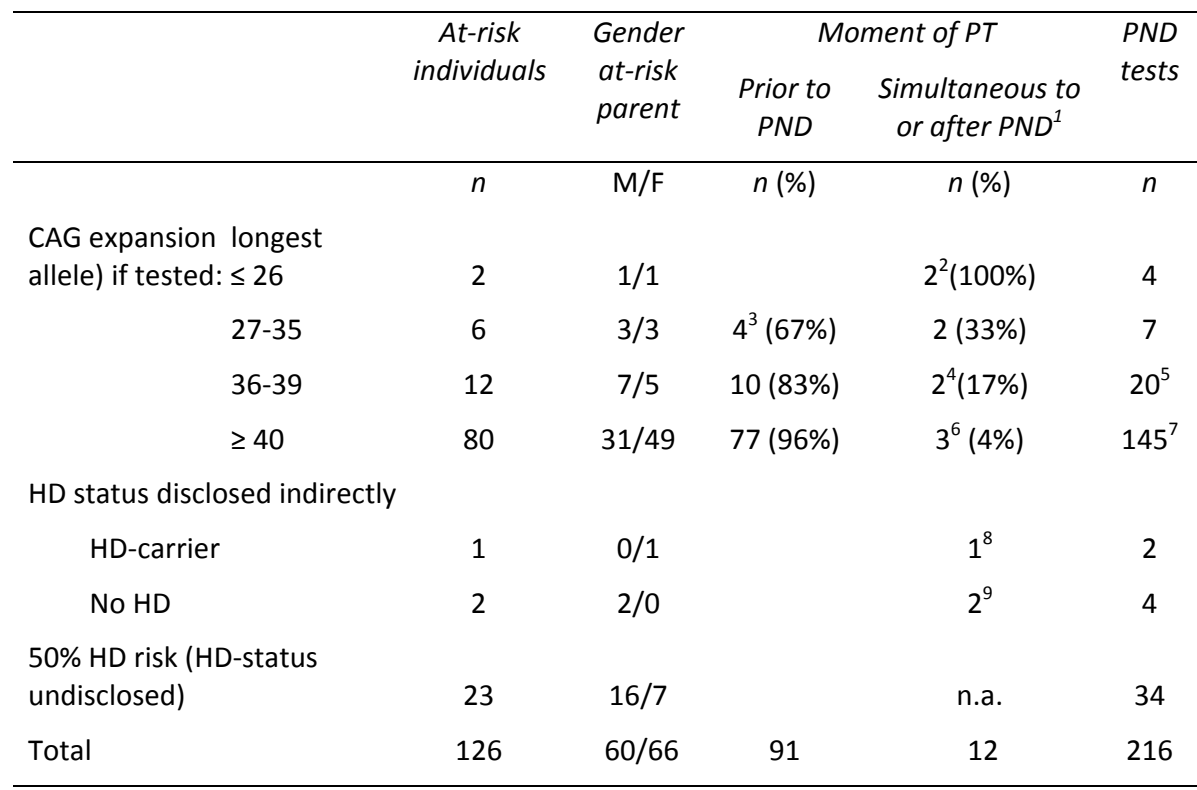

HD, Huntington's disease; PT, presymptomatic test; PND, prenatal diagnosis; TOP, termination of pregnancy

1 Including indirect PT through direct PND, exclusion-definitive test, or simultaneous PT of at-risk partner

2 Two at-risk parents showed no HD-expansion after exclusion-definitive test. One had 2 TOPs for $50 \%$ risk alleles (retrospectively unaffected)

${ }^{3}$ CAG repeat sizes were respectively 29,30 , and 33 repeats (at-risk male) and 31 repeats (at-risk female)

${ }^{4}$ One exclusion-definitive test and one PT after PND had shown HD in foetus

${ }^{5}$ One dichorial twin represented two PND tests

6 Two parents performed PT after PND had shown HD in the foetus, one parent opted for PT after having an unaffected child (PND normal)

7 One dichorial twin represented two PND tests

8 Full HD expansion detected in PND, no confirmative PT in at-risk parent

${ }^{9}$ One couple opted for exclusion-definitive test confirming no HD-carrier. Two direct PND tests in another couple had shown 4 different normal CAG repeats, indirectly suggesting the presence of two normal alleles in the at-risk parent 


\section{Continued pregnancies with CAG expansion $\geq 36$ or $50 \%$ risk haplotype}

Information on the 12 continued pregnancies of foetuses showing CAG repeat expansions associated with HD or 50\% risk haplotypes, is presented in Table 4. The age of the at-risk parents did not significantly differ from the age at PND of other couples (data not shown). The proportion of continued pregnancies (see also Table 2) varied between the different subgroups: seven out of 71 (9.9\%) full penetrance alleles, three out of eight (37.5\%) reduced penetrance alleles and two out of $1250 \%$ risk alleles. No pregnancies were terminated for an intermediate allele. Two out of four pregnancies with a prior risk of $25 \%$ and CAG repeats $\geq 36$ indicating 'double bad news' were continued. In the majority $(8 / 10)$ of continued pregnancies with CAG expansions, the at-risk parent was female. Six couples showed a reproductive history with TOP $(n=3)$, miscarriages $(n=3)$ or threatened abortion $(n=1)$. Two couples had untested children.

Annual PND tests for HD performed in the Netherlands in the period 1988-2008

Figure $1 \mathrm{~A}$ shows the yearly number of PND tests from 1988 to 2008. After the first application of PND in 1989 there was an increase in numbers of PND for several years. Since 1996, the number of PND tests has remained quite stable with approximately 20 tests per year.

The proportion of exclusion tests has gradually decreased since the introduction of direct testing, but the actual number of yearly intentional exclusion tests has remained fairly stable at 3 to 4 exclusion tests per year (Figure 1B). Before 1993, when only linkage testing was available, the number of exclusion tests performed was relatively high. In four cases, exclusion testing was the only technical option, because the haplotypes were uninformative, or there were not enough family members available ${ }^{5}$. In the period from 1988 to 1998 , only 13 out of 17 couples (76\%) intentionally opted for exclusion testing as they did not want to know the HD expansion status of the at-risk parent. Taking this overestimation into account, we can see an even stronger stability of the absolute number of couples requesting exclusion testing.

\section{Uptake of PND}

We estimated the uptake of PND among carriers of an expanded repeat. The HD status of the 103 at-risk persons (Table 3) was (directly or indirectly) disclosed on average 2.2 years before their first PND test (range 14.41 years before to 9.07 years after PND). From this, we concluded that the 11-year period starting October 1996 was the closest way to establish the timing of PT 
in our study population. In this period 1414 presymptomatic tests were performed, in which 962 individuals were at reproductive age at the moment of PT and 406 showed a CAG repeat $\geq 36$ (199 males <50 yrs and 207 females $<40 \mathrm{yrs}$ ). Additionally, three untested individuals of reproductive age turned out to be HD expansion carriers after an unfavourable outcome of exclusiondefinitive testing or direct PND, resulting in a total of 409 HD expansion carriers. Four out of the 93 carriers of an HD expansion $\geq 36$ (Table 3 ) were excluded, because they had had PT performed abroad or had been tested diagnostically. This leads to an estimated uptake of PND of 22\% (89/409) among HD expansion carriers. The age at PT of males and females not opting for PND was significantly higher (34.3 and 29.4 respectively), compared to the age at PT of couples opting for PND (males 31.0 and females 27.0) (age differences: males $p=0.02$; females $p=0.001$ ).

Figure 1A. Prenatal tests for HD in the Netherlands (1988-2008)

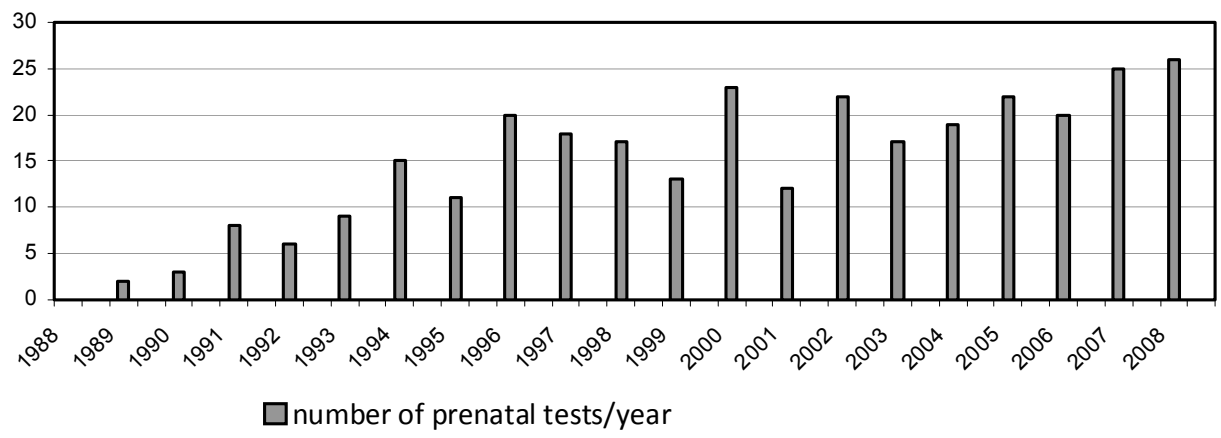

Figure 1B. Exclusion and direct prenatal tests for HD in the Netherlands(1988-2008)

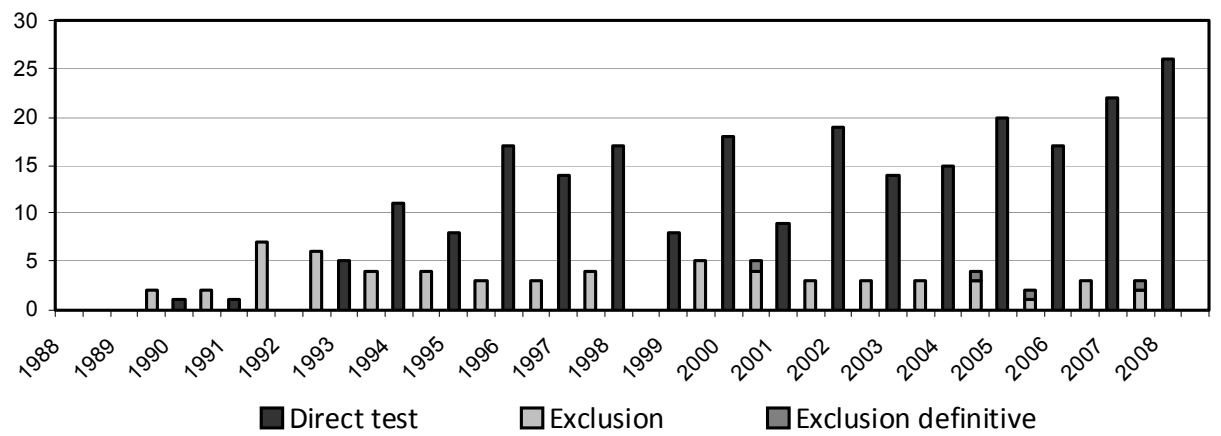

The figures 1A and 1B until 1997 are derived from A. Maat-Kievit, et.al. 19995, completed with the current data until 2008. In the period up to 1997 the exclusion-definitive tests were counted together with the exclusion tests. 


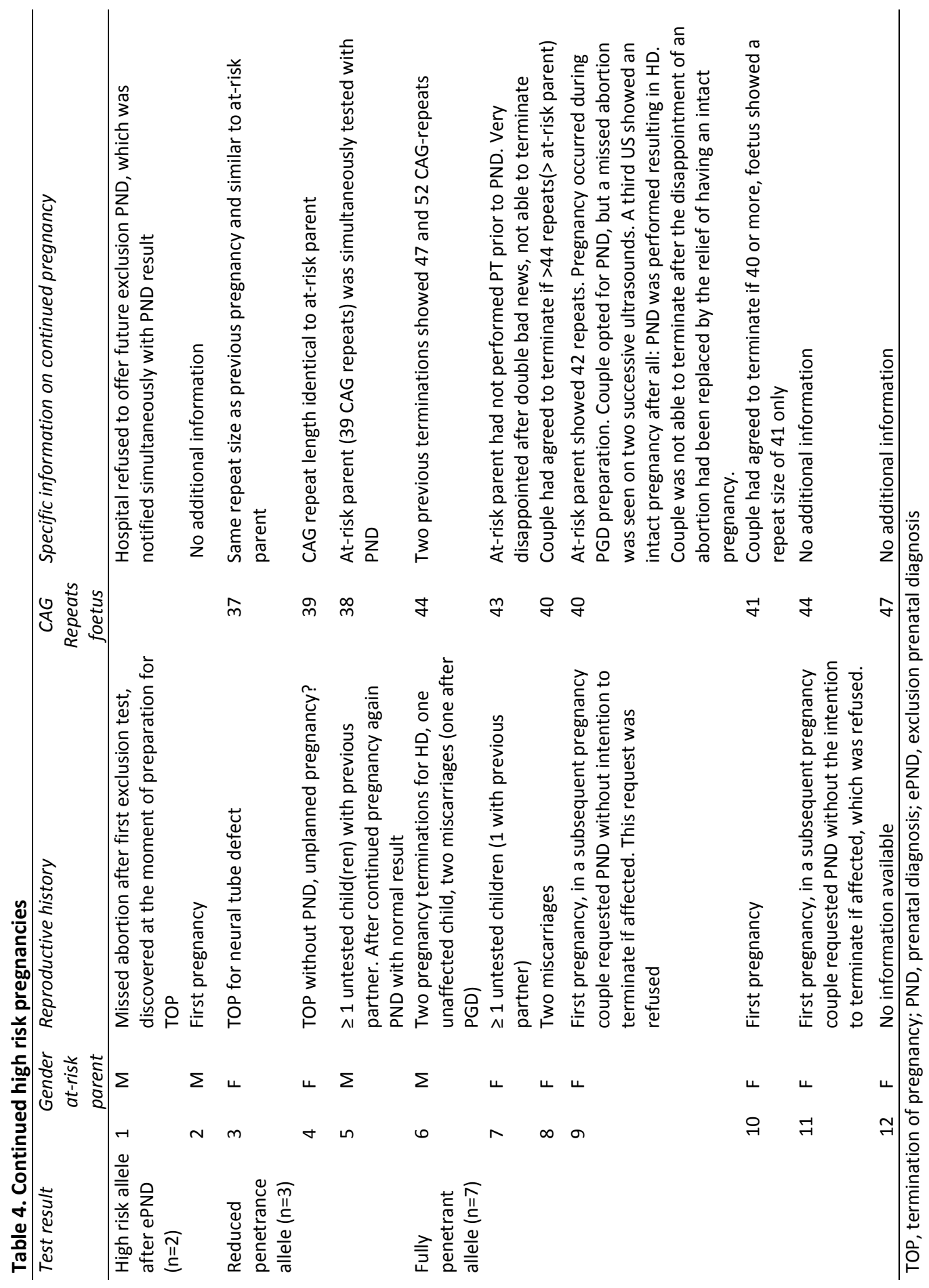




\section{Discussion}

In the 11 years from 1998 to 2008 a total of 126 couples underwent 216 prenatal tests in the Netherlands. Most couples opt for a direct test. The proportion of couples opting for an exclusion test has decreased from about $25 \%$ in the period $1987-1997^{5}$ to $13.5 \%$ in the current study. The proportion of exclusion testing PND vs. direct testing varied from around $30 \%$ in Australia $(1994-2003)^{11}$, to about 10\% in Belgium, 29\% in France, 30\% in Denmark, 42\% in Italy and 48\% in the UK (1993-1998) ${ }^{12-14}$. In Germany, Switzerland, Austria, and Greece no exclusion tests were performed (1993-1998) ${ }^{14-16}$. The absolute number of Dutch couples requesting exclusion tests over the years, even since the availability of direct testing, has remained quite stable. One might conclude that for a subgroup of at-risk individuals this is an attractive option. Apparently these couples prefer the risk of terminating a non-affected foetus over disclosure of their own HD status. The motives of couples opting for exclusion testing are described elsewhere ${ }^{17}$.

The intermediate alleles found in $4 \%$ of direct PND tests (8/189 including 4 exclusion-definitive tests) may be considered a background/population risk. In most foetuses $(6 / 8)$ the origin was clearly different from the HD-causing allele, and in the remaining two ( 27 and 28 CAG repeats respectively) it seems unlikely that these alleles are the ones causing HD in a close relative. In the Western European population, the background prevalence of intermediate alleles (27-35 CAG repeats) is estimated at around $2 \%$ to $6 \%{ }^{18-20}$.

Compared to Maat-Kievit et al. ${ }^{5}$, two new subgroups of PND applicants appeared. First, carriers of an intermediate allele represented $4 \%$ of individuals requesting PND. After receiving their 'grey' $\mathrm{PT}$ result ${ }^{10}$, the main reason to perform PND was to eradicate HD completely. To our knowledge, PND has not been described before for intermediate alleles. However, Decruyenaere et al. described one PND test in a woman with an equivocal repeat size (27-39 repeats) which was continued because the number of CAG repeats, the exact sizes of which were not mentioned ${ }^{21}$, was lower than 40 . The chance of intermediate alleles expanding into a reduced penetrance allele or, very rarely, into the full penetrance allele ranges from $1 \%$ to $20 \%$ of transmissions ${ }^{19,22-26}$. Expansion risk is associated with a longer repeat length of the at-risk parent and mainly with paternal transmission.

Secondly, individuals at 50\% HD risk opting for direct PND (25\% prior risk for the foetus) represented about $8 \%$ of PND applicants ${ }^{5}$. This group represented 
$5 \%$ in a UK study, and $37.5 \%$ in Germany, Austria and Switzerland ${ }^{12,15}$. For individuals who object to terminating a $50 \%$ risk pregnancy, but do accept the $25 \%$ chance of disclosure of their own HD status, this could be a valid alternative ${ }^{5}$. This method may also be applied to save time (compared to the time frame needed for successive PT and PND or exclusion-definitive testing) if couples do not present themselves until during a pregnancy ${ }^{27}$. The main disadvantage is the chance of 'double bad news' should the foetus turn out to carry the CAG expansion, and indirectly confirms its at-risk parent's HD status $^{5,28,29}$.

The majority of CAG expansion or $50 \%$ risk pregnancies were terminated; however, a substantial $13 \%$ were continued to term. According to international guidelines, continuing an CAG expansion or at-risk pregnancy of a late onset disorder like HD can be considered an early form of predictive testing and therefore violates the future child's right not to know ${ }^{8,29,30}$. In the study period 1987-1997, all HD positive and high risk pregnancies $(n=28)$ were terminated. Continuation of a pregnancy with a CAG expansion or $50 \%$ HD risk has been described previously ${ }^{13,15,21,31,32}$. One may speculate about the contributing factors making the decision to terminate such a pregnancy difficult. For some couples the 'double bad news' of an HD test result in a $25 \%$ prior risk pregnancy might have complicated the decision to terminate the affected pregnancy. Furthermore, a reduced penetrance allele in a foetus may induce a sense of hope, despite the disappointing test results as a whole. Individuals at risk of transmitting HD to their offspring do show a tendency to hold on to objectively rather small levels of hope as part of their coping strategy ${ }^{33-35}$. The observation that some couples do eventually continue a pregnancy with a smaller CAG repeat than their own - yet still a full penetrance allele - supports this idea. Therefore, if couples are determined to eradicate HD from their family, and if they expect difficulties to terminate when knowing the exact repeat length, especially in a certain range, they might prefer not to know the exact repeat size. These couples can agree with the counsellor to set a specific cut-off CAG repeat level, above which a 'HD carrier' result will be communicated. Naturally, the exact way of communicating the test result should be thoroughly discussed with each couple prior to the PND test. In individual cases, this form of non-disclosure of the exact CAG repeat size may reduce the reluctance of parents to terminate a pregnancy. According to Dutch law, though, parents are entitled to receive test results in full ${ }^{36}$. Moreover, a reproductive history of miscarriages or pregnancy terminations, as well as the presence of untested children within the same family, may increase parents' 
reluctance to terminate another pregnancy. Confronted with an HD positive or $50 \%$ risk result, the couple may have the complex association of rejecting an already existing child or the at-risk parent when opting for a termination of the pregnancy ${ }^{37}$. Furthermore, the time transpiring between PND intake and test result may affect couples' moral judgement on the acceptability of TOP ${ }^{38}$. The motives of these couples and the long-term consequences of this unfavourable outcome after PND will be the subject of future study.

Compared to the period studied by Maat et al.(1987-1997) ${ }^{5}$, the number of 92 prenatal tests in the Netherlands has more than doubled to 216. A similar twofold increase (11 to $22 \%$ ) was observed in the approximated uptake of PND by HD expansion carriers ${ }^{5}$. We assume that the uptake estimate in the study of Maat-Kievit et al. showed an underestimation of the actual uptake of PND due to the reported time lapse of 19 months between PT and first PND, as was reflected in the bar charts of presymptomatic test applicants and prenatal tests in the Netherlands (1987-1997) $)^{5,39}$. The uptake of PND among PT applicants with reproductive motives, in our study and in the previous study period, may be even higher; however these motives were not centrally collected.

Since PGD can be regarded as an alternative to PND, it is interesting to note that after the introduction of PGD for HD in the Netherlands in 1999, the use of PND in terms of absolute figures did not decline ${ }^{40}$. By contrast, in France PND is only rarely performed after the introduction of $\mathrm{PGD}^{8}$.

The uptake of PND by HD expansion carriers in the Netherlands is relatively high compared with France, Canada, the USA, Germany, Austria, Switzerland, Greece, Australia, and Northern-Ireland ${ }^{8,11,14,16,27,41-43}$ but is roughly comparable with the UK, South Africa (Johannesburg), Belgium, and Denmark ${ }^{12-14,21,44}$. Since 2010, PND for HD has been prohibited in Germany; prenatal testing and termination of a pregnancy for HD are considered a form of genetic discrimination because of the late onset of $\mathrm{HD}^{45}$. In our study the motives for performing a PT were not registered systematically, therefore we assume that the actual uptake among individuals with reproductive motives for PT will most probably be higher. Additional support for this idea is presented in another paper on the uptake of PND and PGD in the Netherlands ${ }^{40}$. Difficulties in calculating the absolute uptake of PT with respect to the at 50\% HD-risk population complicate an accurate calculation and comparison of the uptake between these populations $s^{43,46}$. 


\section{Implications for good practice}

Reproductive counselling issues should be discussed according to the international guidelines ${ }^{29}$. Parents opting for PND should be aware that they are expected to terminate a pregnancy should the foetus show a CAG repeat expansion associated with HD. Sequential use of PND does not imply a moral obligation to use PND in future pregnancies. The willingness and ability of couples to undergo (another) pregnancy termination should be discussed in every single PND intake. Hesitation, at any time during the procedure, should be taken seriously. Couples should be given the opportunity to withdraw from PND at any time, preferably before performing chorionic villus sampling, or at the latest before receiving the PND result.

In some cases non-disclosure of the exact CAG repeat size may reduce the reluctance of parents to terminate an affected pregnancy; this should be discussed prior to PND. Alternative reproductive options such as PGD should be considered during reproductive counselling.

\section{Conclusion}

The use of PND for Huntington's disease in the Netherlands for both direct testing and exclusion has remained reasonably stable over the years. PND was used by two new subgroups: carriers of intermediate alleles, and couples opting for direct testing for a $25 \%$ HD risk for the foetus. A considerable number of affected or at-risk pregnancies were continued, for which we identified some contributing factors. Couples' willingness to undergo TOP on account of HD should be explored thoroughly prior to and during the PND procedure.

\section{References}

1. Bates G, Harper P, Jones L (eds): Huntington's Disease. Oxford University Press, New York 2002.

2. Gusella JF, Wexler NS, Conneally PM et al: A polymorphic DNA marker genetically linked to Huntington's disease. Nature 1983; 306: 234-238.

3. Huntington's Disease Collaborative Research Group: A novel gene containing a trinucleotide repeat that is expanded and unstable on Huntington's disease chromosomes. Cell 1993; 72: 971-983. 
4. Harper PS, Sarfarazi M: Genetic prediction and family structure in Huntington's chorea. British Medical Journal (Clinical research ed) 1985; 290: 1929-1931.

5. Maat-Kievit A, Vegter-van der Vlis $M$, Zoeteweij $M$ et al: Experience in prenatal testing for Huntington's disease in The Netherlands: procedures, results and guidelines (19871997). Prenatal diagnosis 1999; 19: 450-457.

6. Moutou C, Gardes N, Viville S: New tools for preimplantation genetic diagnosis of Huntington's disease and their clinical applications. European Journal of Human Genetics 2004; 12: 1007-1014.

7. Sermon $K$, de Rijcke $M$, Lissens $W$ et al: Preimplantation genetic diagnosis for Huntington's disease with exclusion testing. European Journal of Human Genetics 2002; 10: 591-598.

8. van Rij MC, de Rademaeker M, Moutou C et al: Preimplantation genetic diagnosis (PGD) for Huntington's disease: the experience of three European centres. European Journal of Human Genetics 2012; 20: 368-375.

9. Dreesen J, Drusedau $\mathrm{M}, \mathrm{Smeets} \mathrm{H}$ et al: Validation of preimplantation genetic diagnosis by PCR analysis: genotype comparison of the blastomere and corresponding embryo, implications for clinical practice. Molecular human reproduction 2008; 14: 573-579.

10. Semaka A, Balneaves LG, Hayden MR: "Grasping the Grey": Patient Understanding and Interpretation of an Intermediate Allele Predictive Test Result for Huntington Disease. Journal of genetic counseling 2012; [Epub ahead of print].

11. Tassicker RJ, Marshall PK, Liebeck TA, Keville MA, Singaram BM, Richards FH: Predictive and pre-natal testing for Huntington Disease in Australia: results and challenges encountered during a 10-year period (1994-2003). Clinical genetics 2006; 70: 480-489.

12. Simpson SA, Harper PS: Prenatal testing for Huntington's disease: experience within the UK 1994-1998. Journal of medical genetics 2001; 38: 333-335.

13. Simpson SA, Zoeteweij MW, Nys $\mathrm{K}$ et al: Prenatal testing for Huntington's disease: a European collaborative study. European Journal of Human Genetics 2002; 10: 689-693.

14. Yapijakis C, Laccone F, Sorensen SA: Predictive and prenatal testing for Huntington's disease in Greece, Germany, Austria, Switzerland and Denmark; in: Evers-Kiebooms G (ed): Prenatal testing for late-oset neurogenetic diseases. Oxford, UK: BIOS Scientific Publishers Ltd, 2002, pp 69-82.

15. Laccone F, Engel U, Holinski-Feder $E$ et al: DNA analysis of Huntington's disease: five years of experience in Germany, Austria, and Switzerland. Neurology 1999; 53: 801806.

16. Panas M, Karadima G, Vassos E et al: Huntington's disease in Greece: the experience of 14 years. Clinical genetics 2011; 80: 586-590.

17. van Rij MC, de Die-Smulders CE, Bijlsma EK et al: Evaluation of exclusion prenatal and exclusion preimplantation genetic diagnosis for Huntington's disease in the Netherlands. Clinical genetics 2013; 83(2): 118-124.

18. Maat-Kievit A, Losekoot $\mathrm{M}$, van den Boer-van den Berg $\mathrm{H}$ et al: New problems in testing for Huntington's disease: the issue of intermediate and reduced penetrance alleles. Journal of medical genetics 2001; 38(4): E12. 
19. Semaka A, Collins JA, Hayden MR: Unstable familial transmissions of Huntington disease alleles with 27-35 CAG repeats (intermediate alleles). American journal of medical genetics Part B, Neuropsychiatric genetics : the official publication of the International Society of Psychiatric Genetics 2010; 153B: 314-320.

20. Sequeiros J, Ramos EM, Cerqueira J et al: Large normal and reduced penetrance alleles in Huntington disease: instability in families and frequency at the laboratory, at the clinic and in the population. Clinical genetics 2010; 78: 381-387.

21. Decruyenaere M, Evers-Kiebooms G, Boogaerts A et al: The complexity of reproductive decision-making in asymptomatic carriers of the Huntington mutation. European Journal of Human Genetics 2007; 15: 453-462.

22. Wheeler VC, Persichetti F, McNeil SM et al: Factors associated with HD CAG repeat instability in Huntington disease. Journal of medical genetics 2007; 44: 695-701.

23. Semaka A, Creighton S, Warby S, Hayden MR: Predictive testing for Huntington disease: interpretation and significance of intermediate alleles. Clinical genetics 2006; 70: 283294.

24. Goldberg YP, McMurray CT, Zeisler J et al: Increased instability of intermediate alleles in families with sporadic Huntington disease compared to similar sized intermediate alleles in the general population. Human molecular genetics 1995; 4: 1911-1918.

25. Chong SS, Almqvist $\mathrm{E}$, Telenius $\mathrm{H}$ et al: Contribution of DNA sequence and CAG size to mutation frequencies of intermediate alleles for Huntington disease: evidence from single sperm analyses. Human molecular genetics 1997; 6: 301-309.

26. Brocklebank D, Gayan J, Andresen JM et al: Repeat instability in the 27-39 CAG range of the HD gene in the Venezuelan kindreds: Counseling implications. American journal of medical genetics Part B, Neuropsychiatric genetics : the official publication of the International Society of Psychiatric Genetics 2009; 150B: 425-429.

27. Richards FH, Rea G: Reproductive decision making before and after predictive testing for Huntington's disease: an Australian perspective. Clinical genetics 2005; 67: 404-411.

28. IHA-WFN: International Huntington Association and the World Federation of Neurology Research Group on Huntington's Chorea. Guidelines for the molecular genetics predictive test in Huntington's disease. Journal of medical genetics 1994; 31: 555-559.

29. Macleod R, Tibben A, Frontali $M$ et al: Recommendations for the Predictive Genetic Test in Huntington's Disease. Clinical genetics 2013; 83(3):221-31.

30. Toufexis $M$, Gieron-Korthals $M$ : Early testing for Huntington disease in children: pros and cons. Journal of child neurology 2010; 25: 482-484.

31. Creighton S, Almqvist EW, MacGregor D et al: Predictive, pre-natal and diagnostic genetic testing for Huntington's disease: the experience in Canada from 1987 to 2000. Clinical genetics 2003; 63: 462-475.

32. Tolmie JL, Davidson HR, May HM, McIntosh K, Paterson JS, Smith B: The prenatal exclusion test for Huntington's disease: experience in the west of Scotland, 1986-1993. Journal of medical genetics 1995; 32: 97-101.

33. Quaid KA, Sims SL, Swenson MM et al: Living at risk: concealing risk and preserving hope in Huntington disease. Journal of genetic counseling 2008; 17: 117-128. 
34. Bombard Y, Penziner E, Decolongon J et al: Managing genetic discrimination: strategies used by individuals found to have the Huntington disease mutation. Clinical genetics 2007; 71: 220-231.

35. Quaid KA, Swenson MM, Sims SL et al: What were you thinking?: individuals at risk for Huntington Disease talk about having children. Journal of genetic counseling 2010; 19 : 606-617.

36. Wet Geneeskundige Behandel Overeenkomst, Dutch Civil Law, BW Art. 7:458, 2011.

37. Richards M: Predictive testing for Huntington's disease. Lancet 2001; 357: 883.

38. Scully JL, Porz R, Rehmann-Sutter C: 'You don't make genetic test decisions from one day to the next'--using time to preserve moral space. Bioethics 2007; 21: 208-217.

39. Maat-Kievit A, Vegter-van der Vlis $M$, Zoeteweij $M$, Losekoot $M$, van Haeringen $A$, Roos R: Paradox of a better test for Huntington's disease. Journal of neurology, neurosurgery, and psychiatry 2000; 69: 579-583.

40. van Rij MC, de Koning Gans PA, van Belzen MJ et al: The uptake and outcome of prenatal and preimplantation genetic diagnosis for Huntington's disease in the Netherlands (1998-2008). Clinical Genetics 2013; [Epub ahead of print].

41. Nance MA: Predictive and prenatal testing for late-onset neurogenetic diseases in North-America; in: Evers-Kiebooms G, Zoeteweij MW, Harper PS (eds): Prenatal testing for late-onset neurogenetic diseases. Oxford, UK: BIOS Scientific Publishers Ltd, 2002, pp 191-201.

42. Dufrasne S, Roy M, Galvez M, Rosenblatt DS: Experience over fifteen years with a protocol for predictive testing for Huntington disease. Molecular genetics and metabolism 2011; 102: 494-504.

43. Morrison PJ, Harding-Lester S, Bradley A: Uptake of Huntington disease predictive testing in a complete population. Clinical genetics 2011; 80: 281-286.

44. Sizer EB, Haw T, Wessels TM, Kromberg JG, Krause A: The utilization and outcome of diagnostic, predictive, and prenatal genetic testing for huntington disease in johannesburg, South Africa. Genetic testing and molecular biomarkers 2012; 16: 58-62.

45. Gesetz über genetische Untersuchungen beim Menschen (Regulation on genetic testing in humans). Germany, 2009, Vol Art. 74 Abs. 1 Nr. 26 GG.

46. Tassicker RJ, Teltscher B, Trembath MK et al: Problems assessing uptake of Huntington disease predictive testing and a proposed solution. European Journal of Human Genetics 2009; 17: 66-70. 


\title{
Chapter 3
}

\section{Preimplantation genetic diagnosis (PGD) for Huntington's disease: the experience of three European centres}

\author{
M.C. van Rij \\ M. de Rademaeker \\ C. Moutou \\ J.C.F.M. Dreesen \\ M. de Rycke \\ I. Liebaers \\ J.PM Geraedts \\ C.E.M. de Die-Smulders \\ S. Viville \\ on behalf of the BruMaStra PGD Working Group
}




\section{Abstract}

This study provides an overview of 13 years of experience of preimplantation genetic diagnosis (PGD) for Huntington's disease (HD) at three European PGD centres in Brussels, Maastricht and Strasbourg. Information on all 331 PGD intakes for HD, couples' reproductive history, PGD approach, treatment cycles and outcomes between 1995 and 2008 were collected prospectively. Of 331 couples for intake, $68 \%$ requested direct testing and $32 \%$ exclusion testing (with a preponderance of French couples). At the time of PGD intake, 39\% of women had experienced one or more pregnancies. A history of pregnancy termination after prenatal diagnosis was observed more frequently in the direct testing group (25\%) than in the exclusion group (10\%; $\mathrm{P}=0.0027)$. PGD workup was based on two approaches: (1) direct testing of the CAG-triplet repeat and (2) linkage analysis using intragenic or flanking microsatellite markers of the HTT gene. In total, 257 couples had started workup and 174 couples (70\% direct testing, 30\% exclusion testing) completed at least one PGD cycle. In total, 389 cycles continued to oocyte retrieval (OR). The delivery rates per OR were $19.8 \%$, and per embryo transfer $24.8 \%$, resulting in 77 deliveries and the birth of 90 children. We conclude that PGD is a valuable and safe reproductive option for HD carriers and couples at risk of transmitting HD. 


\section{Introduction}

Huntington's disease (HD; MIM: 143100) is a progressive neurodegenerative disorder seriously affecting the quality of life of patients and their families. Clinical signs are progressive motor disability featuring chorea, as well as mental disturbances such as cognitive decline, changes in personality and depression ${ }^{1}$. The mean age of onset is 35 to 44 years and the median survival time is 15 to 18 years after onset ${ }^{2-4}$. In populations of western European descent, the prevalence varies between 5 and 10 per $100,000^{3,4}$.

The disease-causing mutation is an expanded CAG repeat sequence in exon 1 of the HTT gene (ref. seq NM002111.6) on chromosome 4 (4p16.3), transmitted as an autosomal dominant trait ${ }^{2}$. HD is fully penetrant in patients having $\geq 40$ CAG repeats; 36-39 CAG repeats are associated with reduced penetrance, whereas 27-35 repeats are within the intermediate range. Intermediate repeats are not penetrant, but may lead to expansion if transmitted to offspring.

Reproductive options for gene carriers or at-risk persons include prenatal diagnosis (PND) and preimplantation genetic diagnosis (PGD) $)^{5-8}$. For confirmed carriers, PGD can provide direct testing of embryos obtained after in vitro fertilisation (IVF) via an intracytoplasmic sperm injection (ICSI). The CAG repeat length is tested in one or two blastomeres from each embryo, and, if available, one or two unaffected embryos are selectively transferred into the uterus ${ }^{7}$.

At-risk persons who prefer to be uninformed about their HD carrier status, and do not wish to undergo presymptomatic testing, can be offered exclusion testing either by PND or PGD. The exclusion test is based on identifying the grandparental origin of the two HTT alleles ${ }^{9}$. If one of the two alleles from the affected grandparent is found in the foetus after exclusion PND, a termination of pregnancy (TOP) is offered, although the foetus only has a $50 \%$ risk of being a carrier of the CAG expansion. In exclusion PGD, only embryos with one of the two HTT alleles from the non-affected grandparent are transferred ${ }^{6}$. Both the availability and cooperation of family members in providing a sample for PGD workup is necessary for exclusion testing. An alternative method for those who do not want to know their carrier status is non-disclosure PGD ${ }^{10}$. Embryos are analysed directly for a CAG repeat, without any details of PGD results being revealed to patients. Only embryos without an expansion are transferred ${ }^{11}$. Non-disclosure PGD remains controversial and has been rejected by many PGD centres $^{5,6,12,13}$. 
The PGD centres in Brussels (Belgium), Maastricht (The Netherlands) and Strasbourg (France) offer PGD for HD. We provide an overview of our experience of PGD for HD between 1995 and 2008.

Our aims are as follows: 1) to provide a comparative overview of PGD approaches and technical workup in the three centres, 2) to study differences in the populations who apply for PGD and their reproductive histories, 3) to compare PGD results in the three centres, as well as to compare them with literature data.

\section{Patients and Methods}

The data on all intakes, cycles and outcomes of PGD treatment for HD in the PGD centres in Brussels, Maastricht and Strasbourg from 1995 to 2008 were prospectively collected.

\section{Patients and counselling}

A total of 331 couples obtained genetic and reproductive counselling by a clinical geneticist before being referred for PGD. The PGD intakes were performed by a clinical geneticist, a gynaecologist and/or a PGD co-worker either at the outpatient clinic (Brussels, Maastricht) or by telephone (Strasbourg). Couples were provided with verbal and written information on IVF and ICSI, the single-cell diagnostic procedure, the success rates of the IVF/PGD treatment and the small risk of misdiagnosis ${ }^{14,15}$. The advantages and disadvantages of PGD in comparison with relevant alternative reproduction options were discussed. Informed consent was given by both partners before treatment. The reproductive history concerning fertility problems, previous pregnancies with or without PND and/or TOP, and the number of living children were noted. Couples had to be suitable candidates for IVF/PGD according to the European Society of Human Reproduction and Embryology (ESHRE) IVF and PGD guidelines ${ }^{16,17}$. Reasons for being rejected by the PGD centre were recorded, as well as reasons for couples refraining from PGD if this information was available. If symptoms of HD were observed during intake (Brussels or Maastricht), a neurologist and a psychologist were consulted, and the PGD request was evaluated by the local PGD team and occasionally the ethics committee. In general, it is considered that assisted reproduction technology involves shared responsibility for parental caregivers and healthcare providers in respect of a prospective child. If a couple does not seem to be 
able to provide a stable environment in which the child will grow up, the couple can be rejected for PGD.

\section{PGD workup}

The PCR single-cell protocols applied in this study are based on two approaches: 1 ) direct testing of the (CAG)n triplet repeat, and 2) linkage analysis using one or more intragenic or flanking microsatellite markers, in addition to the direct approach or for exclusion testing (Table 1$)^{5-8}$.

Table 1. Strategies in use for PGD for Huntington's disease in BruMaStra PGD centres

\begin{tabular}{|c|c|c|c|}
\hline & Brussels & Maastricht & Strasbourg \\
\hline Direct testing & $\begin{array}{l}\text { (CAG)n } \\
\text { or (CAG)n + IVS1CA }\end{array}$ & $(\mathrm{CAG}) \mathrm{n}$ & $\begin{array}{l}\text { (CAG)n+D4S127+ } \\
\text { D4S412+IVS1CA }\end{array}$ \\
\hline $\begin{array}{l}\text { Direct testing (if } \\
\text { not informative } \\
\text { for (CAG)n) }\end{array}$ & $(C A G) n+I V S 1 C A$ & $\begin{array}{l}\text { D4S1614+D4S127+ } \\
\text { D4S3034+D4S412 }\end{array}$ & $\begin{array}{l}\text { (CAG)n+D4S127+ } \\
\text { D4S412+IVS1CA }\end{array}$ \\
\hline Exclusion testing & IVS1CA + D4S127 & $\begin{array}{l}\text { D4S1614+D4S127+ } \\
\text { D4S3034+D4S412 }\end{array}$ & $\begin{array}{l}\text { D4S3038+D4S1614+ } \\
\text { D4S127+IVS1CA } \\
\text { +D4S3034+D4S412 }\end{array}$ \\
\hline Alkaline lysis & $50 \mathrm{mM}$ DTT, $200 \mathrm{mM}$ & $50 \mathrm{mM}$ DTT, $200 \mathrm{mM}$ & $50 \mathrm{mM}$ DTT, $200 \mathrm{mM}$ \\
\hline Buffer (ALB) & $\begin{array}{l}\mathrm{NaOH} \\
\text { or } 50 \mathrm{mM} \text { DTT, } 200 \mathrm{mM} \\
\mathrm{KOH}\end{array}$ & $\mathrm{NaOH}$ & $\mathrm{KOH}$ \\
\hline $\begin{array}{l}\text { Freezing post } \\
\text { tubing }\end{array}$ & $\geq 30 \mathrm{~min}-20^{\circ} \mathrm{C}$ & $\geq 30 \mathrm{~min}-20^{\circ} \mathrm{C}$ & $\geq 30 \mathrm{~min}-20^{\circ} \mathrm{C}$ \\
\hline Decontamination & $\begin{array}{l}\text { UV-C and/or restriction } \\
\text { enzyme }\end{array}$ & $\begin{array}{l}\text { UV-C and/or } \\
\text { restriction enzyme }\end{array}$ & UV-C \\
\hline \multirow[t]{3}{*}{ Polymerase } & $\begin{array}{l}\text { Taq Polymerase } \\
\text { (Perkin Elmer) : (CAG)n }\end{array}$ & $\begin{array}{l}\text { Expand }^{\mathrm{TM}} \text { Long } \\
\text { Template PCR system } \\
\text { (Roche Diagnostics) : } \\
\text { (CAG)n }\end{array}$ & $\begin{array}{l}\text { Qiagen }^{\circledR} \text { Multiplex } \\
\text { PCR KIT (Qiagen) }\end{array}$ \\
\hline & Expand ${ }^{\mathrm{TM}}$ Long & Expand $^{\mathrm{TM}} \mathrm{High}$ & \\
\hline & $\begin{array}{l}\text { Template PCR system } \\
\text { (Roche Diagnostics) : } \\
\text { duplex }\end{array}$ & $\begin{array}{l}\text { Fidelity PCR system } \\
\text { (Roche Diagnostics): } \\
\text { linkage }\end{array}$ & \\
\hline $\begin{array}{l}\text { Split for } \\
\text { multiplex PCR }\end{array}$ & Yes & No & No \\
\hline \multirow[t]{3}{*}{ Genetic Analyser } & ALF & $A B \mid 377$ & $A B \mid 3100$ \\
\hline & $A B \mid 3100$ & $A B \mid 3100$ & \\
\hline & & ABI 3730 & \\
\hline
\end{tabular}




\section{Ovarian stimulation and oocyte retrieval}

Controlled ovarian hyperstimulation was carried out in a $\mathrm{GnRH}$ agonist or antagonist protocol. PGD treatment requires a higher minimum follicle count for oocyte retrieval (OR) than regular IVF treatment, as relatively more embryos are 'lost' during the PGD procure (rejected for being affected/at risk). The minimum follicle count for OR was four for Maastricht and six for Strasbourg. In Brussels, the preferred minimum follicle count for OR was nine, the exact number, however, being established on an individual basis ${ }^{18}$.

\section{ICSI and embryo biopsy procedure}

IVF with ICSI was carried out as described previously ${ }^{19}$. After careful assessment of the embryos' development, blastomere biopsy was carried out on day 3. Depending on the total number of embryonic cells and the PGD approach, one or two blastomeres were removed by making a hole in the zona pellucida with a stream of acid Tyrode's solution or with a laser ${ }^{20-22}$.

\section{PGD approach}

Single-cell testing methods were very similar in the three PGD centres (Table 1). After biopsy, blastomeres were washed and tubed in alkaline lysis buffer with $\mathrm{KOH}$ or $\mathrm{NaOH}$ and maintained at -20 or $-80^{\circ} \mathrm{C}$ for at least 30 min. A blank control was made for each blastomere, as recommended by the PGD best practice guidelines at the time ${ }^{17}$. Samples were lysed at $65^{\circ} \mathrm{C}$ for $10 \mathrm{~min}$, before the addition of PCR reaction components. Initially, PCR reactions were based on simplex PCR. Later, multiplex fluorescent PCR was introduced, which allowed simultaneous amplification of two to six loci.

\section{Embryo transfer, pregnancy outcome and children}

One or two unaffected embryos were transferred into the uterus on days 3 to 5 post insemination. The age of the woman, number of unsuccessful previous attempts and embryo quality determined the number of embryos to be transferred. For Belgian patients, the reimbursement policy of July 2003 required a selective single-embryo transfer in patients aged $\leq 36$ years. Supernumerary unaffected embryos of good morphology were cryopreserved $^{23}$. Biochemical pregnancy was confirmed when serum or urine beta hCG concentrations showed an increase at least 10 days after transfer. Clinical pregnancy was recorded when a gestational sac was seen on ultrasound at least 4 weeks after embryo transfer. Ongoing pregnancy was registered if 
ultrasound showed a foetal heartbeat at $\geq 12$ weeks of gestational age. Loss of a fetus or gestational sac $\leq 20$ weeks was recorded as a miscarriage ${ }^{24}$.

The option of a control PND by CVS or amniocentesis was offered to pregnant women. Data on children born were collected through questionnaires addressed to the parents and their gynaecologists. In Brussels, children were examined whenever possible by a trained paediatrician ${ }^{25}$.

\section{Legal aspects}

PGD for HD based on direct testing is allowed in all three centres. In Belgium, PGD practice has been regulated by law since $2007^{26}$. Direct testing was first applied in $1997^{7}$. Exclusion testing has been offered since 2000, whereas nondisclosure PGD was rejected after thorough discussion ${ }^{6}$. In the Netherlands, PGD for direct HD testing has been allowed since 1998, following the directive relating to similar indications for PND and PGD. The first HD test was applied in 1999. In 2002, an embryo law was introduced, which was similar to the one in Belgium. Although HD exclusion testing remains accepted in PND, HD exclusion testing and HD non-disclosure testing has been excluded for PGD since $2006^{27}$. The Maastricht PGD centre is the only certified PGD centre in the Netherlands. In France, specific PGD legislation was introduced in 2000, defining PGD as an ultraprecocious form of PND. Initially, exclusion PGD was not permitted until the law was revised in 2004. PGD can only be practised in centres licensed by the Agence de Biomedecine. Similar to PGD requests, PND requests for HD have to be presented to a local multidisciplinary commission. However, exclusion PND for HD is exceptional, as most local multidisciplinary commissions do not accept TOP of at-risk foetuses and consider PGD as a better solution. Since exclusion PGD has been introduced, exclusion PND is no longer offered in France.

\section{Reimbursement of PGD}

In Belgium, PGD costs for Belgian couples are covered by their health insurance for six cycles, provided embryo transfer rules are respected. The Dutch health insurance companies cover three IVF/PGD cycles. In France, the cost of four IVF/PGD cycles resulting in embryo transfer are covered by the national health system. 


\section{Statistical analyses}

The differences between the centres relating to frequencies within the study populations were calculated using a $\chi^{2}$-test. The mean age of woman at treatment was compared with ANOVA.

\section{Results}

\section{Patients and counselling}

In total, 331 couples had a PGD intake at one of the three centres (Table 2); $68 \%$ of couples (225/331) requested direct testing and 32\% (106/331) requested exclusion PGD. In Strasbourg, significantly more couples asked for exclusion testing compared with Brussels (direct vs exclusion $49: 51 \%$ for Strasbourg and 67:33\% for Brussels; difference between these centres $P=0.0065)$. In Brussels, 71 of 116 intakes were Belgian couples, the remaining were couples from abroad, mainly from Germany. In Maastricht, all couples were Dutch. In Strasbourg, the vast majority of the couples were French.

The male:female ratio of CAG expansion carriers/at-risk persons for the three centres was 1:1.03 (111:114) for direct testing, and 1:0.89 (56:50) for exclusion testing, showing no significant skewing. In the direct testing group, 8.6\% $(15 / 174)$ of CAG expansion carriers had an allele with a reduced penetrance. The mean age of woman at intake was 29.64 years. No significant age difference was seen between the centres and between direct and exclusion testing (data not shown).

\section{Reproductive history}

Fertility problems necessitating IVF/ICSI were reported in 12\% (40/331) of the couples (Table 2). Of the total number of intakes, 39\% (129/331) of women had $\geq 1$ previous pregnancy and $21 \%$ (68/331) had experienced $\geq 1$ TOP after PND for HD. Significantly more women in the direct testing group had experienced TOP $(25 \%, 57 / 225)$ compared with the exclusion group $(10 \%$ (11/106); $P=0.0027)$.

For the exclusion group, more couples in Brussels $(53 \%, 20 / 38)$ than in Strasbourg $(22 \%, 13 / 59)$ had had at least one previous pregnancy $(P=0.007)$. In Brussels, $21 \%(8 / 38)$ of the couples had a history of $\geq 1$ TOP after exclusion PND, whereas in Strasbourg there was only one TOP after PND in the exclusion 
group $(P=0.0045)$. In Strasbourg, eight couples had a TOP without PND compared with one in Maastricht and one in Brussels.

A total of $18 \%$ (60/331) of the couples had at least one living child. Relatively more couples in the direct testing $(21 \%, 47 / 225)$ had offspring than in the exclusion group $(12 \%, 13 / 106)(P=0.08)$. In $45 \%(29 / 65)$ of these children, the risk of HD was excluded by direct testing $(52 \%, 26 / 50)$ or exclusion testing $(20 \%, 3 / 15)$. However, the differences were not significant $(P=0.059)$.

HD was excluded by PND or PGD in 65\% (15/23) of previous children from couples in Brussels, 50\% (10/20) in Maastricht and 18\% (4/22) in Strasbourg ( $P=0.0055$, difference between three centres). One of the couples referred for PGD in Maastricht had continued an affected pregnancy. In 17 out of 35 untested children, the (family) risk of HD was not yet known at the time of the pregnancy (Table 2).

\section{Genetic workup and outcomes after PGD intake}

Couples' genetic workup and outcomes after intake are shown in Table 3. For $78 \%$ (257/331) of the couples, genetic workup was started: $81 \%$ (183/225) for direct testing and $70 \%$ (74/106) for exclusion testing. In Brussels, 95\% (82/86) of the couples continued to at least one PGD cycle after successful genetic workup, in Maastricht this was 52\% (43/82) and in Strasbourg 55\% (49/89). After the closure of data collection (end 2008), in Brussels, Maastricht and Strasbourg, respectively, $5 \%, 7 \%$ and $28 \%$ of the couples were about to start their first cycle.

After intake, 9\% (29/331) of the couples were rejected by the PGD centre, for example because they were considered unsuitable for IVF (3\%). In the majority of these, an anticipated reduced ovarian response was indicated by high basal levels of follicular-stimulating hormones. Other couples were rejected owing to PGD-related technical obstacles (3\%). In Maastricht, relatively more couples $(16 \%, 16 / 100)$ were rejected compared with Brussels $(3.4 \%, 4 / 116)$ and Strasbourg $(8 \%, 9 / 115)$. A total of $18 \%(61 / 331)$ of couples refrained from PGD early or later after intake. Of the latter, one-third (19/61) refrained after achieving a spontaneous pregnancy in the meantime. Nearly $10 \%$ of the couples (32/331) were lost to follow-up. A substantial proportion of the couples refraining, lost to follow-up, or rejected, did complete genetic workup $(52 \%, 48 / 93)$. 


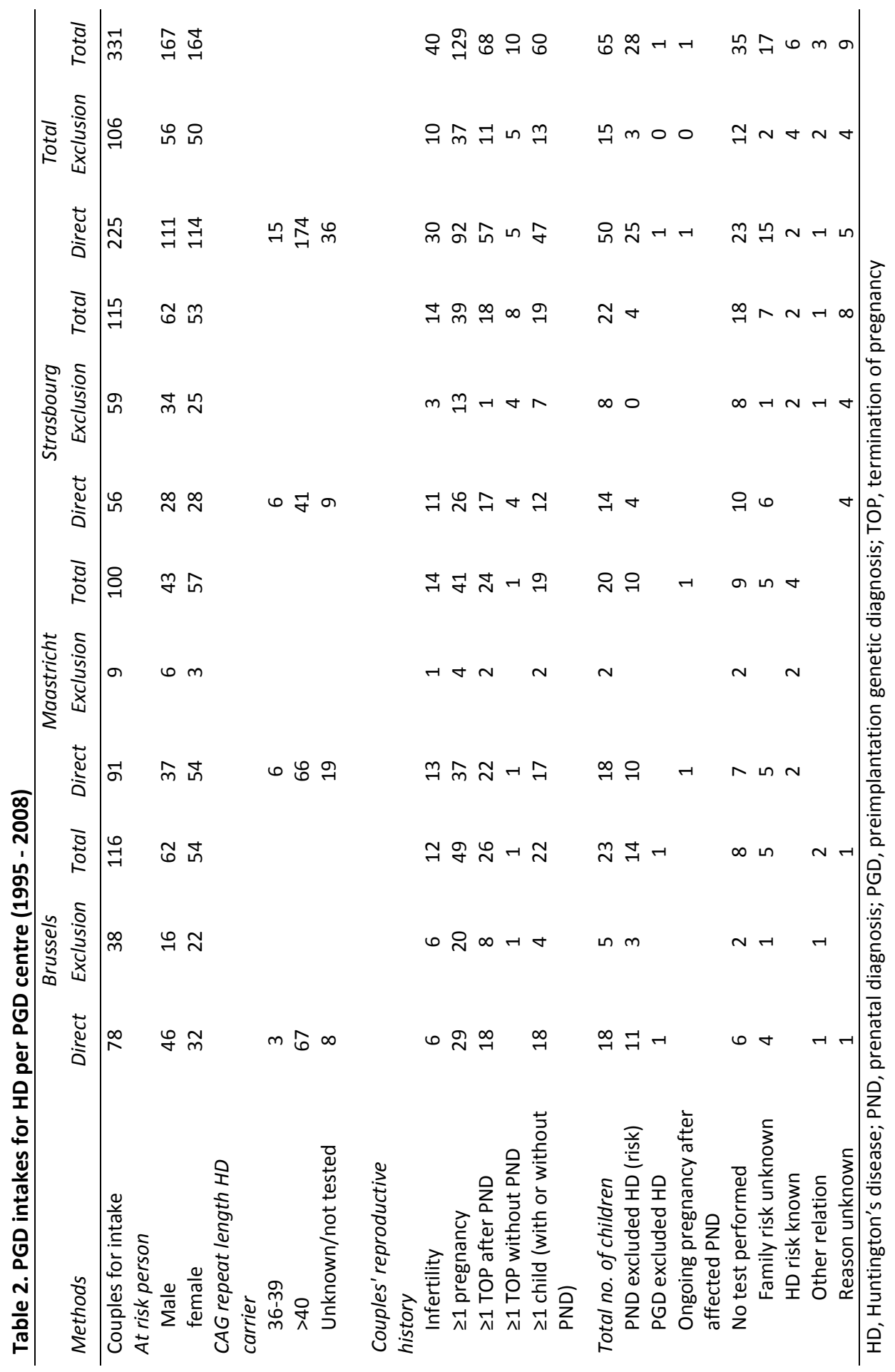




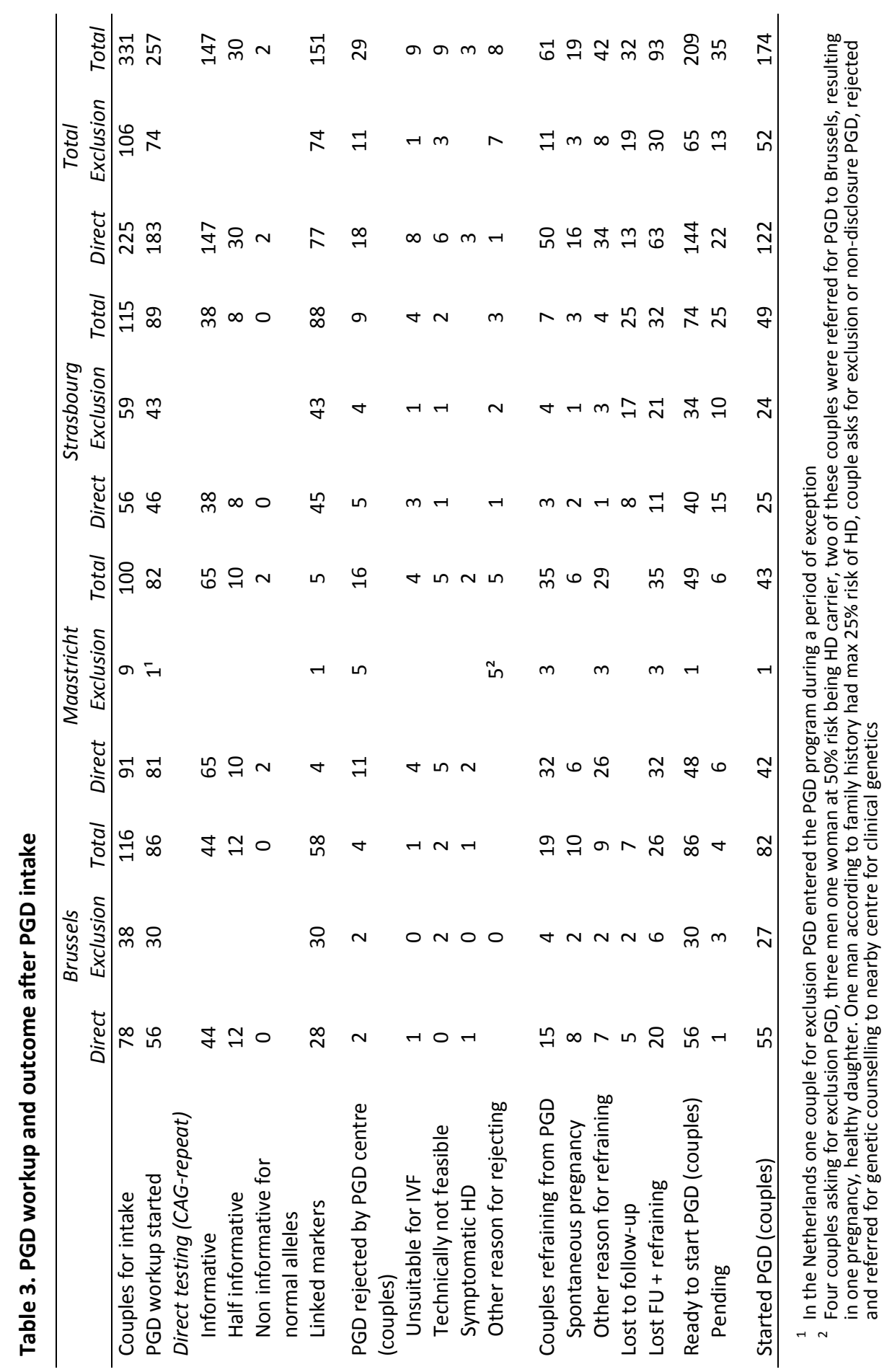


PGD cycles

An overview of all cycles per centre is shown in Table 4 . The mean age of women at the start of the first cycle was 31.3 years. Overall, 53\% (174/331) of couples for intake were treated (122 for direct testing and 52 for exclusion testing), 434 cycles were started and 389 cycles continued to OR. This resulted in 2.5 cycles to OR per couple in Brussels (202/82), 2.0 cycles to OR per couple (86/43) in Maastricht and 2.1 (101/49) in Strasbourg. The mean number of oocytes retrieved per cycle to OR was 15.01 in Brussels, 10.82 in Maastricht and 12.42 in Strasbourg, which shows a significant increase in the number of oocytes per cycle in Brussels compared with the other two centres $(P<0.0001)$. As in the case of the number of oocytes per cycle, the number of inseminated, fertilised and biopsied embryos show significant differences as well $(P<0.0001)$.

Overall, a mean of 11.1 oocytes per OR were inseminated (4318/389) and 8.1 oocytes per cycle to OR were successfully fertilised (3133/389). The mean number of biopsied embryos per cycle to OR was 5.9 (2277/389). The mean number of embryos transferred per cycle was 1.6 (511/310). The mean number of embryos per ET for each centre shows the opposite effect: 1.56 in Brussels, 1.77 in Maastricht and 1.72 in Strasbourg (significantly less embryos per ET in Brussels compared with Maastricht and Strasbourg: $P=0.0048$ ).

\section{Pregnancy outcome and children}

In total, 105 positive hCG tests occurred (84 women), resulting in 84 clinical pregnancies. Of the latter, five were lost in the first trimester. Detailed information on pregnancies and babies per centre are listed in Tables 5 and 6. A summary of cycles, pregnancies and babies is shown in Table 7 . The clinical pregnancy rate was $21.6 \%$ per cycle to OR and $27.1 \%$ per transfer. The delivery rates per OR were $19.8 \%$, and per embryo transfer $24.8 \%$. The overall delivery rate ( $\geq 1$ delivery) of couples starting $\geq 1$ PGD cycle was $37.4 \%$ (65/174). The pregnancy and delivery rates at the three centres did not show any significant differences. The 77 deliveries (65 couples) resulted in the birth of 90 children (65 singletons, 11 pairs of twins and one set of triplets). PND to confirm PGD results was performed more frequently in Brussels (41\%, 19/46 of clinical pregnancies) than in Maastricht (10\%, 2/21) and Strasbourg (0\%). 


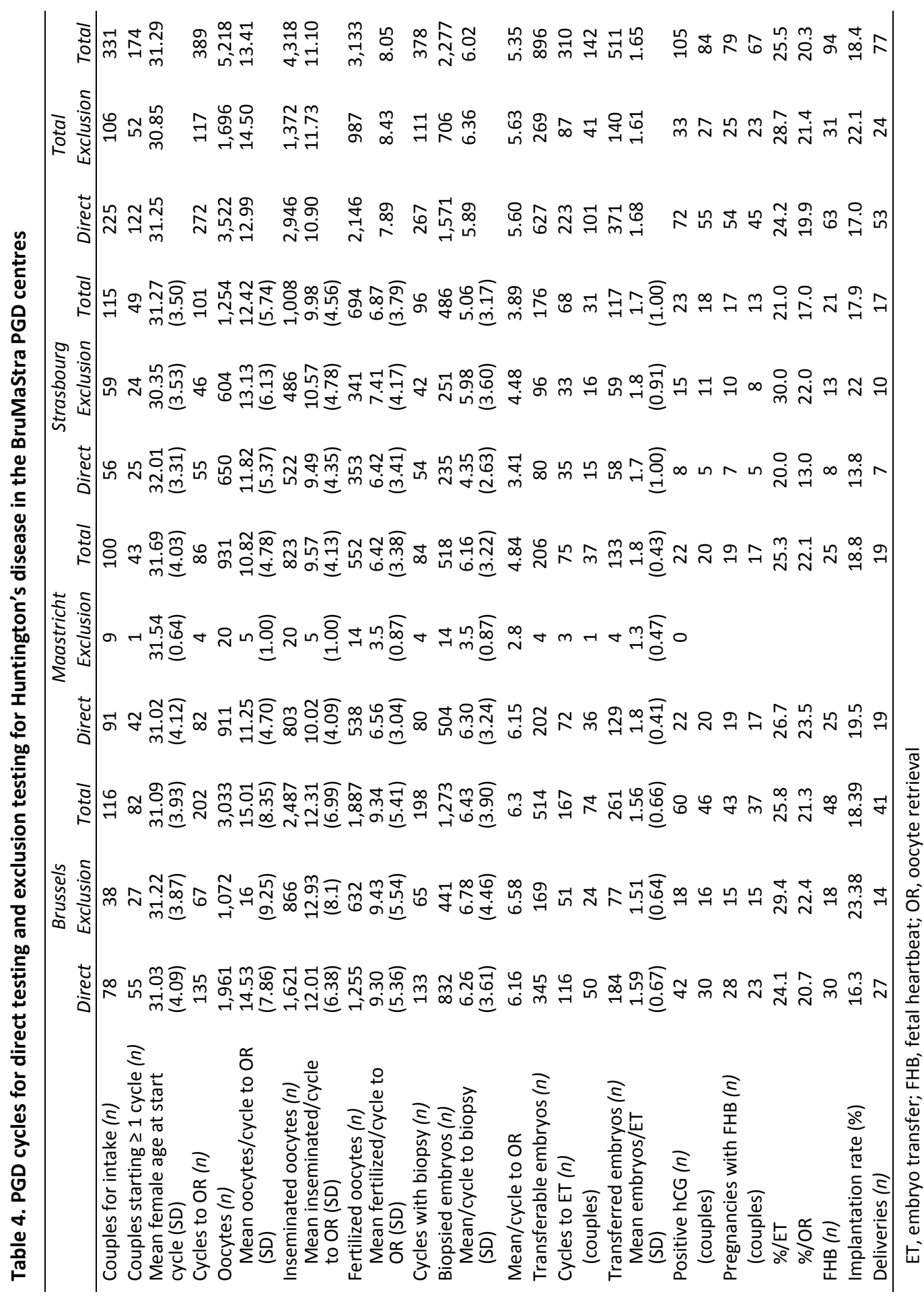


ఫ্் 홀

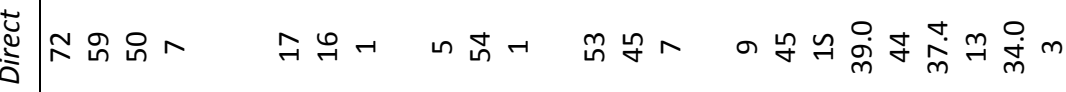

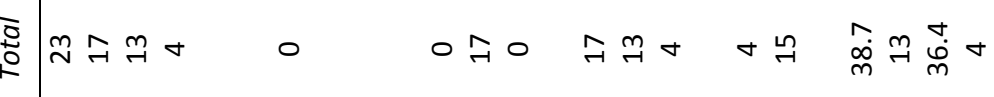
苟

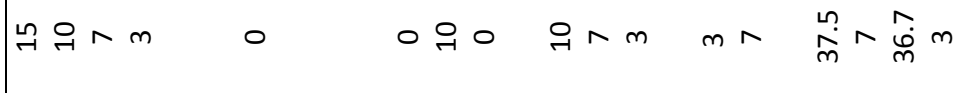

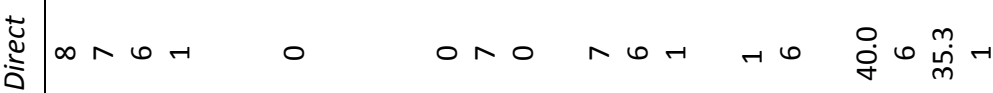
若

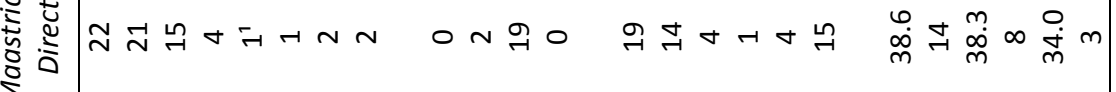
$\sum^{\circ}$

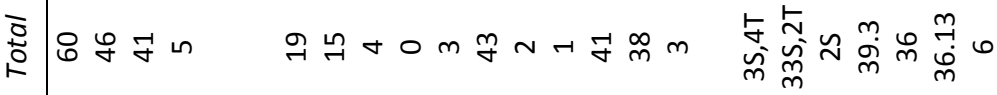
竞总

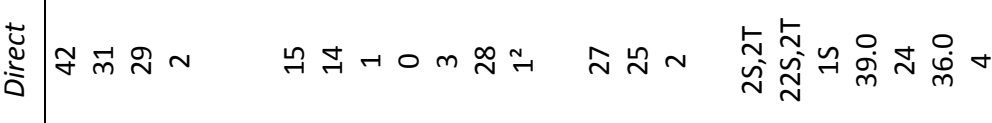

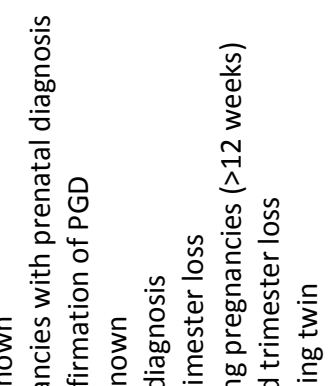




\section{PGD uptake}

To get an impression of the uptake of PGD in the three countries, the couples for PGD intake can be compared with the population at risk for $\mathrm{HD}^{28}$ at $\mathrm{a}$ reproductive age (Table 8 ). According to the literature, the prevalence of HD is similar in the three countries $(7.5 \text { per } 100,000)^{3,4}$. The population with a $50 \%$ risk of being an HD carrier was calculated according to Conneally ${ }^{28}$ : five times the prevalence of HD. The reproductive age group of at-risk (presymptomatic) persons was estimated to be half the total at-risk population, since the average age of onset is 30-40 years and the reproductive age starts around 15 to 20 years. Over a period of 10 years, the uptake of PGD for HD in Belgium was $1.70 \%$, in the Netherlands the uptake was $1.16 \%$ and in France $0.74 \%$.

\section{Discussion}

With an overall delivery rate of $37.4 \%$, we conclude that PGD has become a successful reproductive option for couples at risk of transmitting HD.

\section{PGD outcome}

The success rates of the three PGD centres are similar and match international data on pregnancy rates in $P G D^{5,6,11,29-32}$. The mean age of woman at the beginning of the first cycle (31.3 years), as well as the delivery rates per OR (19.8\% ) and per ET (24.8\%), are similar to those for PGD for HD reported in the ESHRE PGD data collection $X$ (mean age of woman: 32.0 years; delivery rate per OR: $19.8 \%$ and per ET: $23.6 \%)^{30}$. The increased number of oocytes per cycle in Brussels compensated for the reduced number of embryos per ET in Brussels (single ET law since 2003), and did not result in an increased pregnancy rate.

So far, no misdiagnosis has been reported. However, we realise that the choice of PGD to avoid TOP, the late onset of HD and the limited risk of misdiagnosis have led to a low uptake of control PND (21 tests/84 clinical PGD pregnancies) with a predominance of Belgian couples ${ }^{14,15}$. We presume that counselling differences may have contributed to the different numbers of control PND in the three centres. Moreover, presymptomatic testing for HD in newborns or older children is not recommended by the European Society of Human Genetics (ESHG) ${ }^{33}$. In consequence, the chances of tracing a misdiagnosis after PGD for HD within two or three decades will be very limited ${ }^{14}$. 


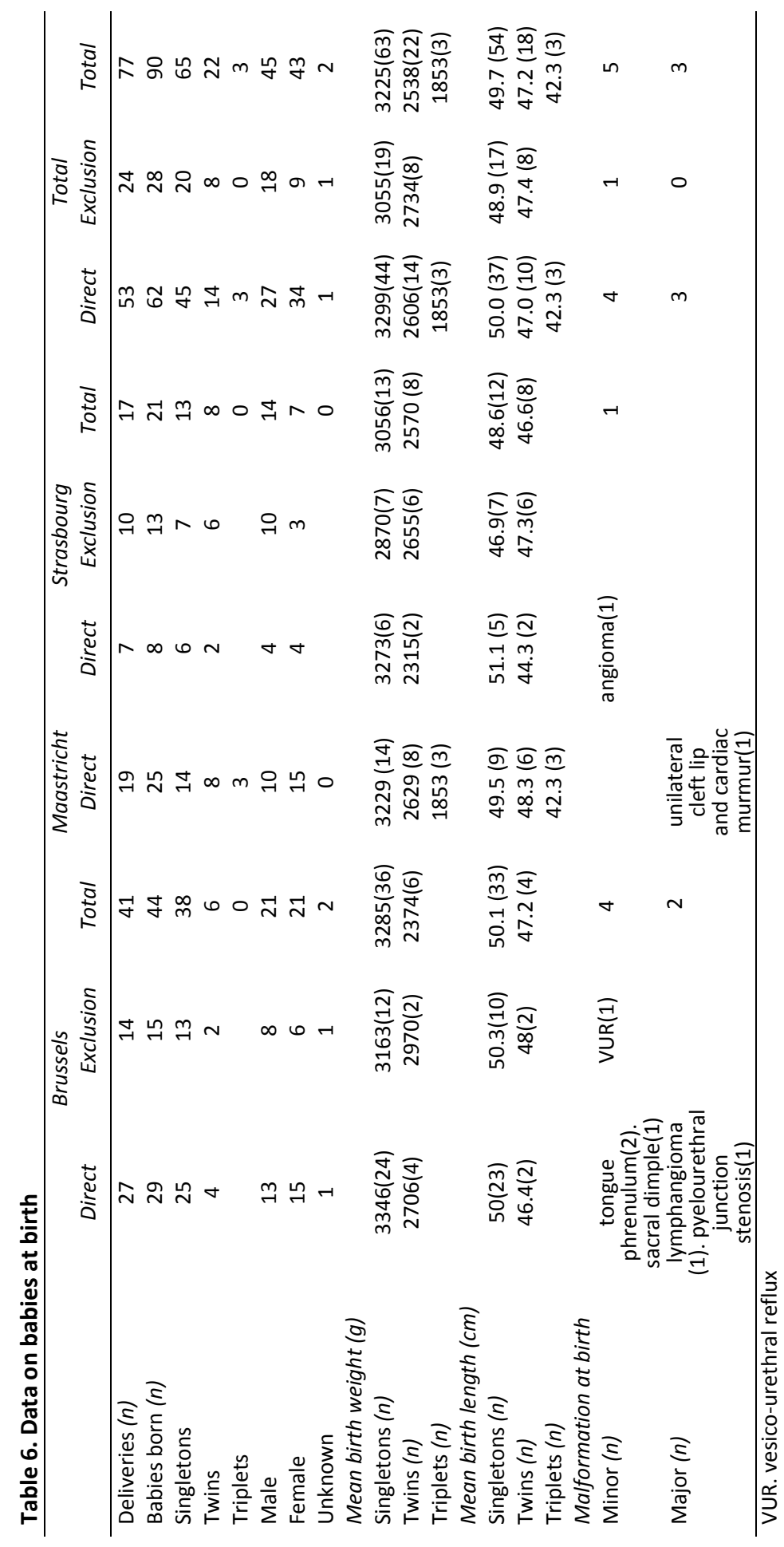






\section{Reproductive history}

In Strasbourg, significantly more couples (51\%) opted for exclusion PGD than in Brussels (33\%; $P=0.0065)$. In Australia, the proportion of exclusion PGD was $33 \%$, which is comparable to Brussels ${ }^{31,32}$. One might speculate that the increased interest in exclusion PGD in France is due to the relatively low uptake of presymptomatic testing for HD in France compared with Belgium and the Netherlands ${ }^{34}$. The position of the French Huntington Associations in favour of exclusion testing, coupled with counselling differences, may contribute to this difference. Another explanation might be that, since the first application of exclusion PGD, exclusion PND was no longer offered in France (personal communication, Moutou). The reluctance of couples to face PND and TOP, as well as the reluctance of care providers to offer (exclusion) PND for HD, may also be a reason for this reduction. A remarkable finding was that in Strasbourg there were eight couples who had a TOP without PND, compared with one in Maastricht and one in Brussels. The reproductive histories of couples opting for PGD exclusion testing showed relatively fewer pregnancies and significantly fewer pregnancy terminations after PND $(P=0.0027)$ compared with couples opting for PGD with direct testing. We conclude that couples opting for exclusion testing are more likely to choose PGD, whereas couples opting for direct testing more frequently choose PGD after a history of TOP. This may support the view that prenatal exclusion testing with subsequent TOP is even more difficult for at-risk couples than PND with subsequent TOP for definite HD carriers. After exclusion PND, 50\% of the terminated pregnancies will in fact be unaffected, whereas after direct PND all terminated pregnancies will be truly affected.

Our study shows an exact 50:50 male:female ratio $(n=331)$ with respect to the HD carriers or at-risk persons at PGD intake. This ratio is somewhat different from the 40:60 (male:female) ratio reported for couples opting for presymptomatic testing ${ }^{35-39}$; and to the 40:60 distribution among the couples opting for $\mathrm{PND}^{34,36,40,41}$. Whether these differences are true or biased, perhaps because of small sample sizes, remains to be elucidated.

\section{PGD approach}

During the period covered by this study, PGD procedures for each centre evolved from simplex PCR for the CAG repeat length to multiplex PCR in which several microsatellite markers flanking the HTT gene are combined alone or with the CAG repeat. With the increasing number of markers applied, the chances of 
couples being unsuitable for PGD because of non-informativity have decreased over the years ${ }^{5-7}$. In addition, this combined approach improves the reliability of the proposed tests.

The number of couples rejected after PGD counselling is significantly higher in Maastricht (16\%) than in Brussels (3.4\%) and Strasbourg (8\%), even after subtracting the exclusion PGD requests in Maastricht (12\%, 11/91). One causative difference is that before the introduction of marker testing, halfinformative couples were rejected in Maastricht, whereas they were treated in Brussels. In Strasbourg, PGD was combined with linkage analyses for all halfinformative couples from the beginning. Maastricht introduced marker testing for HD 2 years later (2006) than Brussels and Strasbourg (2004) 5,6. Moreover, the inclusion criteria for IVF in Maastricht are stricter than in Brussels and Strasbourg. A considerable proportion of couples (18\%) refrained from PGD after intake, and $10 \%$ of the couples were lost to follow-up after intake. The relatively high number of couples lost to follow-up in France could be because of the distances the couples had to travel to the PGD centre in Strasbourg, as well as because of the long delays between intake and PGD.

\section{Uptake}

France had a lower uptake of PND between 1993 and 1998 (0.12 PND per million) compared with other European countries studied (Belgium 2.9 PND per million, The Netherlands 5.7 PND per million) ${ }^{34}$. Calculating the PGD uptake, we used the 1:5 (HD prevalence:50\% HD risk) ratio proposed by Conneally ${ }^{28}$. As the PGD population consists of both couples at a $50 \%$ risk and confirmed presymptomatic carriers, we did not correct for the presymptomatic HD carriers as recently proposed ${ }^{42}$. The 10 -year uptake of PGD for HD in Belgium in the at-risk population in the reproductive age was $1.7 \%$, in the Netherlands it was $1.16 \%$ and in France $0.74 \%$. In the first few years after the implementation of PGD, the yearly data showed some fluctuation, but after a gradual increase the yearly implementation of PGD is now showing more stability. If we consider the proportion of exclusion testing in Brussels and the proportion in Strasbourg, the uptake of direct testing in Brussels and the Netherlands shows great similarity. In addition, the uptake of exclusion PGD in France and Belgium seems quite similar. The limitations of our uptake calculations are the limited period of study and the time lapse between the intake of PGD couples and their first cycle, making it difficult to define the right period. Furthermore, many refraining couples are still of reproductive age and might still reconsider starting PGD. In a previous study on heterogeneous PGD candidates, we 
observed that $5 \%$ of the couples actually starting PGD had refrained from PGD previously ${ }^{43}$. For a more accurate calculation of the PGD uptake in the future, a longer period should be studied, excluding the first years of implementation of PGD.

\section{Conclusion}

We conclude that in the past two decades PGD has become an appropriate reproductive option for couples at risk of transmitting HD. For the relatively large number of at-risk persons who decide to remain uninformed about their own carrier status, exclusion PND or exclusion PGD are options leading to biological offspring free from HD. The availability of exclusion PGD for countries where it is not yet permitted has to be reconsidered, as it is clear that this procedure supplies a need. Finally, the importance of proper genetic and reproductive counselling for all couples considering PND or PGD should be emphasised.

\section{References}

1. Bates G, Harper P, Jones L (eds): Huntington's Disease. Oxford University Press, New York, 2002.

2. Huntington's Disease Collaborative Research Group: A novel gene containing a trinucleotide repeat that is expanded and unstable on Huntington's disease chromosomes. Cell 1993; 72: 971-983.

3. Novak MJ, Tabrizi SJ: Huntington's disease. British Medical Journal (Clinical research ed) 2010; 340: c3109.

4. Roos RA: Huntington's disease: a clinical review. Orphanet journal of rare diseases 2010; 5: 40.

5. Moutou C, Gardes N, Viville S: New tools for preimplantation genetic diagnosis of Huntington's disease and their clinical applications. European Journal of Human Genetics 2004; 12: 1007-1014.

6. Sermon $K$, de Rijcke $M$, Lissens $W$ et al: Preimplantation genetic diagnosis for Huntington's disease with exclusion testing. European Journal of Human Genetics 2002; 10: 591-598.

7. Sermon K, Goossens V, Seneca S et al: Preimplantation diagnosis for Huntington's disease (HD): clinical application and analysis of the HD expansion in affected embryos. Prenatal diagnosis 1998; 18: 1427-1436. 
8. Sermon $K$, Seneca $S$, de Rycke $M$ et al: PGD in the lab for triplet repeat diseases myotonic dystrophy, Huntington's disease and Fragile-X syndrome. Molecular and cellular endocrinology 2001; 183 Suppl 1: S77-85.

9. Harper PS, Sarfarazi M: Genetic prediction and family structure in Huntington's chorea. British Medical Journal (Clinical research ed) 1985; 290: 1929-1931.

10. Schulman JD, Black SH, Handyside A, Nance WE: Preimplantation genetic testing for Huntington disease and certain other dominantly inherited disorders. Clinical genetics 1996; 49: 57-58.

11. Stern $\mathrm{HJ}$, Harton GL, Sisson ME et al: Non-disclosing preimplantation genetic diagnosis for Huntington disease. Prenatal diagnosis 2002; 22: 503-507.

12. Braude PR, de Wert GM, Evers-Kiebooms G, Pettigrew RA, Geraedts JP: Non-disclosure preimplantation genetic diagnosis for Huntington's disease: practical and ethical dilemmas. Prenatal diagnosis 1998; 18: 1422-1426.

13. Evers-Kiebooms G, Zoeteweij M, Harper PS: Prenatal Testing for Late-onset Neurogenetic Diseases. Oxford: BIOS Scientific Publishers Ltd, 2002.

14. Dreesen J, Drusedau $\mathrm{M}, \mathrm{Smeets} \mathrm{H}$ et al: Validation of preimplantation genetic diagnosis by PCR analysis: genotype comparison of the blastomere and corresponding embryo, implications for clinical practice. Molecular human reproduction 2008; 14: 573-579.

15. Wilton L, Thornhill A, Traeger-Synodinos J, Sermon KD, Harper JC: The causes of misdiagnosis and adverse outcomes in PGD. Human reproduction (Oxford, England) 2009; 24: 1221-1228.

16. Gianaroli L, Plachot M, van Kooij R et al: ESHRE guidelines for good practice in IVF laboratories. Committee of the Special Interest Group on Embryology of the European Society of Human Reproduction and Embryology. Human reproduction (Oxford, England) 2000; 15: 2241-2246.

17. Thornhill AR, de Die-Smulders CE, Geraedts JP et al: ESHRE PGD Consortium 'Best practice guidelines for clinical preimplantation genetic diagnosis (PGD) and preimplantation genetic screening (PGS)'. Human reproduction (Oxford, England) 2005; 20: 35-48.

18. Vandervorst $\mathrm{M}$, Liebaers $\mathrm{I}$, Sermon $\mathrm{K}$ et al: Successful preimplantation genetic diagnosis is related to the number of available cumulus-oocyte complexes. Human reproduction (Oxford, England) 1998; 13: 3169-3176.

19. Devroey P, van Steirteghem A: A review of ten years experience of ICSI. Human reproduction update 2004; 10: 19-28.

20. de Vos A, van Steirteghem A: Aspects of biopsy procedures prior to preimplantation genetic diagnosis. Prenatal diagnosis 2001; 21: 767-780.

21. Goossens V, de Rycke M, de Vos A et al: Diagnostic efficiency, embryonic development and clinical outcome after the biopsy of one or two blastomeres for preimplantation genetic diagnosis. Human reproduction (Oxford, England) 2008; 23: 481-492.

22. van Landuyt L, de Vos A, Joris H, Verheyen G, Devroey P, van Steirteghem A: Blastocyst formation in in vitro fertilization versus intracytoplasmic sperm injection cycles: influence of the fertilization procedure. Fertility and sterility 2005; 83: 1397-1403. 
23. Sermon K, van Steirteghem A, Liebaers I: Preimplantation genetic diagnosis. Lancet 2004; 363: 1633-1641.

24. Zegers-Hochschild F, Adamson GD, de Mouzon J et al: The International Committee for Monitoring Assisted Reproductive Technology (ICMART) and the World Health Organization (WHO) Revised Glossary on ART Terminology, 2009. Human reproduction (Oxford, England) 2009; 24: 2683-2687.

25. Bonduelle $M$, Liebaers I, Deketelaere $V$ et al: Neonatal data on a cohort of 2889 infants born after ICSI (1991-1999) and of 2995 infants born after IVF (1983-1999). Human reproduction (Oxford, England) 2002; 17: 671-694.

26. Wet betreffende medisch begeleide voortplanting en de bestemming van de overtollige embryo's en gameten (Law concerning assisted reproduction and the handeling of surpluss embryos and gametes). Belgisch Staatsblad 2007: 38575-38586.

27. Bussemaker M: Regeling preïmplantatie genetische diagnostiek van de staatssecretaris van Volksgezondheid, Welzijn en Sport (Regulations of the State Secretary of Health on the rules concerning PGD): Staatscourant: Koninkrijk der Nederlanden, 2009, Nr. 42 edn, Vol 42, pp 1-12.

28. Conneally PM: Huntington disease: genetics and epidemiology. American journal of human genetics 1984; 36: 506-526.

29. Decruyenaere M, Evers-Kiebooms G, Boogaerts A et al: The complexity of reproductive decision-making in asymptomatic carriers of the Huntington mutation. European Journal of Human Genetics 2007; 15: 453-462.

30. Harper JC, Coonen E, de Rycke $M$ et al: ESHRE PGD Consortium data collection X: cycles from January to December 2007 with pregnancy follow-up to October 2008. Human reproduction (Oxford, England) 2010; 25: 2685-2707.

31. Jasper MJ, Hu DG, Liebelt J et al: Singleton births after routine preimplantation genetic diagnosis using exclusion testing (D4S43 and D4S126) for Huntington's disease. Fertility and sterility 2006; 85: 597-602.

32. Tassicker RJ, Marshall PK, Liebeck TA, Keville MA, Singaram BM, Richards FH: Predictive and pre-natal testing for Huntington Disease in Australia: results and challenges encountered during a 10-year period (1994-2003). Clinical genetics 2006; 70: 480-489.

33. Borry P, Evers-Kiebooms G, Cornel MC, Clarke A, Dierickx K: Genetic testing in asymptomatic minors: background considerations towards ESHG Recommendations. European Journal of Human Genetics 2009; 17: 711-719.

34. Simpson SA, Zoeteweij MW, Nys $\mathrm{K}$ et al: Prenatal testing for Huntington's disease: a European collaborative study. European Journal of Human Genetics 2002; 10: 689-693.

35. Craufurd D, Dodge A, Kerzin-Storrar L, Harris R: Uptake of presymptomatic predictive testing for Huntington's disease. Lancet 1989; 2: 603-605.

36. Creighton S, Almqvist EW, MacGregor D et al: Predictive, pre-natal and diagnostic genetic testing for Huntington's disease: the experience in Canada from 1987 to 2000. Clinical genetics 2003; 63: 462-475.

37. Evers-Kiebooms G, Nys K, Harper P et al: Predictive DNA-testing for Huntington's disease and reproductive decision making: a European collaborative study. European Journal of Human Genetics 2002; 10: 167-176. 
38. Harper PS, Lim C, Craufurd D: Ten years of presymptomatic testing for Huntington's disease: the experience of the UK Huntington's Disease Prediction Consortium. Journal of medical genetics 2000; 37: 567-571.

39. Maat-Kievit A, Vegter-van der Vlis M, Zoeteweij M, Losekoot M, van Haeringen A, Roos R: Paradox of a better test for Huntington's disease. Journal of neurology, neurosurgery, and psychiatry 2000; 69: 579-583.

40. Adam S, Wiggins S, Whyte $P$ et al: Five year study of prenatal testing for Huntington's disease: demand, attitudes, and psychological assessment. Journal of medical genetics 1993; 30: 549-556.

41. Maat-Kievit A, Vegter-van der Vlis $M$, Zoeteweij $M$ et al: Experience in prenatal testing for Huntington's disease in The Netherlands: procedures, results and guidelines (19871997). Prenatal diagnosis 1999; 19: 450-457.

42. Tassicker RJ, Teltscher B, Trembath MK et al: Problems assessing uptake of Huntington disease predictive testing and a proposed solution. European Journal of Human Genetics 2009; 17: 66-70.

43. van Rij MC, Gielen M, Lulofs R et al: Profiles and motives for PGD: a prospective cohort study of couples referred for PGD in the Netherlands. Human reproduction (Oxford, England) 2011; 26: 1826-1835. 
Chapter 4

The uptake and outcome of prenatal and preimplantation genetic diagnosis for Huntington's disease in the Netherlands (1998-2008)

M.C. van Rij

P.A.M. de Koning Gans

M.J. van Belzen

R.A.C. Roos

J.P.M. Geraedts

M. de Rademaeker

E.K. Bijlsma

C.E.M. de Die-Smulders 


\section{Abstract}

We aimed to study reproductive behaviour of couples opting for prenatal diagnosis (PND) and preimplantation genetic diagnosis (PGD) for Huntington's disease (HD). In the Netherlands exclusion PND is available for persons at $50 \%$ risk, whereas exclusion PGD is not allowed.

All 162 couples who underwent PND or PGD for HD between 1998 and 2008 and referrals for exclusion PGD to Belgium were included. Couples' reproductive information was collected until December 2010.

132 couples (81.5\%) underwent PND in 262 pregnancies, 54 (33.3\%) started PGD, 25 used both. 16\% of PND-couples used exclusion-PND, 6\% used exclusion-PGD. Outcome: $76.5 \%$ of PND couples delivered $\geq 1$ unaffected child(ren) after PND, and $44.4 \%$ of PGD couples delivered $\geq 1$ PGD-child(ren) (mean 2.5 cycles/couple). Couples opting for PGD secondarily (after a previous pregnancy), had more frequently terminated a pregnancy for HD (87.0\%), compared with couples secondarily opting for PND (55.2\%) ( $p=0.015)$. At-risk or HD expansion carrier males were underrepresented in the group of couples primarily opting for PGD (25\%), and overrepresented in the secondary PGD group (64\%).

We conclude that couples reconsider their choices in every subsequent pregnancy based on their previous experience, personal beliefs and the gender of the at-risk partner. 


\section{Introduction}

Huntington's disease (HD) is a severe progressive autosomal dominant neurodegenerative disorder characterized by chorea and hypokinesia, dementia, and psychiatric disorders ${ }^{1}$. Currently, there is no curative treatment available $e^{2,3}$. The mean age at onset is between 35 and 44 years. The median duration of illness is 17 years. HD is caused by an expanded CAG repeat in the HTT gene on chromosome $4(4 p 16.3)^{4}$. Up to 26 CAG repeats are considered normal, 27-35 repeats are within the intermediate range, 36-39 CAG repeats are associated with reduced penetrance, whereas full penetrance is observed from 40 repeats onwards.

Since the introduction of direct testing for HD in 1993, an estimated $24 \%$ of atrisk persons in the Netherlands opted for a presymptomatic test $(P T)^{5-7}$. Reproductive decisions are among the most frequently mentioned reasons for performing $\mathrm{PT}^{5,8,9}$.

HD expansion carriers may want to avoid transmission of the disease to their offspring. They have various reproductive options, such as a spontaneous pregnancy with prenatal diagnosis (PND) and termination of pregnancy (TOP) in case of a foetus with the CAG expansion, or preimplantation genetic diagnosis (PGD) ${ }^{10}$. In PGD one or two blastomeres of each embryo, obtained by IVF, are biopsied and analysed for the presence of the CAG expansion, and/or the presence of genetically linked markers associated with the CAG expansion $^{11-13}$.

For individuals with $50 \%$ HD risk, who do not want to know their own status, exclusion testing using PND or PGD is a possibility. Linked markers are used to establish the origin of the HTT allele present in the foetus ${ }^{11,12}$. The detection of an HTT allele from the affected grandparent is associated with a $50 \% \mathrm{HD}$ risk, identical to the at-risk parent. In this case the pregnancy will be terminated or the PGD embryo will be discarded. In the Netherlands exclusion PND (ePND) is applied since $1989^{5}$. However, exclusion PGD (ePGD) is prohibited for the following reasons: roughly half of the couples at risk will 'unnecessarily' undergo an invasive IVF/PGD treatment and discarding embryos with a $50 \%$ risk of not being an HD expansion carrier is considered unethical $^{14,15}$.

This retrospective cohort study surveys the complete reproductive behaviour of a cohort of all HD expansion carriers and at-risk persons opting for PND and PGD in the Netherlands from 1998 to 2008. The efficacy of PND and PGD is illustrated by comparing the cumulative outcomes of PND and PGD and the uptake was estimated. 


\section{Materials and methods}

\section{Organisation of PND and PGD in the Netherlands}

PND for HD has been available in the Netherlands since $1987^{5}$. Chorionic villus sampling (CVS) or amniocentesis (AC) can take place in one of 8 centres for PND. All samples for PND analyses are examined at the Leiden University Medical Centre (LUMC). In 1995 the Maastricht University Medical Centre (MUMC), started the only licensed PGD centre in the Netherlands. In 1999 the first PGD cycle for HD was performed. IVF treatment necessary for PGD, and biopsy of the embryo, can also take place in two IVF centres in Utrecht and Groningen, in which case blastomeres are transported to Maastricht for PGD analysis. At first, only direct testing was offered ${ }^{16}$. Since 2006 ePGD for HD is prohibited by law ${ }^{13,15}$. Couples requesting ePGD may be referred to the PGD centre in Brussels.

\section{Patients}

Those included were all HD expansion carriers or at-risk persons who had performed PND in one or more pregnancies and HD expansion carriers or at-risk persons who started PGD between 1998 and 2008. The databases of PND analyses (LUMC) and PGD referrals and treatments (MUMC and UZ Brussels) were combined in order to match identical individuals. Information on the age of both partners and the gender of the HD expansion carrier or at-risk person was collected from the patients' files of the centres for PND throughout the country and the PGD centre in Maastricht. The date of PT was registered. We collected detailed information on reproductive history and all consecutive pregnancies and PGD cycles until December 2010.

\section{Definitions}

Each natural conception with or without PND and each PGD cycle started was defined as an attempt to have a child. All possible attempts recorded are listed in Box 1. All reproductive attempts and their outcomes were ordered chronologically, including pregnancies preceding the first PND or PGD attempt (miscarriage, untested child).

\section{Primary or secondary reproductive choices}

We distinguished couples primarily opting for PND or PGD with no previous pregnancy and couples who started PND or PGD secondarily, after a history of PGD or PND, or an untested pregnancy. Every PND attempt involves many possible outcomes, depending on the test result and the course of the pregnancy after PND (Box 1). We assumed that the experience of PND and its 
Box 1. Decision-making process with respect to conception, diagnosis, and outcome of all attempts

1. Spontaneous conception

a. Pregnancy without prenatal diagnosis

i. Pregnancy loss

ii. Pregnancy termination (TOP)

iii. Birth of $\geq 1$ child

b. Pregnancy with prenatal diagnosis

i. Pregnancy loss

ii. Pregnancy termination (TOP)

iii. Normal pregnancy and child unaffected with HD

iv. Continued pregnancy of HD carrier or at-risk foetus

2. IVF and PGD treatment cycle

a. No pregnancy

b. Pregnancy after PGD

i. Pregnancy loss

ii. Pregnancy termination (TOP)

iii. Birth of $\geq 1$ child unaffected with HD

GA, gestational age; TOP, termination of pregnancy; HD, Huntington's disease; PGD, preimplantation genetic diagnosis

variation of possible outcomes contributed to the choice of the following attempt ${ }^{17}$. For this reason, couples repeatedly using PND were included in the secondary PND group (after the first attempt). In contrast, the most likely PGD outcome is 'pregnant yes/no', and the chance of an adverse effect resulting in TOP for HD due to misdiagnosis after PGD is very limited ${ }^{18}$. Moreover, successive PGD use is, as a rule, only offered after a PGD treatment has resulted in the birth of a child after a maximum of 3 to 4 cycles. Because of these biases, the couples repeatedly using PGD were regarded as a separate group.

\section{Outcome and uptake of PND and PGD}

To compare the efficacy of both PND and PGD the cumulative outcome after (repeated) PND or PGD attempts per couple was monitored. The uptake of PND and PGD among HD expansion carriers of reproductive age (arbitrarily set at females $\leq 40$ years, and males $\leq 50$ years) was estimated. Details on the calculation of uptake are described elsewhere ${ }^{19}$. 
Data were analysed in coded form. According to the Dutch law governing the rights and duties of patients and medical practitioners (WGBO) ${ }^{20}$, all couples involved implicitly consent to their anonymous data being used for scientific research. Approval of the Medical Ethics Committee of the MUMC was obtained.

\section{Statistics}

Comparisons of differences regarding the gender of the partner at risk or HD expansion carrier, and couples' reproductive histories (frequencies between groups) were performed by $\chi^{2}$ tests (corrected for continuity). Continuous data (age at certain moments and time intervals) were compared using a $t$-test.

All reported p-values are two-sided and results were considered statistically significant if $p \leq 0.05$. The analyses were conducted with SPSS for Windows version 17.

\section{Results}

A total of 162 couples were included in the study. The index cases were 89 female and 73 male HD expansion carriers or persons at $50 \%$ risk. More females than males had performed a PT prior to their first PND or PGD attempt (85.4\% versus $69.9 \%, p=0.017)$.

One hundred and eight couples exclusively used PND in one or more pregnancies, 29 couples exclusively had one or more PGD cycles, 25 couples used both PND and PGD. Two couples used PND to check for misdiagnosis in a PGD pregnancy.

An overview of all 458 recorded attempts by the 162 couples is listed in Table 1. The mean number of attempts per couple was 2.8 (range 1-9). 137 couples had 322 spontaneous conceptions. In all, 132 couples (81.5\%) opted for PND in 262 pregnancies. The majority were direct tests $(84.1 \%)$, whereas in $12.9 \%$ of couples ePND was performed and in $3 \%$ exclusion-definitive testing.

Of all couples opting for PND, $47.0 \%$ had $\geq 1$ TOP for HD, and $76.5 \%$ had delivered $\geq 1$ child free from HD. Twelve couples (9.1\%) continued their pregnancy with an HD expansion or $50 \%$ risk allele. Two withdrew without obtaining the PND result (Table 1).

Fifty-four couples started PGD cycles. Three of these (5.6\%) used ePGD. Four couples continued PGD treatment after interruption with a spontaneous pregnancy. A total of 136 PGD cycles were performed (mean 2.5 cycles per couple). In $44.4 \%$ (24/54) of the PGD couples 26 ongoing pregnancies resulted 
Table 1. Overview of details of all couples and attempts recorded

\begin{tabular}{|c|c|c|c|c|c|c|}
\hline & ples $^{1}$ & $\begin{array}{l}\% \text { of } \\
\text { total }\end{array}$ & $\begin{array}{l}\% \text { of } \\
\text { sub- } \\
\text { total }\end{array}$ & $\begin{array}{l}\text { Attempts } \\
\text { /cycles }\end{array}$ & $\begin{array}{l}\% \text { of } \\
\text { total }\end{array}$ & $\begin{array}{l}\% \text { of } \\
\text { sub- } \\
\text { total }\end{array}$ \\
\hline Total attempts & 162 & 100 & & 458 & 100 & \\
\hline Total PND in spontaneous pregnancy & 132 & 81.5 & 100 & 262 & $\mathbf{5 7 . 2}$ & 100 \\
\hline Direct test & 114 & 70.4 & 86.4 & 224 & 48.9 & 85.5 \\
\hline Exclusion test & 17 & 10.5 & 12.9 & 34 & 7.4 & 13.0 \\
\hline Exclusion test followed by direct PND & 4 & 2.5 & 3.0 & 4 & 0.9 & 1.5 \\
\hline \multicolumn{7}{|l|}{ Outcome after PND } \\
\hline Miscarriage or late pregnancy loss ${ }^{2}$ & 8 & 4.9 & 6.1 & 9 & 2.0 & 3.4 \\
\hline Total TOP after PND & 62 & 38.3 & 47.0 & 101 & 22.1 & 38.5 \\
\hline TOP affected & 53 & 32.7 & 40.2 & 83 & 18.1 & 82.2 \\
\hline TOP at-risk & 8 & 4.9 & 6.1 & 13 & 2.8 & 12.9 \\
\hline TOP other reason ${ }^{3}$ & 5 & 3.1 & 3.8 & 5 & 1.1 & 1.9 \\
\hline Continued pregnancy affected/at-risk ${ }^{4}$ & 12 & 7.4 & 9.1 & 12 & 2.6 & 4.6 \\
\hline Withdrew without obtaining PND & 2 & 1.2 & 1.5 & 2 & 0.4 & 0.8 \\
\hline Lost to follow up after PND ${ }^{5}$ & 3 & 1.9 & 2.3 & 3 & 0.7 & 1.1 \\
\hline Child $(\geq 1)$ no HD & 101 & 62.3 & 76.5 & 135 & 29.5 & 51.5 \\
\hline Total started PGD & 54 & 33.3 & 100 & 136 & 29.7 & 100 \\
\hline Direct testing cycles & 51 & 31.5 & 94.4 & 126 & 92.6 & 92.6 \\
\hline Exclusion testing cycles ${ }^{6}$ & 3 & 1.9 & 5.6 & 8 & 5.9 & 5.9 \\
\hline \multicolumn{7}{|l|}{ Outcome after PGD } \\
\hline No pregnancy & 42 & 25.9 & 77.8 & 105 & 22.9 & 77.2 \\
\hline Miscarriage after PGD & 5 & 3.1 & 9.3 & 5 & 1.1 & 3.7 \\
\hline PGD child $(\geq 1)$ delivered & 24 & 14.8 & 44.4 & 26 & 5.7 & 19.1 \\
\hline Total pregnancies without PND & 43 & 26.5 & 100 & 60 & 13.1 & 100 \\
\hline Miscarriage (without PND) & 23 & 14.2 & 53.5 & 30 & 6.6 & 50.0 \\
\hline TOP without PND & 3 & 1.9 & 7.0 & 3 & 0.7 & 5.0 \\
\hline Child without PND & 21 & 13.0 & 48.8 & 27 & 5.9 & 45.0 \\
\hline
\end{tabular}

1 The number of couples does not add up to 162 or $100 \%$, since couples show combinations of different attempts

2 Three pregnancies (unaffected with HD) were lost after the first trimester due to intrauterine or perinatal death

3 Termination of singleton pregnancies for neural tube defect or aneuploidy

4 Ten couples continued their pregnancy with a HD expansion carrier foetus; two continued pregnancies showed $50 \%$ HD risk alleles in the foetus

5 Two unaffected foetuses, one $50 \%$ risk allele

6 Two couples were treated at the PGD centre of Brussels University Hospital (five cycles), one couple in the Maastricht University Medical Centre before exclusion PGD was prohibited in the Netherlands 
in the birth of 33 PGD children. Of the total group ( $n=162$ ), 23 couples (14.2\%) had $\geq 1$ miscarriages in spontaneous pregnancies (without PND). Three couples had a TOP without PND (1.9\%), and 21 couples $(13.0 \%)$ had $\geq 1$ ongoing pregnancies without PND.

\section{Patterns in the use of PND and PGD}

Figure 1 shows a summary of the reproductive choices of all 162 couples who used PND and/or PGD during the period of study. Of these couples, 99 couples opted for PND in their first pregnancy, 28 couples primarily opted for PGD. Thirty-five couples had $\geq 1$ pregnancies before their first PND or PGD attempt, resulting in $\geq 1$ miscarriages (14 couples) or live-born untested child(ren) (21 couples).

In the primary PND as well as in the primary PGD group more females were at risk/HD expansion carriers ( $75 \%$ and $57 \%$ respectively), whereas in the primary non-PND/PGD groups the majority of at-risk/HD expansion carriers were male (71\% and $57 \%$ respectively) $\left(\chi^{2}: p=0.01\right.$ ) (Table 2 ).

Thirty-four of the 99 primary PND couples stopped using a form of testing after their first attempt (Figure 1 ). The majority of these couples (25/34) had

Table 2. Characteristics of couples in the primary choice groups

\begin{tabular}{|c|c|c|c|c|c|c|c|c|c|}
\hline & \multicolumn{2}{|c|}{ Primary PND } & \multicolumn{2}{|c|}{ Primary $P G D$} & \multicolumn{4}{|c|}{ Primary no $P N D / P G D$} & \multirow{3}{*}{$\begin{array}{c}\text { Difference } \\
\text { between } \\
\text { groups }^{1} \\
\text { (p-value) }\end{array}$} \\
\hline & $n=99$ & & $n=28$ & & $\begin{array}{c}\text { Unteste } \\
n=21\end{array}$ & $d$ child & $\begin{array}{c}\text { Miscarric } \\
n=14\end{array}$ & & \\
\hline & $n(\%)$ & $S D$ & $n(\%)$ & $S D$ & $n(\%)$ & $S D$ & $n(\%)$ & $S D$ & \\
\hline $\begin{array}{l}\text { Male } \\
\text { carrier/at- } \\
\text { risk (\%) }\end{array}$ & $\begin{array}{c}43 \\
(43.4 \%)\end{array}$ & & $\begin{array}{c}7 \\
(25.0 \%)\end{array}$ & & $\begin{array}{c}15 \\
(71.4 \%)\end{array}$ & & $\begin{array}{c}8 \\
(57.1 \%)\end{array}$ & & 0.01 \\
\hline $\begin{array}{l}\text { Female } \\
\text { carrier/at- } \\
\text { risk (\%) }\end{array}$ & $\begin{array}{c}56 \\
(56.6 \%)\end{array}$ & & $\begin{array}{c}21 \\
(75.0 \%)\end{array}$ & & $\begin{array}{c}6 \\
(28.6 \%)\end{array}$ & & $\begin{array}{c}6 \\
(42.9 \%)\end{array}$ & & \\
\hline $\begin{array}{l}\text { Mean } \\
\text { male age } \\
\text { at PT }(n)\end{array}$ & $\begin{array}{l}29.4 \\
(27)\end{array}$ & 3.5 & $\begin{array}{c}32.2 \\
(6)\end{array}$ & 5.0 & $\begin{array}{l}31.9 \\
(11)\end{array}$ & 5.3 & $\begin{array}{c}34.5 \\
(7)\end{array}$ & 11.8 & 0.18 \\
\hline $\begin{array}{l}\text { Mean } \\
\text { female age } \\
\text { at PT }(n)\end{array}$ & $\begin{array}{l}26.0 \\
(46)\end{array}$ & 4.8 & $\begin{array}{l}26.6 \\
(19)\end{array}$ & 3.1 & $\begin{array}{c}25.9 \\
(5)\end{array}$ & 3.9 & $\begin{array}{c}31.1 \\
(6)\end{array}$ & 4.0 & 0.06 \\
\hline
\end{tabular}

1 Frequencies: $\chi^{2}$ corrected for continuity calculated per couple, continuous data compared by 2-tailed t-test. 
one healthy child after PND. Twenty-three of these 34 couples were CAG expansion carriers, 11 were at $50 \%$ risk; four of the latter were shown to be non-HD expansion carriers during or after their first attempt. Six pregnancies in the primary PND group were continued after showing either an HD expansion in the foetus $(n=4)$, or a $50 \%$ risk allele $(n=1)$, or without obtaining the PND result $(n=1)$. Three of these 34 couples had affected pregnancies terminated.

Of the 65 couples who continued their attempts after primary PND, 9 opted for PGD for their next pregnancies and 56 again opted for PND.

For 14 of the 28 couples in the primary PGD group, PGD treatment (1-4 cycles/attempts) resulted in the birth of at least one PGD baby; five of these couples started a second PGD treatment, whereas 9 stopped using PGD after delivery. After PGD treatment did not result in a pregnancy, three couples had a spontaneous pregnancy with PND, while for 11 couples no PND attempts were registered.

In the primary non-PND/PGD group, 21 couples had 27 children untested for $\mathrm{HD}$ as well as 4 miscarriages, and 14 couples had 18 miscarriages in all.

\section{Secondary choices}

A total of 99 couples opted for PND secondarily (Figure 1); 14 of those 99 continued to use PGD afterwards. For a comparison of the secondary PND and secondary PGD groups, these 14 couples were regarded as belonging to the PGD group, since PGD was their last choice.

The cumulative reproductive history of both secondary PND $(n=75)$ and secondary PGD $(n=28)$ groups are listed and compared in Table 3. Significantly more female HD expansion carriers (80\%) opted secondarily for PND compared to PGD (20\%), while male expansion carriers showed a 50:50 distribution between the PND and PGD group $(p=0.009)$. The reproductive history of the secondary PND and PGD groups showed an equal distribution of couples with previous pregnancies, miscarriages and proportion of pregnancies with PND (Table 3). However, the couples with a history of PND in the secondary PND group had a TOP for HD significantly less frequently (32/58, $55.2 \%)$ than the couples in the PGD group $(20 / 23,87.0 \%)(p=0.015)$. The couples opting for PND secondarily more frequently had $\geq 1$ child $(54 / 75$, $72.0 \%)$ compared to couples starting PGD secondarily $(13 / 28,46.4 \%)$ $(p=0.029)$. The proportion of children born after PND or untested did not differ significantly between these groups.

Finally, after using PGD, 9 of the 28 couples continued to use PND (once more) (Figure 1). 





Table 3. Characteristics and cumulative reproductive history ${ }^{1}$ of couples opting secondarily for PGD versus repeatedly or secondarily for PND

\begin{tabular}{|c|c|c|c|c|c|}
\hline & $\begin{array}{l}P N D \\
n=75\end{array}$ & & $\begin{array}{l}P G D \\
n=28\end{array}$ & & $\begin{array}{c}\text { Difference } \\
\text { between } \\
\text { groups }^{2}\end{array}$ \\
\hline & $n$ & $S D$ & $n$ & $S D$ & $p$-value \\
\hline Male carrier & $18(50 \%)$ & & $18(50 \%)$ & & \multirow{2}{*}{0.009} \\
\hline Female carrier & $36(80 \%)$ & & $9(20 \%)$ & & \\
\hline Male at risk & 15 (100\%) & & $0(0 \%)$ & & \multirow{2}{*}{ n.a. ${ }^{3}$} \\
\hline Female at risk & $6(85.7 \%)$ & & $1(14.3 \%)$ & & \\
\hline Mean male age at PT (n) & $32.0(18)$ & 7.45 & $30.8(18)$ & 5.28 & n.s. \\
\hline Mean female age at PT (n) & $25.8(36)$ & 0.84 & $27.1(9)$ & 4.90 & n.s. \\
\hline Total pregnancies (couples) & $148(73)$ & & $57(28)$ & & n.s. \\
\hline Miscarriage (no PND) (couples) & $19(13)$ & & $10(10)$ & & n.s. \\
\hline $\begin{array}{l}\text { Total pregnancies with PND } \\
\text { (couples) }\end{array}$ & $104(58)$ & & $37(23)$ & & n.s. \\
\hline TOP for HD (couples) & $53(32)$ & & $27(20)$ & & $0.015^{4}$ \\
\hline $\begin{array}{l}\text { Total pregnancy loss after PND } \\
\text { (couples) }\end{array}$ & $7(6)$ & & $0(0)$ & & n.a. \\
\hline PGD started (couples) & $2(2)$ & & $4(4)$ & & n.a. \\
\hline Total children (couples) & $64(54)$ & & $14(3)$ & & $0.029^{6}$ \\
\hline Children with no HD PND (couples) & $39(37)$ & & 77) & & n.s. ${ }^{7}$ \\
\hline PGD child (couples) & $0(0)$ & & $3(3)$ & & n.a. \\
\hline Untested children (couples) & $23(17)$ & & $4(4)$ & & n.s. \\
\hline Continued affected (couples) & $2(2)^{8}$ & & $0(0)$ & & n.a. \\
\hline
\end{tabular}

PGD, preimplantation genetic diagnosis; PND, prenatal diagnosis; PT, presymptomatic test; n.a., not applicable; n.s., not significant; TOP, termination of pregnancy; HD, Huntington's disease.

${ }^{1}$ Cumulative reproductive history before the last registered PGD or PND attempt

2 Frequencies: Chi square corrected for continuity calculated per couple, continuous data compared by 2 -tailed t-test.

${ }^{3}$ N.a.: not applicable, numbers are too small for statistics

${ }^{4}$ Couples with $\geq 1$ TOP for HD per couples performing PND

${ }^{5}$ Miscarriage after PND, late pregnancy loss after PND

${ }^{6}$ Couples without child vs with child (PND, PGD, or ongoing affected, untested)

7 Couples with $\geq 1$ child after PND compared to couples with $\geq 1$ child

8 Prenatal test showed 39 and 45 repeats respectively

\section{Total PND and PGD use and outcome}

The total number of 175 PND or PGD pregnancies resulted in the birth of 183 children (Table 4). PND was applied in 149/175 (85.1\%) of spontaneous pregnancies; $12 / 149$ (8.1\%) pregnancies were continued with an HD expansion 
or $50 \%$ risk allele. Additionally, two pregnancies were continued without being informed of the test result. A total of $14.9 \%$ of pregnancies resulted from PGD treatment. Of all 183 live-born children, 5.5\% were HD expansion carriers, $2.2 \%$ have a 50\% HD risk, and $92.3 \%$ are free from HD. For 39 couples (24.1\%), PND and/or PGD did not lead to childbirth.

Figure 2 shows the cumulative outcome of all 262 PND attempts of the 132 couples performing PND. The outcome of each attempt was ordered chronologically as first, second, and third attempt until the birth of a child. After the birth of a child, any following attempt was considered another first attempt to conceive a child. The attempts resulted in 135 ongoing pregnancies (52\%) and the birth of a child without HD, 110 pregnancies (42\%) were terminated or lost.

Figure 3 shows the cumulative outcome of each of the 136 PGD cycles (attempts) performed by 54 couples. For couples who continued PGD cycles after the birth of a PGD child, any following attempt was considered a new first attempt. The majority of the 26 ongoing pregnancies (19\% per cycle) resulted from the first or second PGD cycles. The proportion of favourable outcome (in terms of a live-born child with a reduced HD risk) after PND was relatively high compared to PGD.

\section{Uptake of PND and PGD}

Couples in our study performed their PT on average 1.8 years before their first attempt to have a child (range 11.5 prior to first attempt to 6.0 years after first attempt). Therefore the 11-year period starting from October 1996 is the closest way to approximate the moment of PT of our study group. In this period 1414 presymptomatic tests were performed in the Netherlands on 587 males (42\%) and 827 females (58\%). Of the 962 individuals of reproductive age, a total of 406 (199 males <50 yrs and 207 females $<40$ yrs) showed CAG repeats $\geq 36$. Additionally, five untested individuals of reproductive age indirectly turned out to be HD expansion carriers after an unfavourable outcome of PND. In our study population 162 couples performed PND and/or PGD. Of these couples, 26 did not undergo PT (as of December 2010). Of the remaining 136 couples, 5 took their PT abroad $(n=2)$ or were diagnostically tested $(n=3)$, possibly because they had mild HD features. These 5 couples were excluded from the calculation. The estimated uptake of PND and/or PGD was $32 \%$ (131/411) of presymptomatic HD expansion carriers of reproductive age. The age at the moment of PT for males and females not opting for PND or PGD was significantly higher (34.2 yrs and 29.4 yrs, respectively) compared to the age at PT of couples opting for PND or PGD in our study population (males $31.4 \mathrm{yrs}$ and females $26.6 \mathrm{yrs}$ ) (age differences: males $p=0.02$; females $p=0.0003)$. 


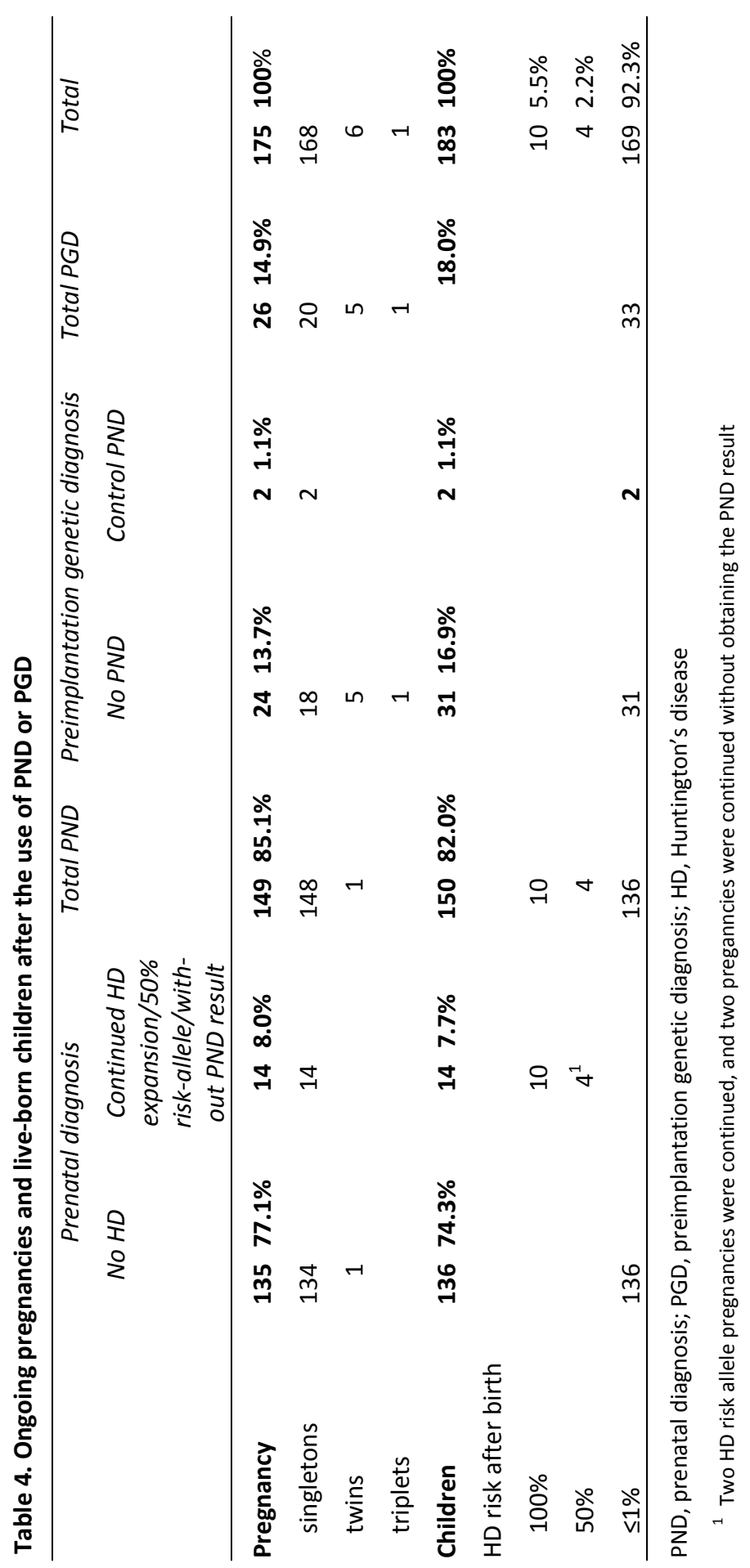


Figure 2. Cumulative outcome per PND pregnancy until live birth



* Normal pregnancy and child

$\checkmark$ Total TOP or loss

$\triangle$ Continued affected or at risk

+ Lost to FU after PND

Figure 3. Cumulative outcome per PGD cycle until live birth

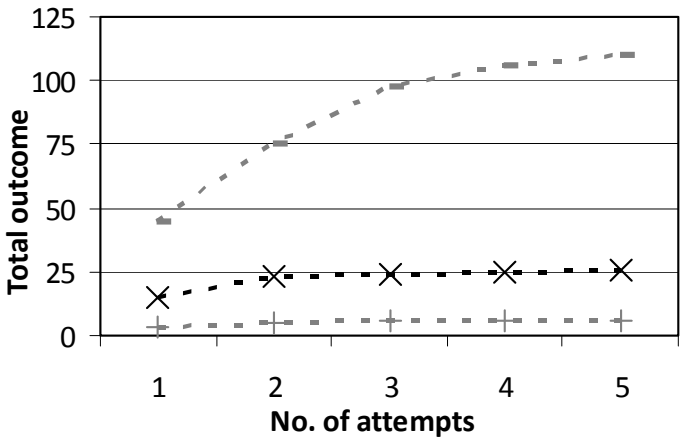

- - - - No pregnancy or miscarriage

- - - - Normal pregnancy and child

-+- - Scheduled for more attempts

Figure 4. Cumulative outcome per PND or PGD attempt until live birth

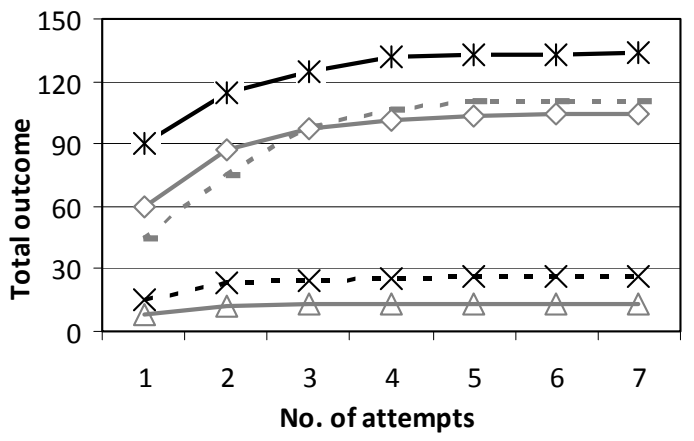

- - PND Normal pregnancy and child

- - - - PGD No pregnancy or miscarriage

$\checkmark$ PND Total TOP or loss

- - X- PGD Normal pregnancy and child

$\triangle$ PND Continued affected or at risk 


\section{Discussion}

This retrospective cohort study provides a complete overview of PND and PGD use among HD expansion carriers and at-risk persons who applied for PND or PGD in the Netherlands in the period 1998-2008. In the period under review, $81.5 \%$ of 162 couples opted for PND in 262 pregnancies, 52\% of which resulted in the birth of children without HD. PGD was performed by $33 \%$ of couples, showing a live-birth rate of $19 \%$ per started cycle. Though, couples may have undertaken more PND/PGD attempts after the collection of data ceased.

The introduction of PGD for HD in the Netherlands in 1999 does not seem to have reduced the use of PND in terms of absolute figures. We assume that PGD has attracted a separate group of individuals, who selectively opt for PGD. The majority of couples who opt for PND or PGD do stick to their primary choice, even when a large number of treatments are needed. Consecutive failure of PGD or TOP after PND, however, may lead to a shift from PND to PGD or vice versa. Couples secondarily opting for PND more frequently had a child compared to couples secondarily opting for PGD. For some a successful previous PND might have strengthened the preference to use PND again, for others the practical obstacle of having a child when going through PGD might have contributed to a preference for PND $^{17}$.

The male/female (M/F) ratio of HD expansion carriers or at-risk persons in our total study population was 45:55, comparable with that found in the literature ${ }^{5,7,21,22}$. However, for several groups the $M / F$ ratio was distorted. Male HD expansion carriers/at-risk persons were overrepresented $(71.4 \%)$ in the group with an untested child prior to PND or PGD compared with the other primary groups. Differences might be explained by $M / F$ difference in responsibility towards family life and caretaking, and a more reluctant attitude of males towards $\mathrm{PT}^{22}$. A paradoxical shift was observed from the primary PGD group, which consisted of $75 \%$ female HD expansion carriers/at-risk persons, to the secondary PGD group, in which $36 \%$ carrier/at-risk persons were females $(p=0.013)$. It may be speculated that at-risk males, when making their primary choice, may underestimate the impact of PND and overestimate the impact of PGD. The impact of PND resulting in TOP may also be correlated with the gender of the at-risk partner. After experiencing PND and TOP, these males may be prompted to change their point of view and shift towards PGD.

Although the absolute numbers of PND have considerably increased compared to the 11-year period studied by Maat-Kievit et al. (1987-1997) ${ }^{5}$, the yearly use of PND has remained rather stable since $1996^{19}$. The use of ePND was reduced from $30 \%$ of couples $(13 / 43)^{5}$ to $16 \%$ in our study. The proportion of ePND was 
found to be around 30\% in Australia (1994-2003) ${ }^{23}$. European studies (19931998) showed a proportion of $10 \%$ of prenatal tests performed by exclusion testing in Belgium, $29 \%$ in France, 30\% in Denmark, $42 \%$ in Italy and $48 \%$ in the $\mathrm{UK}^{7,24,25}$. In Germany, Switzerland, Austria and Greece no ePND was performed ${ }^{25-27}$. The proportion of the use of PGD compared with that of PND in our study is quite low in comparison to Australia and France and comparable to the proportion of PGD use described in a Belgian study ${ }^{13,22,23}$. This difference may be explained by a more liberal attitude towards TOP and the restrictions on the use of ePGD in the Netherlands. The proportion of ePGD by Dutch couples opting for PGD is relatively low compared to the proportions of ePGD in Belgium (33\%) and France (49\%), most probably due to restrictions on the application of ePGD ${ }^{13,15}$.

The $32 \%$ uptake of PND or PGD by HD carriers in the Netherlands nowadays is relatively high compared with that in France, Canada, the USA, Germany, Austria, Switzerland, Greece, Australia, Northern-Ireland and a diagnostic centre in Johannesburg (South Africa) ${ }^{13,21,23,25,27-31}$ and to some extent comparable with the UK, Belgium and Denmark ${ }^{7,22,24,25}$. In our study population the motives for performing a PT were not registered systematically. In other studies, only about $60-80 \%$ of individuals choose to perform PT for reproductive reasons ${ }^{8,9}$, and around $20-50 \%$ of individuals performing PT for reproductive reasons decide not to have children after testing HD positive $\mathrm{e}^{22,32,33}$. Therefore we assume that the actual uptake among individuals with reproductive motives for PT will most probably be higher than $32 \%$. Otherwise, there may be symptomatic individuals who reproduce. They are not included in these calculations, though their offspring shows a similar $50 \%$ HDrisk.

Difficulties in calculating the absolute uptake of PT with respect to the at $50 \%$ HD-risk population complicate an accurate calculation and comparison of the uptake between countries ${ }^{34}$.

We found that $44.4 \%(24 / 54)$ of the PGD couples delivered children without $\mathrm{HD}$, whereas $52 \%$ of spontaneous pregnancies with PND resulted in the birth of a child without HD. However, if we look at the results of all attempts, we see that the outcome in terms of live-born children without HD after PND is relatively favourable compared to the success rate of PGD. If the first two PGD attempts were unsuccessful, a couple was less likely to conceive an ongoing pregnancy resulting in the birth of a child in a later PGD cycle (Figure 3).

A direct and exclusively quantitative comparison between PND and PGD is probably not fair, as the psychological impact of both methods on partners may differ greatly. The artificial character of PGD and the time investment, the 
costs, the risks to mother and child, and the chance of misdiagnosis are frequently mentioned disadvantages of PGD ${ }^{16,22}$. By contrast, the physical and psychological consequences of an unfavourable outcome of PND resulting in TOP must not be underestimated ${ }^{22}$. Although the chances are in favour of PND, some individuals have stated the negative impact of TOP to be much greater than the disappointment after a failed PGD cycle ${ }^{35,36}$. Another factor complicating PND is the chance of a continued HD expansion or $50 \%$ risk allele pregnancy. In our study this occurred quite frequently (12 pregnancies) and it has previously been described by others ${ }^{7,22,26,37,38}$. According to the international guidelines on PND, continuing an affected or at-risk pregnancy can be considered an early form of presymptomatic testing and therefore it violates the future child's right not to $\mathrm{know}^{39}$. Specific details on these pregnancies are described elsewhere ${ }^{19}$. The motives of these couples and the long-term consequences of this unfavourable outcome after PND will be subject to future study.

\section{Conclusion}

PND and PGD are well-accepted reproductive options in the Netherlands for HD. PND is used considerably more frequently than PGD. This study shows that only a minority of couples decide to change their reproductive strategy after a disappointing outcome of their primary choice. Although chances are in favour of PND, the psychological impact of both methods may differ greatly. To make a balanced choice between the available options, it is important for candidate couples to be well informed about the differences between PND, PGD and alternatives. We recommend repeated reproductive counselling prior to every attempt with an open approach to all available options.

\section{References}

1. Harper P: Huntington's Disease. Saunders, London, 1996.

2. Roos RA: Huntington's disease: a clinical review. Orphanet journal of rare diseases 2010; 5: 40.

3. Novak MJ, Tabrizi SJ: Huntington's disease. British Medical Journal (Clinical research ed) 2010; 340: c3109.

4. HDCRG: A novel gene containing a trinucleotide repeat that is expanded and unstable on Huntington's disease chromosomes. Cell 1993; 72: 971-983.

5. Maat-Kievit A, Vegter-van der Vlis $M$, Zoeteweij $M$ et al: Experience in prenatal testing for Huntington's disease in The Netherlands: procedures, results and guidelines (19871997). Prenatal diagnosis 1999; 19: 450-457. 
6. Maat-Kievit A, Vegter-van der Vlis $M$, Zoeteweij $M$, Losekoot $M$, van Haeringen $A$, Roos R: Paradox of a better test for Huntington's disease. Journal of neurology, neurosurgery, and psychiatry 2000; 69: 579-583.

7. Simpson SA, Zoeteweij MW, Nys $\mathrm{K}$ et al: Prenatal testing for Huntington's disease: a European collaborative study. European Journal of Human Genetics 2002; 10: 689-693.

8. Decruyenaere M, Evers-Kiebooms G, Boogaerts A et al: Non-participation in predictive testing for Huntington's disease: individual decision-making, personality and avoidant behaviour in the family. European Journal of Human Genetics 1997; 5: 351-363.

9. Richards F: Couples' experiences of predictive testing and living with the risk or reality of Huntington disease: a qualitative study. American journal of medical genetics 2004; 126A: 170-182.

10. IHA-WFN: International Huntington Association and the World Federation of Neurology Research Group on Huntington's Chorea. Guidelines for the molecular genetics predictive test in Huntington's disease. Journal of medical genetics 1994; 31: 555-559.

11. Moutou C, Gardes N, Viville S: New tools for preimplantation genetic diagnosis of Huntington's disease and their clinical applications. European Journal of Human Genetics 2004; 12: 1007-1014.

12. Sermon $K$, de Rijcke $M$, Lissens $W$ et al: Preimplantation genetic diagnosis for Huntington's disease with exclusion testing. European Journal of Human Genetics 2002; 10: 591-598.

13. van Rij MC, de Rademaeker M, Moutou $C$ et al: Preimplantation genetic diagnosis (PGD) for Huntington's disease: the experience of three European centres. European Journal of Human Genetics 2012; 20: 368-375.

14. Ross-van Dorp CIJM: Letter of the State Secretary of Public Health and Sport. The Hague: Sdu Uitgevers, 2006, Vol 30300 XVI, nr 36.

15. Bussemaker M: Regeling preïmplantatie genetische diagnostiek van de staatssecretaris van Volksgezondheid, Welzijn en Sport (Regulations of the State Secretary of Health on the rules concerning PGD): Staatscourant: Koninkrijk der Nederlanden, 2009, Vol 42, pp 1-12.

16. Braude PR, de Wert GM, Evers-Kiebooms G, Pettigrew RA, Geraedts JP: Non-disclosure preimplantation genetic diagnosis for Huntington's disease: practical and ethical dilemmas. Prenatal diagnosis 1998; 18: 1422-1426.

17. van Rij MC, Gielen M, Lulofs R et al: Profiles and motives for PGD: a prospective cohort study of couples referred for PGD in the Netherlands. Human reproduction 2011; 26: 1826-1835.

18. Wilton L, Thornhill A, Traeger-Synodinos J, Sermon KD, Harper JC: The causes of misdiagnosis and adverse outcomes in PGD. Human reproduction 2009; 24: 1221-1228.

19. van Rij MC, de Koning Gans PA, Aalfs CM et al: Prenatal testing for Huntington's disease in The Netherlands from 1998 to 2008. Clinical Genetics 2013; [Epub ahead of print].

20. Wet Geneeskundige Behandel Overeenkomst, Dutch Civil Law, BW Art. 7:458, 2011.

21. Dufrasne $S$, Roy $M$, Galvez $M$, Rosenblatt DS: Experience over fifteen years with a protocol for predictive testing for Huntington disease. Molecular genetics and metabolism 2011; 102: 494-504. 
22. Decruyenaere M, Evers-Kiebooms G, Boogaerts A et al: The complexity of reproductive decision-making in asymptomatic carriers of the Huntington mutation. European Journal of Human Genetics 2007; 15: 453-462.

23. Tassicker RJ, Marshall PK, Liebeck TA, Keville MA, Singaram BM, Richards FH: Predictive and pre-natal testing for Huntington Disease in Australia: results and challenges encountered during a 10-year period (1994-2003). Clinical genetics 2006; 70: 480-489.

24. Simpson SA, Harper PS: Prenatal testing for Huntington's disease: experience within the UK 1994-1998. Journal of medical genetics 2001; 38: 333-335.

25. Yapijakis C, Laccone F, Sorensen SA: Predictive and prenatal testing for Huntington's disease in Greece, Germany, Austria, Switzerland and Denmark; in: Evers-Kiebooms G (ed): Prenatal testing for late-oset neurogenetic diseases. Oxford, UK: BIOS Scientific Publishers Ltd, 2002, pp 69-82.

26. Laccone F, Engel $U$, Holinski-Feder $E$ et al: DNA analysis of Huntington's disease: five years of experience in Germany, Austria, and Switzerland. Neurology 1999; 53: 801806.

27. Panas M, Karadima G, Vassos $\mathrm{E}$ et al: Huntington's disease in Greece: the experience of 14 years. Clinical genetics 2011; 80: 586-590.

28. Nance MA: Predictive and prenatal testing for late-onset neurogenetic diseases in North-America; in: Evers-Kiebooms G, Zoeteweij MW, Harper PS (eds): Prenatal testing for late-onset neurogenetic diseases. Oxford, UK: BIOS Scientific Publishers Ltd, 2002, pp 191-201.

29. Richards FH, Rea G: Reproductive decision making before and after predictive testing for Huntington's disease: an Australian perspective. Clinical genetics 2005; 67: 404-411.

30. Sizer EB, Haw T, Wessels TM, Kromberg JG, Krause A: The utilization and outcome of diagnostic, predictive, and prenatal genetic testing for huntington disease in johannesburg, South Africa. Genetic testing and molecular biomarkers 2012; 16: 58-62.

31. Morrison PJ, Harding-Lester S, Bradley A: Uptake of Huntington disease predictive testing in a complete population. Clinical genetics 2011; 80: 281-286.

32. Evers-Kiebooms G, Nys K, Harper P et al: Predictive DNA-testing for Huntington's disease and reproductive decision making: a European collaborative study. European Journal of Human Genetics 2002; 10: 167-176.

33. Tibben A, Frets PG, van de Kamp JJ et al: On attitudes and appreciation 6 months after predictive DNA testing for Huntington disease in the Dutch program. American Journal of Medical Genetics 1993; 48: 103-111.

34. Tassicker RJ, Teltscher B, Trembath MK et al: Problems assessing uptake of Huntington disease predictive testing and a proposed solution. European Journal of Human Genetics 2009; 17: 66-70.

35. van Rij MC, de Die-Smulders CE, Bijlsma EK et al: Evaluation of exclusion prenatal and exclusion preimplantation genetic diagnosis for Huntington's disease in the Netherlands. Clinical genetics 2013; 83(2): 118-124.

36. Jacopini G: Case reports on couples experiencing prenatal diagnosis; in: Evers-Kiebooms G, Zoeteweij MW, Harper PS (eds): Prenatal testing for late-onset neurogenetic diseases. Oxford, UK: BIOS Scientific Publishers Ltd, 2002. 
37. Creighton S, Almqvist EW, MacGregor D et al: Predictive, pre-natal and diagnostic genetic testing for Huntington's disease: the experience in Canada from 1987 to 2000. Clinical genetics 2003; 63: 462-475.

38. Tolmie JL, Davidson HR, May HM, McIntosh K, Paterson JS, Smith B: The prenatal exclusion test for Huntington's disease: experience in the west of Scotland, 1986-1993. Journal of medical genetics 1995; 32: 97-101.

39. Macleod R, Tibben A, Frontali $M$ et al: Recommendations for the Predictive Genetic Test in Huntington's Disease. Clinical genetics 2013; 83(3):221-31. 
Chapter 5

Profiles and motives for PGD:

a prospective cohort study of couples referred for PGD in the Netherlands

M.C. van Rij

M. Gielen

R. Lulofs

J.L.H. Evers

L. van Osch

N. Muntjewerff

J.P.M. Geraedts

C.E.M. de Die-Smulders

Human Reproduction 2011; 26(7):1826-35 


\section{Abstract}

PGD is nowadays a well-established alternative to prenatal diagnosis. However, information with respect to couples' motives and profiles for choosing PGD is scarce.

A prospective cohort of 264 couples referred for PGD was interviewed semistructurally after intake, and follow-up data were collated after 6-8 years. Outcome measures were: the primary choice shortly after intake (PGD intention), and their definitive use, until maximum 8 years later (PGD use). Logistic regression analysis was performed with clinical impact of the genetic disorder, couples' experiences, obstetric history, and psychosocial factors as putative predictors.

About $53.4 \%$ of the couples showed PGD intention. The experience of one or more miscarriages, the loss of an affected child and the absence of (acceptable) alternatives for the female partner positively contributed to PGD intention. For PGD use ( $45.8 \%$ of couples), infertility, a history of pregnancy termination(s) and the absence of alternatives according to the female partner were positive determinants. A living affected child reduced PGD use. Mode of inheritance and clinical impact of the disorder did not contribute.

In conclusion, fewer than $50 \%$ of the referred couples actually started PGD treatment. Personal experiences and reproductive history (the presence of a living affected child, infertility or a history of a pregnancy termination) were more important determinants of eventual PGD use than the mode of inheritance or the expected clinical impact of the disorder. 


\section{Introduction}

Since the first application of preimplantation genetic diagnosis (PGD) for an Xlinked condition ${ }^{1}$, PGD has proliferated rapidly throughout the world. At present, more than 4500 pregnancies have been reported ${ }^{2}$. Recently, PGD has become available for couples at risk for late-onset diseases and inherited cancer syndromes ${ }^{3-6}$.

Although at present, PGD is widely available for many diseases, not much is known about the motives of couples choosing PGD. The literature shows a 38$100 \%$ theoretical acceptability of PGD by at-risk couples in countries where PGD was prohibited at the time of study ${ }^{7-10}$. However, a difference may exist between theoretical acceptability and the decision to actually embark on PGD. Furthermore, the profiles and motives of high-risk couples, for whom PGD is intended, are relatively uncharted.

We present a prospective long-term study on couples referred for PGD. We explored the motives of referred couples actually choosing PGD, with the aim of defining factors contributing to their eventual choice. Determinants of couples' initial preference for PGD (PGD intention) and their final choice (PGD use) were studied. Personal characteristics (age and educational level), mode of inheritance, clinical impact of the specific genetic disorders, personal experience with the disorder, as well as couples' reproductive history were recorded. These latter factors have previously been suggested or shown to effect couples' attitudes towards PGD ${ }^{9-14}$. As we presumed that also clinical impact of the disorder may be one of the determining factors for selecting PGD treatment, we divided disorders into 4 categories: miscarriage risk, lethal childhood disorders, chronic childhood disease and late onset disorders. Furthermore, we studied psychosocial factors that we expected to be of influence for the choice of PGD.

The results of this study may contribute to better understanding of reproductive choices and optimization of counselling couples at a high risk of offspring with a genetic disorder. 


\section{Materials and Methods}

\section{$P G D$ in the Netherlands}

The Maastricht University Medical Centre operates the only approved PGD centre in the Netherlands. PGD is an accepted alternative to prenatal diagnosis in the Netherlands. PGD is available for couples at a high risk of transmitting a genetic or chromosomal abnormality to their offspring ${ }^{15}$. In the Netherlands, three IVF/PGD cycles are covered by health insurance. Usually, couples are referred for PGD by a clinical geneticist or gynaecologist, after having obtained basic counselling on their reproductive options and after having indicated interest in PGD. Nearly all couples referred were actually treated in Maastricht. In our centre, couples are offered maximum three cycles, incidentally four, and the mean number of cycles per couple is 2.2. A small minority was treated in collaboration with the PGD centre in Brussels. These included a couple requesting PGD for HLA typing and couples with myotonic dystrophy in the woman, which, because of their risk of cardiovascular and respiratory complications $^{16}$, until recently was a contraindication for IVF/PGD in our centre. Aneuploidy screening (PGS) was not included in this study.

\section{Study design}

In a 3-year period (2002-2004), all couples referred for PGD were asked for consent to participate in this study. Prior to the first appointment, information leaflets on IVF and PGD and information on this study were sent to the couples. They were scheduled for a counselling session lasting about one hour with a clinical geneticist. During this session, the couple was provided with detailed information on PGD for their specific situation, including a realistic timeline for test availability, details on IVF by ICSI, single-cell diagnostic procedure and limited success rates of the treatment ${ }^{15}$. Advantages and disadvantages of PGD compared with relevant alternative reproductive options were also discussed. The clinical geneticist collated relevant information on the couples' obstetric history, family history and health status of both partners. This intake session was immediately followed by an interview by the psychologist. During this interview, a quantitative (semi-structured) questionnaire, including questions on personal experience with the disorder as well as info on socio-psychological factors, was used as guidance. Answers were verbally scored and filled out on the questionnaire by the psychologist. Where needed, couples had the opportunity to give personal comments and the psychologist could ask for additional qualitative data. 
Further data were collected from patient files eventually completed by personal contact with the couple or their physician. As we are the only PGD centre in the Netherlands, we have full data available for all couples who either used or refrained from PGD.

\section{Outcome variables}

Two moments of choice with respect to continuing PGD were set as outcome measures; $t_{0}$ was set after intake as soon as the couple officially reported their decision (PGD intention) to the clinical geneticist involved. For most couples, this was immediately after intake. For couples who decided to continue treatment, preparation (gynaecological and technical workup) was started ${ }^{15}$. PGD use $\left(t_{1}\right)$ was set 'yes' as soon as the couples started their first PGD cycle. Couples who did not start PGD until March 2010 were contacted by their clinical geneticist in order to confirm possible refraining and to learn reasons for their refraining. They were recorded as non-PGD use. The time lapse between $t_{0}$ and $t_{1}$ was maximum 8 years. At the closing of data collection, mean female age had reached 38 years, at which age the chance of still entering the programme is limited.

\section{Study population}

The patients' flow is shown in Figure 1. A total of 292 couples were initially included. At $t_{0}, 123$ couples refrained from treatment, whereas 169 couples intended to start PGD. In the following years, six couples changed their minds regarding PGD treatment (no to yes): three had a(nother) termination of pregnancy (TOP) in the meantime and three couples changed their minds without specific motivation. Another 26 couples (9.8\%) refrained from treatment during or after the work-up for PGD: 12 women had a spontaneous pregnancy before starting PGD, three couples had relationship problems, two couples did not have health insurance, one couple refrained because of the health risk for the female, and the remaining eight couples refrained without mentioning a specific reason.

Finally, 28 couples were considered unsuitable for PGD for ethical, gynaecological or technical reasons. They were excluded from the present study since they were not given the chance to choose to have PGD at $t_{1}$. 


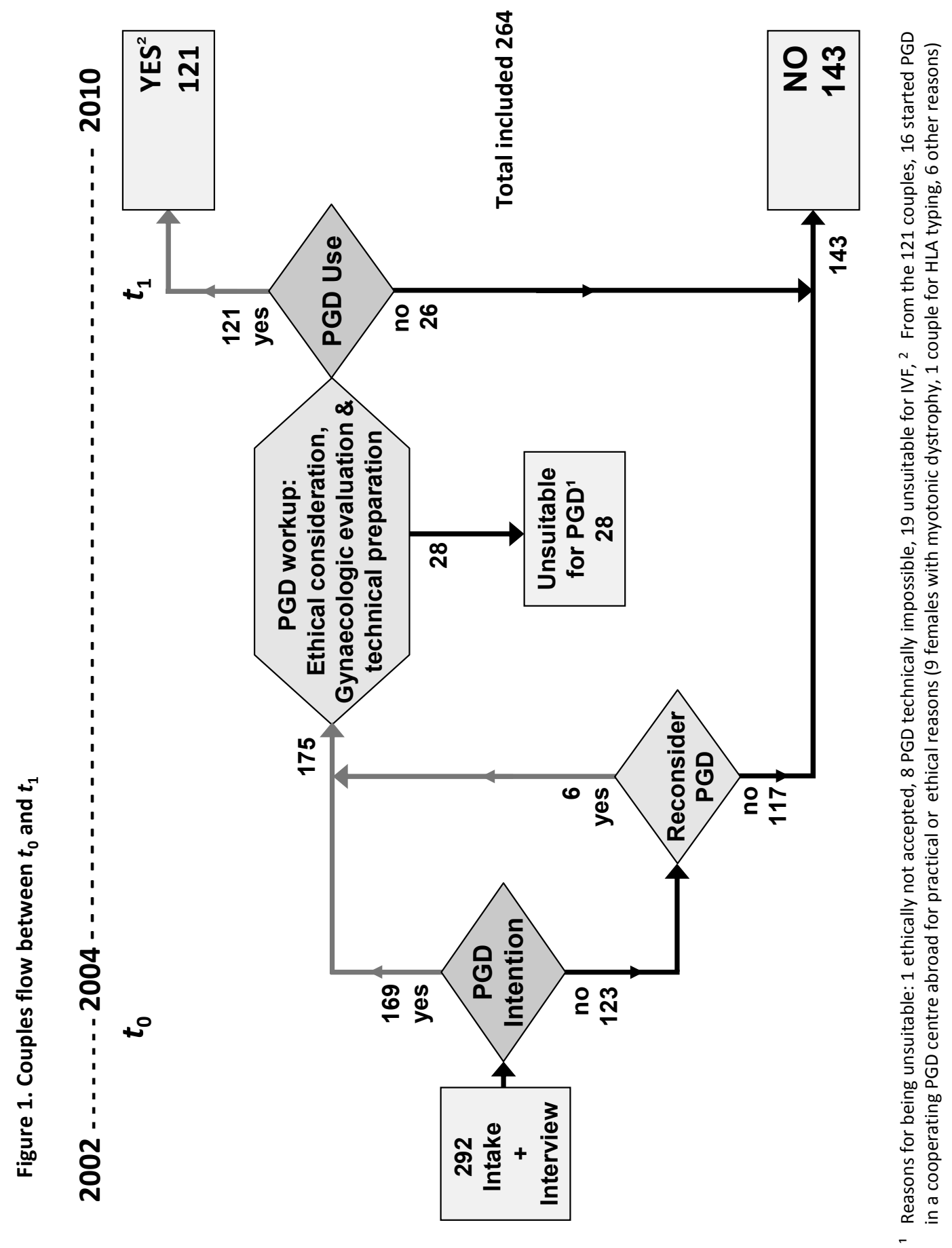


Thus, 264 couples were included for analysis. At $\boldsymbol{t}_{0}, 141$ initially preferred PGD (PGD intention 53.4\%). At $t_{1}, 121$ couples had actually started PGD and 143 had refrained from treatment (PGD use $45.8 \%$ ).

\section{Determinants}

Couples' characteristics

Data on age and level of education (low, middle, high) were collected and compared with the age and education level of the general population in the Netherlands (CBS-National Office for Statistics).

Clinical impact of the specific genetic disorders

Table 1 shows the indications for referral grouped according to diagnosis and the (expected) impact of the genetic disorder. Disorders with variable expression (e.g. myotonic dystrophy) were grouped according to the most likely impact for the couple. Table 2 refines this clinical impact of the disorders by recording the specific disease characteristics, availability of treatment and life expectancy, if applicable.

Genetic characteristics of disorders

Mode of inheritance was recorded as chromosomal ( $\mathrm{CH}$ ) (translocations, inversions, insertions and mosaic Turner syndrome), autosomal dominant (AD), autosomal recessive (AR), X-linked (XL) and miscellaneous (MS). We also recorded which of the two partners was the carrier (Table 3).

Reproductive history and personal experience

Fertility was scored in terms of 'infertility' (simultaneous IVF indication), 'reduced fertility' for couples in need of fertility supporting treatment other than IVF, or 'normal or not yet started' for couples who had achieved a previous spontaneous pregnancy or who had not previously tried to conceive. Miscarriages, terminations of pregnancy (TOP) or (un)complicated pregnancies were recorded, if applicable (yes/no).

Couples' experience with the disease was measured in terms of the presence of an affected living child, loss of a child due to the genetic disorder, or the presence of at least one healthy child (Table 3). 
Table 1. Referrals by clinical impact of disorder

$$
\begin{array}{r}
\text { Mode of } \\
\text { inheritance }^{1}
\end{array}
$$

Increased miscarriage risk

$66(25.1)$

Chromosomal inversion

$\mathrm{CH}$

Chromosomal translocation

$\mathrm{CH}$

63

Turner mosaicism

$\mathrm{CH}$

Lethal childhood disorders, $<18$ years

ARPKD

$A R$

Bloom syndrome

AR

Cartilage-hair hypoplasia

AR

CDG-la

AR

Centronuclear myopathy

$\mathrm{XL}$

$A R$

Ceroid lipofuscinoses type I

$\mathrm{CH}^{2}$

Chromosomal inversion

AR

Fanconi anaemia

AR

Mrabo's disease

$X \mathrm{~L}$

$A R$

$A R$

$A R$

Tyroxine hydrolase deficiency

Translocation

$\mathrm{CH}^{2}$

Zellweger syndrome

AR

\section{Chronic childhood disease}

With mental retardation

ATRX (suspected) ${ }^{3}$

$\mathrm{MS}^{4}$

Chromosomal insertion

$\mathrm{CH}^{2}$

Chromosomal inversion

$\mathrm{CH}^{2}$

Fragile $X$ syndrome

$X \mathrm{~L}$

Hydrocephaly/MASA

$\mathrm{XL}$

Lugan/Frijns syndrome

$\mathrm{XL}$

Marker for cat-eye syndrome

$\mathrm{CH}^{2}$

Mitochondrial disorder

$\mathrm{MS}^{4}$

Myotonic dystrophy

$A D$

Translocation

$\mathrm{CH}^{2}$

Tuberous sclerosis

$A D$

Velo cardio facial syndrome (22q11 deletion)

$A D$ 
Table 1. Referrals by clinical impact - continued

\begin{tabular}{|c|c|c|}
\hline & $\begin{array}{l}\text { de of } \\
\text { ance }\end{array}$ & $n(\%)$ \\
\hline $\begin{array}{l}\text { In need of chronic treatment to extend } \\
\text { life expectancy/without mental } \\
\text { retardation }\end{array}$ & \multicolumn{2}{|r|}{$43(16.3)$} \\
\hline Cystic fibrosis & $A R$ & 20 \\
\hline \multirow{2}{*}{$\begin{array}{l}\text { Duchenne/Becker muscular } \\
\text { dystrophy }\end{array}$} & $X L$ & 8 \\
\hline & $\mathrm{MS}^{4}$ & 1 \\
\hline Haemophilia A/B & $X L$ & 14 \\
\hline Physical disability & \multicolumn{2}{|r|}{$11(4.2)$} \\
\hline Androgen insensitivity syndrome & $X L$ & 1 \\
\hline Aniridia & $A D$ & 2 \\
\hline Choroideremia & $X L$ & 2 \\
\hline Hypochondroplasia & $A D$ & 1 \\
\hline Retinoblastoma & $A D$ & 3 \\
\hline Retinal schisis & $X L$ & 1 \\
\hline Usher type I & $A R$ & 1 \\
\hline Late-onset disorders & \multicolumn{2}{|r|}{47 (17.9) } \\
\hline Amyloid polyneuropathy & $A D$ & 1 \\
\hline Cadasil & $A D$ & 1 \\
\hline Ehlers Danlos Syndrome type IV & $A D$ & 1 \\
\hline FAMMM (p16 Leiden) & $A D$ & 1 \\
\hline $\begin{array}{l}\text { Familial adenomatous colon polyps } \\
\text { (FAP) }\end{array}$ & $A D$ & 2 \\
\hline Huntington's disease & $A D$ & 25 \\
\hline Marfan syndrome & $A D$ & 3 \\
\hline Multiple endocrine neoplasm 2A & $A D$ & 1 \\
\hline Neurofibromatosis type 1 & $A D$ & 1 \\
\hline Spinocerebellar ataxia type 3 & $A D$ & 9 \\
\hline Von Hippel-Lindau disease & $A D$ & 2 \\
\hline Miscellaneous & & $1(0.4)$ \\
\hline $\begin{array}{l}\mathrm{HLA}^{5} \text { typing to create HLA identical } \\
\text { donor to treat } \mathrm{AML}^{6} \text { in previous child }\end{array}$ & $\mathrm{MS}^{4}$ & 1 \\
\hline Total & & $264(100)$ \\
\hline
\end{tabular}

1 Mode of inheritance: $\mathrm{CH}$, chromosomal abnormality; $A R$, autosomal recessive; $A D$, autosomal dominant inheritance; $\mathrm{XL}$, $X$ linked; MS, referrals labelled 'miscellaneous'.

2 Note that all chromosomal abnormalities are characterized by an increased miscarriage risk; only if the couples' history described the birth of a living affected child or family member with an imbalanced chromosomal pattern or if the risk of an affected live born child was assessed over $10 \%$, was the couple included in one of both childhood disorders groups according to the specific history.

3 ATRX: Alpha thalassemia/ mental retardation syndrome X-linked was strongly suspected, but genetically not confirmed.

4 Couples labelled miscellaneous (mitochondrial disorder, suspected ATRX in son, de novo Duchenne muscular dystrophy in son and HLA typing for myeloid leukaemia in previous child) were excluded from analysis of the effect of the mode of inheritance.

5 HLA or human leucocyte antigen inherited in an autosomal recessive fashion, however labelled for 'miscellaneous inheritance'.

6 AML for sporadic acute myeloid leukaemia, recurrence risk for analysis labelled 'low unpredictable'. 
Table 2. Referrals by specific disease characteristics

\begin{tabular}{lc}
\hline Clinical signs (expected) in affected foetus or (at risk) person & $n(\%)^{1}$ \\
\hline Mental retardation or (progressive) cognitive impairment & $167(63.3)$ \\
Chronic disease (in need for medical treatments) & $84(31.8)$ \\
Physical disability without life threat & $12(4.5)$ \\
Progressive condition & $114(43.2)$ \\
Late-onset & $47(17.8)$ \\
Available treatment & \\
No treatment available & $199(75.4)$ \\
Chronic treatment needed to extend life expectancy & $54(20.5)$ \\
Preventive screening or curative surgery & $11(4.2)$ \\
Life expectancy & \\
Miscarriage or intrauterine death & $83(31.4)$ \\
Lethal < 18 years & $33(12.5)$ \\
Lethal in adulthood 18-50 or 15-20 years after onset & $102(38.6)$ \\
Normal & $46(17.4)$
\end{tabular}

1 Since most inheritable disorders are characterized by more than one clinical sign, totals do not necessarily equal to $100 \%(n=264)$.

\section{Psychosocial factors}

Table 4 shows the items scored by the psychologist by means of the questionnaire. The choice of the items is based on the literature available at that time, completed with items constructed on the basis of our clinical impressions in the preceding years. Information was collected for male and female partners separately. Openness regarding discussion of PGD treatment was recorded on a five-point scale ranging from 'taboo' to 'tell everybody'. The amount of social support was scored on a five-point scale ranging from 'much support' to 'insufficient support'. The acceptability or availability of an alternative reproductive option was measured on a four-point scale ranging from 'no alternative' to 'preferred alternative'. 
Table 3. Characteristics of referrals for PGD $(n=264)$

\begin{tabular}{|c|c|}
\hline Characteristics & $n(\%)$ \\
\hline \multicolumn{2}{|l|}{ Genetic characteristics of disorder } \\
\hline \multicolumn{2}{|l|}{ Mode of inheritance } \\
\hline Autosomal dominant & $75(28.4)$ \\
\hline Autosomal recessive & $48(18.2)$ \\
\hline X-linked & $53(20.1)$ \\
\hline Chromosomal & $84(31.8)$ \\
\hline Miscellaneous & $4(1.6)$ \\
\hline \multicolumn{2}{|l|}{ Carrier } \\
\hline Female & $149(56.4)$ \\
\hline Male & 63 (23.9) \\
\hline Both & 49 (18.6) \\
\hline Miscellaneous & $3(1.2)$ \\
\hline \multicolumn{2}{|l|}{ Couples' personal experience $^{1}$} \\
\hline \multicolumn{2}{|l|}{ Reproductive history } \\
\hline Previous pregnancy & $182(68.9)$ \\
\hline Infertility (IVF indication) & $39(14.8)$ \\
\hline Sub-fertility & $14(5.3)$ \\
\hline Normal fertility or not yet started & 211 (79.9) \\
\hline Spontaneous abortion(s) & $88(33.3)$ \\
\hline Pregnancy termination(s) & $58(22.0)$ \\
\hline Uncomplicated pregnancy & $58(22.0)$ \\
\hline \multicolumn{2}{|l|}{ Couples' experience with the disease } \\
\hline Affected child alive & $55(20.8)$ \\
\hline Affected child deceased & $11(4.2)$ \\
\hline Healthy child & $62(23.5)$ \\
\hline
\end{tabular}

${ }^{1}$ Since reproductive history might include previous pregnancies with different outcomes, totals do not necessarily equal to $100 \%$ 
Table 4. Psychosocial factors

\begin{tabular}{|c|c|c|}
\hline Psychosocial factors & $\begin{array}{c}\text { Female } \\
n(\%)\end{array}$ & $\begin{array}{l}\text { Male } \\
n(\%)\end{array}$ \\
\hline \multicolumn{3}{|l|}{ Alternative reproductive option } \\
\hline No alternative & $77(29.2)$ & $74(28.0)$ \\
\hline Available but preference PGD & $118(44.7)$ & $120(45.5)$ \\
\hline Alternative considered & $56(21.6)$ & $57(21.6)$ \\
\hline Preference alternative & $13(4.9)$ & $13(4.9)$ \\
\hline \multicolumn{3}{|l|}{ Disagreement reproductive choice } \\
\hline Strongest wish for PGD & $44(16.7)$ & $34(12.9$ \\
\hline \multicolumn{3}{|l|}{ Openness about PGD plans } \\
\hline Taboo & 0 & $3(1.1)$ \\
\hline Only to partner & $22(8.3)$ & 44 (16.7) \\
\hline To intimates & $93(35.2)$ & $76(28.8)$ \\
\hline Family and friends & $83(31.4)$ & $80(30.3)$ \\
\hline To everybody & $66(25.0)$ & $61(23.1)$ \\
\hline \multicolumn{3}{|l|}{ Social support } \\
\hline No need for support & $11(4.2)$ & $23(8.7)$ \\
\hline Much support & $110(41.7)$ & $108(41.1)$ \\
\hline Sufficient support & $69(26.1)$ & $65(24.7)$ \\
\hline Support and criticism & $56(21.2)$ & $54(20.5)$ \\
\hline Insufficient support & $18(6.8)$ & $13(5.0)$ \\
\hline Missing & 0 & $1(0.4)$ \\
\hline \multicolumn{3}{|l|}{ Time pressure for PGD treatment } \\
\hline High time pressure (<3 years) & $66(25.3)$ & \\
\hline Moderate pressure ( $3-5$ years) & $102(39.1)$ & \\
\hline Light pressure (5-10 years) & $28(10.7)$ & \\
\hline No time pressure ( $>10$ years) & 65 (24.9) & \\
\hline Missing & $3(1.1)$ & \\
\hline
\end{tabular}


In addition, it was documented whether or not the two partners agreed with the reproductive decision. The time pressure for PGD treatment was quantified by recording on a four-point scale ranging from 'no time pressure ( $>10$ years)' to 'high time pressure ( $<3$ years)'. The time pressure was an objectively estimated measure based on the remaining years till reaching the female age of 40 years (exclusion criterium IVF/PGD) and the presence of a late onset disorder.

\section{Statistical analyses}

Comparisons of the couples' characteristics with the general population were performed by $\chi^{2}$ tests for comparison of education level, while for comparing mean age, a $t$-test was used.

Logistic regression analyses were performed to evaluate the contribution of the determinants to PGD intention $\left(t_{0}\right)$ and PGD use $\left(t_{1}\right)$. Analyses were performed both unadjusted and adjusted for potential confounders. These confounders were identified from the unadjusted regression analyses. In the multivariable logistic regression analysis for PGD intention, we corrected for the significant confounders 'presence of an affected child', 'miscarriages' and 'alternative reproductive option'. In the multivariable logistic regression analysis for PGD use, we corrected for the significant confounders 'presence of an affected child', 'pregnancy terminations' and 'alternative reproductive options'. All P-values are two-sided and results were considered statistically significant if $\mathrm{P} \leq 0.05$ and $95 \%$ confidence intervals $(\mathrm{Cl})$ of the odds ratios (ORs) were calculated.

The analyses were conducted with the SAS version 9.1 software package (SAS Institute Inc., Cary, NC, USA).

\section{Results}

\section{Couples' characteristics}

The mean age was 31.1 years [range 22-40 (SD 3.65)] for the female partners and 33.3 years [range 22-51 (SD 4.78)] for the male partners. Educational levels of males in our study [lower, middle, high: respectively $23.6 \%, 39.8 \%$, $36.6 \%(n=246)$ ] as well as females [lower, middle, high: respectively $18.7 \%$, $43.9 \%, 37.4 \%(n=246)]$ show a slight, but non-significant overrepresentation of couples with a higher education compared with the general population of 
the Netherlands (CBS-National Office for Statistics). Neither educational level nor age contributed significantly to the choice for PGD (data not shown).

\section{Logistic regression analyses}

The adjusted ORs are presented, since in most cases, unadjusted and adjusted ORs did not differ substantially. An overview of the results is listed in Table 5. Only considerable differences between unadjusted and adjusted results will be discussed in more detail.

\section{Clinical impact of the specific genetic disorders}

None of the variables measuring impact of the specific disorders influenced the PGD choice (Table 5).

\section{Genetic characteristics of the disorders}

Couples at risk of transmitting AR disorders showed significantly reduced PGD use compared with couples with an AD disorder. However, after adjusted analysis, this effect disappeared (Table 5). In the group of $A D$ and $\mathrm{CH}$ inheritance, females were significantly more often carriers than males (48/27 and $47 / 36$, respectively). Analyses of the gender of the carrier for both modes of inheritance did not show any effect on the PGD intention $\left(t_{0}\right)$ or the PGD use $\left(t_{1}\right)$ (data not shown).

\section{Reproductive history and personal experience}

Infertility tended to result in increased PGD intention and significantly increased PGD use (OR 2.3, 95\% Cl 1.0-5.2) compared with couples with normal fertility (Table 5). Subfertility did not show this effect. Couples with a history of miscarriages showed an increased PGD intention (OR 3.0, 95\% Cl 1.5-5.8). However, the effect of miscarriages lost significance and PGD use was comparable to couples without such experience. In contrast, the experience of a TOP moderately increased PGD intention, but in time, actual PGD use was significantly increased (OR 3.1, 95\% Cl 1.5-6.4) compared with couples without such experience.

In contrast to the clinical impact of the genetic disorder, the couples' 'personal experience' with the disease did contribute significantly to the choice. Couples with a living affected child showed a tendency towards reduced PGD intention $\left(t_{0}\right.$ : OR $\left.0.5,95 \% \mathrm{Cl} 0.3-1.1\right)$ compared with couples without an affected child. 
Table 5. Results unadjusted and adjusted analysis

\begin{tabular}{|c|c|c|c|c|c|c|c|c|}
\hline \multirow[t]{3}{*}{ Variables } & \multirow{2}{*}{\multicolumn{2}{|c|}{$\begin{array}{l}\text { Effect on PGD } \\
\text { intention }\left(t_{0}\right) \\
\text { Unadjusted }\end{array}$}} & \multirow{2}{*}{\multicolumn{2}{|c|}{$\begin{array}{c}\text { Effect on PGD } \\
\text { intention }\left(t_{0}\right) \\
\text { Adjusted }^{1}\end{array}$}} & \multirow{2}{*}{\multicolumn{2}{|c|}{$\begin{array}{l}\text { Effect on PGD } \\
\text { use }\left(t_{1}\right) \\
\text { Unadjusted }\end{array}$}} & \multirow{2}{*}{\multicolumn{2}{|c|}{$\begin{array}{l}\text { Effect on PGD } \\
\text { use }\left(t_{1}\right) \\
\qquad \text { Adjusted }^{2}\end{array}$}} \\
\hline & & & & & & & & \\
\hline & OR & $95 \% \mathrm{Cl}$ & $O R$ & $95 \% \mathrm{Cl}$ & $O R$ & $95 \% \mathrm{Cl}$ & $O R$ & $95 \% \mathrm{Cl}$ \\
\hline \multicolumn{9}{|l|}{$\begin{array}{l}\text { Clinical impact of the } \\
\text { condition }\end{array}$} \\
\hline Miscarriage risk & 1.4 & $0.6-2.9$ & 0.8 & $0.3-2.2$ & 0.9 & $0.4-2.0$ & 1.3 & $0.5-2.9$ \\
\hline Lethal childhood disorder & 0.6 & $0.2-1.5$ & 0.6 & $0.2-2.3$ & 0.6 & $0.2-1.5$ & 0.8 & $0.2-3.0$ \\
\hline Chronic childhood disease & 1.0 & $0.5-1.9$ & 1.5 & $0.6-3.5$ & 1.1 & $0.5-2.1$ & 1.7 & $0.7-3.9$ \\
\hline Late onset disorder & & Ref. & & Ref. & & Ref. & & Ref. \\
\hline \multicolumn{9}{|l|}{$\begin{array}{l}\text { Specific disease } \\
\text { characteristics }\end{array}$} \\
\hline $\begin{array}{l}\text { Mental retardation or } \\
\text { (progressive) cognitive } \\
\text { impairment }^{3}\end{array}$ & 1.3 & $0.8-2.1$ & 0.8 & $0.4-1.5$ & 1.2 & $0.7-1.9$ & 0.9 & $0.5-1.6$ \\
\hline $\begin{array}{l}\text { Physical disability without } \\
\text { life threat }\end{array}$ & 1.2 & $0.4-4.0$ & 1.5 & $0.3-6.5$ & 1.7 & $0.5-5.5$ & 1.6 & $0.4-6.6$ \\
\hline $\begin{array}{l}\text { Chronic disease (in need } \\
\text { for medical treatments) }\end{array}$ & 0.8 & $0.5-1.3$ & 1.4 & $0.7-2.7$ & 1.0 & $0.6-1.6$ & 1.3 & $0.7-2.3$ \\
\hline Progressive condition ${ }^{3}$ & 0.9 & $0.5-1.4$ & 1.1 & $0.6-2.0$ & 1.0 & $0.6-1.6$ & 0.9 & $0.5-1.6$ \\
\hline Late onset $^{3}$ & 1.1 & $0.6-2.1$ & 1.1 & $0.5-2.4$ & 1.0 & $0.6-2.0$ & 0.8 & $0.4-1.6$ \\
\hline \multicolumn{9}{|l|}{ Available treatment } \\
\hline $\begin{array}{l}\text { Preventive screening or } \\
\text { curative surgery }\end{array}$ & 0.7 & $0.2-2.3$ & 0.7 & $0.2-3.2$ & 1.0 & $0.3-3.3$ & 1.0 & $0.2-4.3$ \\
\hline $\begin{array}{l}\text { Chronic treatment needed } \\
\text { to extend life expectancy }\end{array}$ & 0.8 & $0.4-1.5$ & 1.7 & $0.8-3.8$ & 0.9 & $0.5-1.7$ & 1.6 & $0.7-3.3$ \\
\hline No treatment available & & Ref. & & Ref. & & Ref. & & Ref. \\
\hline \multicolumn{9}{|l|}{ Lethality } \\
\hline $\begin{array}{l}\text { Miscarriage or antenatal } \\
\text { death }\end{array}$ & 2.1 & $1.0-4.3$ & 1.2 & $0.4-3.3$ & 1.3 & $0.6-2.7$ & 1.4 & $0.6-3.3$ \\
\hline Lethal $<18$ years & 0.8 & $0.3-2.1$ & 0.7 & $0.2-2.6$ & 0.8 & $0.3-2.0$ & 1.0 & $0.3-3.3$ \\
\hline $\begin{array}{l}\text { Lethal } 18-50 \text { or } 15-20 \\
\text { years after onset }\end{array}$ & 1.6 & $0.8-3.3$ & 2.2 & $1.0-4.9$ & 1.4 & $0.7-2.8$ & 1.7 & $0.7-3.7$ \\
\hline Normal life expectancy & & Ref. & & Ref. & & Ref. & & Ref. \\
\hline \multicolumn{9}{|l|}{$\begin{array}{l}\text { Genetic characteristics of } \\
\text { disorder }\end{array}$} \\
\hline \multicolumn{9}{|l|}{ Mode of inheritance } \\
\hline Chromosomal & 1.2 & $0.7-2.2$ & 0.7 & $0.3-1.7$ & 0.8 & $0.4-1.5$ & 0.9 & $0.5-1.8$ \\
\hline X-linked & 0.5 & $0.3-1.0$ & 0.5 & $0.2-1.0$ & 0.6 & $0.3-1.1$ & 0.7 & $0.3-1.6$ \\
\hline Autosomal recessive & 0.7 & $0.3-1.3$ & 0.7 & $0.3-1.6$ & 0.5 & $0.2-0.9$ & 0.7 & $0.2-2.3$ \\
\hline Autosomal dominant & & Ref. & & Ref. & & Ref. & & Ref. \\
\hline
\end{tabular}


Table 5. Results unadjusted and adjusted analysis - continued

\begin{tabular}{|c|c|c|c|c|c|c|c|c|}
\hline \multirow[t]{3}{*}{ Variables } & \multicolumn{2}{|c|}{$\begin{array}{l}\text { Effect on PGD } \\
\text { intention }\left(t_{0}\right)\end{array}$} & \multicolumn{2}{|c|}{$\begin{array}{l}\text { Effect on } P G D \\
\text { intention }\left(t_{0}\right)\end{array}$} & \multicolumn{2}{|c|}{$\begin{array}{l}\text { Effect on PGD } \\
\left.\text { use ( } t_{1}\right)\end{array}$} & \multicolumn{2}{|c|}{$\begin{array}{l}\text { Effect on PGD } \\
\left.\text { use ( } t_{1}\right)\end{array}$} \\
\hline & \multicolumn{2}{|c|}{ Unadjusted } & \multicolumn{2}{|c|}{ Adjusted $^{1}$} & \multicolumn{2}{|c|}{ Unadjusted } & \multicolumn{2}{|c|}{ Adjusted $^{2}$} \\
\hline & $O R$ & $95 \% \mathrm{Cl}$ & $O R$ & $95 \% \mathrm{Cl}$ & $O R$ & $95 \% \mathrm{Cl}$ & $O R$ & $95 \% \mathrm{Cl}$ \\
\hline \multicolumn{9}{|l|}{ Carrier } \\
\hline Both & 0.8 & $0.4-1.5$ & 1.3 & $0.5-3.5$ & 0.7 & $0.4-1.2$ & 1.0 & $0.4-2.6$ \\
\hline Male & 1.2 & $0.7-2.2$ & 1.2 & $0.6-2.3$ & 1.4 & $0.8-2.4$ & 1.3 & $0.7-2.5$ \\
\hline Female & & Ref. & & Ref. & & Ref. & & Ref. \\
\hline \multicolumn{9}{|l|}{ Reproductive history } \\
\hline Previous pregnancies ${ }^{3}$ & 1.1 & $0.6-1.8$ & 0.5 & $0.2-1.2$ & 0.7 & $0.4-1.2$ & 0.7 & $0.3-1.3$ \\
\hline Infertility (IVF indication) & 2.5 & $1.2-5.2$ & 2.2 & $0.9-5.4$ & 2.4 & $1.2-4.9$ & 2.3 & $1.0-5.2$ \\
\hline Sub-fertility & 0.7 & $0.2-2.2$ & 0.6 & $0.1-2.6$ & 1.0 & $0.3-3.0$ & 1.2 & $0.3-4.1$ \\
\hline $\begin{array}{l}\text { Normal fertility/not yet } \\
\text { started }\end{array}$ & & Ref. & & Ref. & & Ref. & & Ref. \\
\hline Miscarriage $(s)^{3}$ & 2.5 & $1.5-4.3$ & 3.0 & $1.5-5.8$ & 1.4 & $0.8-2.3$ & 1.1 & $0.6-1.9$ \\
\hline $\begin{array}{l}\text { Pregnancy termination(s) } \\
(\mathrm{TOP})^{3}\end{array}$ & 1.4 & $0.8-2.6$ & 1.9 & $0.9-4.0$ & 2.1 & $1.2-3.8$ & 3.1 & $1.5-6.4$ \\
\hline Uncomplicated $^{3}$ & 0.5 & $0.3-0.9$ & 0.6 & $0.3-1.5$ & 0.5 & $0.3-0.8$ & 0.7 & $0.3-1.6$ \\
\hline \multicolumn{9}{|l|}{$\begin{array}{l}\text { Couples' experience with } \\
\text { disease }\end{array}$} \\
\hline Healthy child ${ }^{3}$ & 1.1 & $0.6-1.9$ & 0.9 & $0.5-1.9$ & 1.3 & $0.8-2.4$ & 1.5 & $0.7-2.9$ \\
\hline Affected child alive & 0.5 & $0.3-0.9$ & 0.5 & $0.3-1.1$ & 0.4 & $0.2-0.7$ & 0.3 & $0.1-0.6$ \\
\hline Loss of affected child & 1.3 & $0.4-4.7$ & 6.0 & $1.0-35.4$ & 1.2 & $0.3-4.0$ & 2.1 & $0.4-10.0$ \\
\hline No affected child & & Ref. & & Ref. & & Ref. & & Ref. \\
\hline \multicolumn{9}{|l|}{ Psychosocial factors } \\
\hline \multicolumn{9}{|l|}{$\begin{array}{l}\text { Alternative reproductive } \\
\text { option (f) }\end{array}$} \\
\hline No alternative & 12.9 & $2.7-62.9$ & 14.4 & $2.8-73.9$ & 8.6 & $1.8-41.6$ & 12.1 & $2.3-63.4$ \\
\hline $\begin{array}{l}\text { Available but preference } \\
\text { PGD }\end{array}$ & 11.1 & $2.4-52.7$ & 10.7 & $2.2-52.7$ & 6.7 & $1.4-31.8$ & 8.4 & $1.7-42.7$ \\
\hline Alternative considered & 0.7 & $0.1-3.7$ & 0.5 & $0.1-3.1$ & 0.8 & $0.1-4.3$ & 0.8 & $0.1-4.5$ \\
\hline Preference alternative & & Ref. & & Ref. & & Ref. & & Ref. \\
\hline \multicolumn{9}{|l|}{$\begin{array}{l}\text { Alternative reproductive } \\
\text { option }(m)\end{array}$} \\
\hline No alternative & 13.9 & $2.8-68.0$ & 3.8 & $0.3-42.7$ & 9.0 & $1.9-43.8$ & 1.9 & $0.2-22.0$ \\
\hline $\begin{array}{l}\text { Available but preference } \\
\text { PGD }\end{array}$ & 10.2 & $2.2-48.3$ & 3.3 & $0.3-32.8$ & 6.3 & $1.3-29.6$ & 1.9 & $0.2-20.8$ \\
\hline Alternative considered & 0.9 & $0.2-4.8$ & 1.1 & $0.1-14.0$ & 1.0 & $0.2-5.5$ & 0.9 & $0.1-13.1$ \\
\hline Preference alternative & & Ref. & & Ref. & & Ref. & & Ref. \\
\hline \multicolumn{9}{|l|}{$\begin{array}{l}\text { Agreement decision } \\
\text { (preference PGD) }\end{array}$} \\
\hline Male stronger preference & 0.4 & $0.2-0.8$ & 0.6 & $0.2-1.5$ & 0.4 & $0.2-0.9$ & 0.6 & $0.2-1.4$ \\
\hline $\begin{array}{l}\text { Female stronger } \\
\text { preference }\end{array}$ & 1.0 & $0.5-2.0$ & 0.8 & $0.4-1.7$ & 1.2 & $0.6-2.3$ & 0.9 & $0.5-2.0$ \\
\hline Equal support & & Ref. & & Ref. & & Ref. & & Ref. \\
\hline
\end{tabular}


Table 5. Results unadjusted and adjusted analysis - continued

\begin{tabular}{|c|c|c|c|c|c|c|c|c|}
\hline \multirow[t]{3}{*}{ Variables } & \multirow{2}{*}{\multicolumn{2}{|c|}{$\begin{array}{c}\text { Effect on PGD } \\
\text { intention }\left(t_{0}\right) \\
\text { Unadjusted }\end{array}$}} & \multirow{2}{*}{\multicolumn{2}{|c|}{$\begin{array}{c}\text { Effect on PGD } \\
\text { intention }\left(t_{0}\right) \\
\text { Adjusted }^{1}\end{array}$}} & \multirow{2}{*}{\multicolumn{2}{|c|}{$\begin{array}{l}\text { Effect on PGD } \\
\text { use }\left(t_{1}\right) \\
\text { Unadjusted }\end{array}$}} & \multirow{2}{*}{\multicolumn{2}{|c|}{$\begin{array}{l}\text { Effect on PGD } \\
\text { use }\left(t_{1}\right) \\
\text { Adjusted }^{2}\end{array}$}} \\
\hline & & & & & & & & \\
\hline & $O R$ & $95 \% \mathrm{Cl}$ & $O R$ & $95 \% \mathrm{Cl}$ & $O R$ & $95 \% \mathrm{Cl}$ & $O R$ & $95 \% \mathrm{Cl}$ \\
\hline \multicolumn{9}{|l|}{$\begin{array}{l}\text { Openness about PGD } \\
\text { treatment }(f)\end{array}$} \\
\hline Only partner & 0.9 & $0.4-2.5$ & 1.1 & $0.3-3.5$ & 1.1 & $0.4-2.8$ & 0.9 & $0.3-3.0$ \\
\hline Intimates & 0.8 & $0.4-1.6$ & 0.8 & $0.4-1.8$ & 0.8 & $0.4-1.4$ & 0.8 & $0.4-1.7$ \\
\hline Close family and friends & 0.5 & $0.3-1.0$ & 0.7 & $0.3-1.5$ & 0.5 & $0.3-1.0$ & 0.5 & $0.2-1.1$ \\
\hline Everybody & & Ref. & & Ref. & & Ref. & & Ref. \\
\hline \multicolumn{9}{|l|}{$\begin{array}{l}\text { Openness about PGD } \\
\text { treatment }(\mathrm{m})\end{array}$} \\
\hline Taboo & 0.3 & $0.0-3.8$ & 4.0 & $0.3-60.8$ & 0.4 & $0.0-4.6$ & 6.5 & $0.4-107^{4}$ \\
\hline Only partner & 1.0 & $0.5-2.3$ & 1.1 & $0.4-2.8$ & 0.9 & $0.4-1.9$ & 0.7 & $0.3-1.7$ \\
\hline Intimates & 0.7 & $0.4-1.4$ & 0.7 & $0.3-1.6$ & 0.6 & $0.3-1.1$ & 0.5 & $0.2-1.3$ \\
\hline Close family and friends & 0.5 & $0.3-1.0$ & 0.7 & $0.3-1.6$ & 0.5 & $0.3-1.0$ & 0.4 & $0.2-0.9$ \\
\hline Everybody & & Ref. & & Ref. & & Ref. & & Ref. \\
\hline $\begin{array}{l}\text { Support (f) } \\
\text { Insufficient support }\end{array}$ & 1.1 & $0.4-3.1$ & 0.7 & $0.2-2.6$ & 1.2 & $0.4-3.3$ & 1.0 & $0.3-3.3^{5}$ \\
\hline Support and criticism & 0.9 & $0.5-1.9$ & 1.1 & $0.5-2.7$ & 0.9 & $0.4-1.8$ & 0.9 & $0.4-2.2$ \\
\hline Much support & 1.1 & $0.6-2.0$ & 1.0 & $0.5-2.0$ & 1.0 & $0.6-1.9$ & 0.9 & $0.4-1.8$ \\
\hline No need for support & 0.5 & $0.1-1.8$ & 0.5 & $0.1-2.1$ & 0.7 & $0.2-2.5$ & 0.6 & $0.1-2.6$ \\
\hline Sufficient support & & Ref. & & Ref. & & Ref. & & Ref. \\
\hline $\begin{array}{l}\text { Support (m) } \\
\text { Insufficient support }\end{array}$ & 0.3 & $0.1-1.1$ & 0.2 & $0.1-1.0$ & 0.4 & $0.1-1.5$ & 0.2 & $0.0-1.0^{6}$ \\
\hline Support and criticism & 0.9 & $0.4-1.8$ & 1.0 & $0.4-2.5$ & 0.8 & $0.4-1.6$ & 0.5 & $0.2-1.4$ \\
\hline Much support & 0.9 & $0.5-1.6$ & 0.8 & $0.4-1.6$ & 0.9 & $0.5-1.6$ & 0.5 & $0.2-1.3$ \\
\hline No need for support & 0.5 & $0.2-1.2$ & 0.5 & $0.2-1.4$ & 0.5 & $0.2-1.4$ & 0.3 & $0.1-1.0$ \\
\hline Sufficient support & & Ref. & & Ref. & & Ref. & & Ref \\
\hline \multicolumn{9}{|l|}{ Time pressure: } \\
\hline High (<3 years) & 0.8 & $0.4-1.9$ & 0.7 & $0.2-2.1$ & 0.7 & $0.3-1.7$ & 0.8 & $0.3-2.2$ \\
\hline Moderate ( $3-5$ years) & 1.6 & $0.7-3.3$ & 1.5 & $0.6-3.8$ & 1.5 & $0.7-3.0$ & 1.4 & $0.6-3.4$ \\
\hline Light (5-10 years) & 1.5 & $0.8-2.7$ & 1.2 & $0.6-2.4$ & 1.6 & $0.9-2.9$ & 1.4 & $0.7-2.6$ \\
\hline No time pressure & & Ref. & & Ref. & & Ref. & & Ref. \\
\hline
\end{tabular}

1 Adjusted for: 'affected child alive', 'miscarriage(s)', and 'alternative reproductive option'.

2 Adjusted for: 'affected child alive', 'pregnancy termination(s)', and 'alternative reproductive option'.

3 Yes/no; no is reference.

4 Adjusted additionally for 'infertility' and 'referred for PGD by'.

5 Adjusted additionally for 'referred for PGD by'.

6 Adjusted additionally for 'infertility', 'referred for PGD by' and 'openness about PGD treatment $(\mathrm{m})^{\prime}$. 
In time, this effect appeared to grow even stronger, resulting in a significant decrease in PGD use $\left(t_{1}\right.$ : OR $\left.0.3,95 \% \mathrm{Cl} 0.1-0.6\right)$. Interestingly, the experience of the loss of a child due to the genetic disorder showed the opposite effect: PGD intention was significantly increased, whereas PGD use was not affected.

\section{Psychosocial factors}

The strongest effect on both PGD intention and PGD use was the absence of a morally acceptable or practical alternative, labelled 'no alternative' (Table 5). Unadjusted analyses showed similar effects of these variables in both males and females. However, after adjusted analyses, this effect was only observed in females ( $t_{0}$ : OR $14.4,95 \% \mathrm{Cl} 2.8-73.9$ and $t_{1}$ : OR $12.1,95 \% \mathrm{Cl} 2.3-63.4$ ). This finding was in line with the unadjusted analysis of 'agreement of reproductive decision' between partners. Here we observed that if the female was less inclined towards PGD than her partner, the couple was less likely to express PGD intention or ultimately PGD use. However, in adjusted analysis, this effect of disagreement disappeared.

The opposite gender effect was seen in the reported openness: males stating 'openness to only family and friends' showed significantly decreased use of PGD in comparison to males reporting 'openness to everybody' (OR $0.4,95 \% \mathrm{Cl}$ 0.2-0.9). Likewise, the amount of support experienced by males only contributed to PGD use. Males reporting 'insufficient support' showed a tendency towards decreased PGD intention and significantly decreased PGD use (t1: OR 0.2, 95\% $\mathrm{Cl} 0.0-1.0)$. In females, this effect was not significant. Finally, the level of time pressure did not show any correlation with PGD intention or to PGD use.

\section{Discussion}

We present a long-term prospective study on PGD use and the profiles and motives of couples referred for PGD. While $53 \%$ of the couples initially tended to use PGD, only $46 \%$ actually embarked on PGD treatment. Our study shows that couples with infertility problems or couples who underwent one or more pregnancy terminations were more prone to opt for PGD, while the presence of a living affected child was a negative predictor for the eventual use of PGD. Couples with a history of miscarriage(s) showed increased PGD intention, but many refrained from factual treatment. Neither the clinical impact of the disorder nor the mode of inheritance determined the choice of PGD. So, we conclude that the actual experience of couples is the main determining factor 
to choose for PGD, rather than theoretical data on recurrence risks or type of disorder. The preference for PGD in the woman rather than possible alternatives turned out to be the strongest psychological determinant for PGD. Other psychological factors such as time pressure, social support or openness were less important. As the partners were interviewed together, we cannot exclude the possibility of partners mutually influencing each other's responses.

A correlation between increased PGD interest and fertility problems was found in several studies and is in line with our results ${ }^{9,11,13,17}$. The simple explanation may be that these infertile couples are dependent on assisted reproduction techniques to conceive.

We observed a rather paradoxical shift between PGD intention and PGD use in the couples who have an affected child. Loss of an affected child resulted in increased PGD intention, whereas PGD use was not significantly affected. The presence of a living affected child, however, led to slightly decreased PGD intention and significantly decreased PGD use. Contrary to our findings, a positive attitude towards PGD was observed in subjects with an affected child in three other studies ${ }^{8,9,11}$. We assume that the theoretical setting of these studies in countries where PGD had not yet, or only recently, been introduced (Saudi Arabia, Italy, Hong Kong) and the substantial number of females who were pregnant at the time of study (not reported/30, 155/155 and 24/141, respectively) might have contributed to a more positive attitude towards PGD, since doubts and fears about their current pregnancy and the unknown outcome might have predisposed them to demonstrate a hypothetical willingness to use PGD. On the other hand, the shift towards reduced PGD intention among couples having an affected child might be explained by the impracticality of actually combining an invasive and time-consuming procedure like PGD/IVF with the demanding and time-consuming care for an affected child. Another reason for this reduced PGD intention may be that couples feel uneasy towards their affected child, as if by performing PGD for subsequent offspring, they 'reject' the previous child. This effect, however, would be probably even stronger concerning PND with a possible TOP.

Couples who have experienced TOP might have a more fundamental motive for PGD driven by the desire to avoid another pregnancy termination. In the literature, some studies show a positive attitude towards PGD among couples with a previous TOP ${ }^{9,10,18}$, while others found no such correlation ${ }^{11,13,19}$.

We speculate that the choice of PGD in the group of patients with previous miscarriages might be prompted primarily by the desire to achieve a successful 
pregnancy. The actual method of choice to reach this goal (PGD or spontaneously) seems to be of minor importance. In our study, nine out of 16 couples with previous miscarriage(s) eventually refrained because of a current pregnancy, compared to three out of ten couples without a previous miscarriage. In the 26 refraining couples, 62\% (16/26) showed a history of miscarriages, compared with $33 \%$ (88/264) of the total numer of referrals.

In contrast to our findings, in a recent qualitative study, couples reported 'experiencing previous miscarriages' to be a common motive for using PGD ${ }^{20}$. This apparent discrepancy might be caused by the different design of the studies. We studied a large and heterogeneous group of couples who did and did not start PGD and performed a quantitative analyses, while Karatas studied a selected small sample $(n=14)$ during PGD treatment in a qualitative way.

Our finding that the clinical impact of the disorder was not of influence is in contrast with studies on the acceptability of PGD in the general population. In Germany, a correlation between the increased clinical impact of disorders and the acceptability as well as intended use of PGD and was found in a randomly selected population ${ }^{17,21}$. Again the theoretical setting of these studies might have influenced study results in favour of PGD. However, we assume that both the general acceptability of PGD and other reproductive alternatives are affected by their (expected) impact. Furthermore, in our study design, we cannot rule out a pre-selection of PGD candidates according to higher or lower impact of the disease before intake to our PGD centre.

All in all, the strongest predictor for PGD was the woman's preference for PGD measured in the 'alternative reproductive option'. From this finding we conclude that the opinion of the female partner is dominant in the decisionmaking process concerning PGD.

Comparing our study with others, we observed four major differences. First, our study population consisted solely of patients referred for PGD, who were already relatively well informed before referral. Other study samples consisted of couples approached actively for their increased risk of affected offspring ${ }^{7-}$ $11,13,14,19$ or of a random sample from the general population ${ }^{17,21,22}$. Two studies have explored couples' attitudes toward PGD prior to PGD or IVF treatment ${ }^{23}$ or their experiences and attitudes after undergoing PGD or IVF treatment ${ }^{12}$.

Second, our study group was large and heterogeneous, consisting of couples with a high risk of miscarriage (25-50\%) or a high risk of having a child with a 
serious genetic disorder with different modes of inheritance, whereas other studies described couples at risk of transmitting (mainly) autosomal recessive disorders $^{9-14,18,19}$.

Third, there is a great gap in prior knowledge about PGD and information supplied to participants between our study and others. Our population is generally well informed about the existence of PGD, and all our participants received basic information prior to being referred. Unawareness of PGD in the subjects studied in the literature is generally high $(40-100 \%)^{7,8,14,17,21,24}$. Detailed information on PGD supplied to participants is limited: in only three other studies were participants provided with oral information about $\mathrm{PGD}^{7,19,25}$. Other populations received only limited written information about PGD by way of leaflets ${ }^{9-11,13,14,18,21,24}$ or even only short definitions ${ }^{26-28}$.

Fourth, PGD accessibility varies from one country to another. Internationally, most studies have been carried out in countries (Germany, Italy, Saudi Arabia and Lebanon) where PGD had not (yet) been legalized ${ }^{7-10,17,19,21,22}$. Other studies have explored the acceptability of new indications for PGD (HLA typing or inheritable cancer) in countries where PGD was already operational ${ }^{26,29}$.

As a consequence, in the literature, choices of PGD were measured on a rather hypothetical basis.

One would expect our population of referrals to be biased towards a more positive attitude to PGD. However, in spite of this selection bias, in our study, the percentage of couples intending to start PGD (53\%) is relatively low compared with the $19-100 \%$ of couples at risk of transmitting (mainly) autosomal recessive disorders described in the literature ${ }^{9-14,18,19,27}$. The theoretical setup of most studies, combined with the limited information given about the disadvantages, might result in a more positive (theoretical) attitude towards PGD. In our opinion, it is only after extensive counselling about the burden and risk of IVF treatment, the limited success rate, and the timeconsuming procedure, that couples are able to make a well-informed choice for or against PGD.

Our data confirm that the original reason for developing PGD, namely to offer an alternative for prenatal diagnosis, is still valid. On the other hand, we have shown that most normal fertile couples with an uncomplicated reproductive history and without obvious moral or religious objections to PGD decide to refrain from PGD after extensive counselling. They presumably show 
preference for prenatal diagnostic testing. This is in accordance with the results of others ${ }^{10,13,14}$. Since PGD in the Netherlands is covered by the general health insurance, generalizability of our study to countries without such reimbursement might be limited.

\section{Conclusion}

The overall picture obtained from this study is that around $50 \%$ of the couples referred for PGD actually continue to PGD treatment. PGD is particularly attractive for couples who have terminated one or more pregnancies and for infertile couples. The female preference for PGD over alternatives is a very strong determinant of couples eventually using PGD. On the other hand, prenatal diagnosis is the most likely alternative for couples who have no experience of prenatal testing. This information can be of value in reproductive counselling of couples with an increased genetic risk to enable them to make a well-motivated choice.

\section{References}

1. Handyside $\mathrm{AH}$, Kontogianni EH, Hardy K, Winston RM: Pregnancies from biopsied human preimplantation embryos sexed by Y-specific DNA amplification. Nature 1990; 344: 768-770.

2. Harper JC, Coonen $\mathrm{E}$, de Rycke $\mathrm{M}$ et al: ESHRE PGD Consortium data collection $\mathrm{X}$ : cycles from January to December 2007 with pregnancy follow-up to October 2008. Human reproduction 2010; 25: 2685-2707.

3. Jasper MJ, Liebelt J, Hussey ND: Preimplantation genetic diagnosis for BRCA1 exon 13 duplication mutation using linked polymorphic markers resulting in a live birth. Prenatal diagnosis 2008; 28: 292-298.

4. Offit K, Kohut K, Clagett B et al: Cancer genetic testing and assisted reproduction. J Clin Oncol 2006; 24: 4775-4782.

5. Sagi M, Weinberg N, Eilat $A$ et al: Preimplantation genetic diagnosis for BRCA1/2--a novel clinical experience. Prenatal diagnosis 2009; 29: 508-513.

6. Spits $\mathrm{C}$, de Rycke $\mathrm{M}$, van Ranst $\mathrm{N}$ et al: Preimplantation genetic diagnosis for cancer predisposition syndromes. Prenatal diagnosis 2007; 27: 447-456.

7. Alkuraya FS, Kilani RA: Attitude of Saudi families affected with hemoglobinopathies towards prenatal screening and abortion and the influence of religious ruling (Fatwa). Prenatal diagnosis 2001; 21: 448-451.

8. Alsulaiman A, Hewison J: Attitudes to prenatal and preimplantation diagnosis in Saudi parents at genetic risk. Prenatal diagnosis 2006; 26: 1010-1014. 
9. Chamayou S, Guglielmino A, Giambona A et al: Attitude of potential users in Sicily towards preimplantation genetic diagnosis for beta-thalassaemia and aneuploidies. Human reproduction 1998; 13: 1936-1944.

10. Palomba ML, Monni G, Lai R, Cau G, Olla G, Cao A: Psychological implications and acceptability of preimplantation diagnosis. Human reproduction 1994; 9: 360-362.

11. Hui PW, Lam YH, Chen $M$ et al: Attitude of at-risk subjects towards preimplantation genetic diagnosis of alpha- and beta-thalassaemias in Hong Kong. Prenatal diagnosis 2002; 22: 508-511.

12. Lavery SA, Aurell $\mathrm{R}$, Turner $\mathrm{C}$ et al: Preimplantation genetic diagnosis: patients' experiences and attitudes. Human reproduction 2002; 17: 2464-2467.

13. Miedzybrodzka Z, Templeton A, Dean J, Haites N, Mollison J, Smith N: Preimplantation diagnosis or chorionic villus biopsy? Women's attitudes and preferences. Human reproduction 1993; 8: 2192-2196.

14. Snowdon C, Green JM: Preimplantation diagnosis and other reproductive options: attitudes of male and female carriers of recessive disorders. Human reproduction 1997; 12: 341-350.

15. Thornhill AR, de Die-Smulders CE, Geraedts JP et al: ESHRE PGD Consortium 'Best practice guidelines for clinical preimplantation genetic diagnosis (PGD) and preimplantation genetic screening (PGS)'. Human reproduction 2005; 20: 35-48.

16. Aldridge LM: Anaesthetic problems in myotonic dystrophy. A case report and review of the Aberdeen experience comprising 48 general anaesthetics in a further 16 patients. British journal of anaesthesia 1985; 57: 1119-1130.

17. Borkenhagen A, Brahler E, Wisch S, Stobel-Richter Y, Strauss B, Kentenich H: Attitudes of German infertile couples towards preimplantation genetic diagnosis for different uses: a comparison to international studies. Human reproduction 2007; 22: 2051-2057.

18. Pergament E: Preimplantation diagnosis: a patient perspective. Prenatal diagnosis 1991; 11: 493-500.

19. Farra C, Nassar AH, Usta IM, Salameh P, Souaid M, Awwad J: Acceptance of preimplantation genetic diagnosis for beta-thalassemia in Lebanese women with previously affected children. Prenatal diagnosis 2008; 28: 828-832.

20. Karatas JC, Barlow-Stewart K, Strong KA, Meiser B, McMahon C, Roberts C: Women's experience of pre-implantation genetic diagnosis: a qualitative study. Prenatal diagnosis 2010; 30: 771-777.

21. Meister U, Finck C, Stobel-Richter Y, Schmutzer G, Brahler E: Knowledge and attitudes towards preimplantation genetic diagnosis in Germany. Human reproduction 2005; 20 : 231-238.

22. Finck C, Meister U, Stobel-Richter Y, Borkenhagen A, Brahler E: Ambivalent attitudes towards pre-implantation genetic diagnosis in Germany. European journal of obstetrics, gynecology, and reproductive biology 2006; 126: 217-225. 
23. Katz MG, Fitzgerald L, Bankier A, Savulescu J, Cram DS: Issues and concerns of couples presenting for preimplantation genetic diagnosis (PGD). Prenatal diagnosis 2002; 22: $1117-1122$.

24. Musters AM, Twisk $M$, Leschot NJ et al: Perspectives of couples with high risk of transmitting genetic disorders. Fertility and sterility 2010; 94: 1239-1243.

25. Alsulaiman A, Al-Odaib A, Rijjal A, Hewison J: Preimplantation genetic diagnosis in Saudi Arabia: parents' experience and attitudes. Prenatal diagnosis 2010; 30: 753-757.

26. Lammens $\mathrm{C}$, Bleiker $\mathrm{E}$, Aaronson $\mathrm{N}$ et al: Attitude towards pre-implantation genetic diagnosis for hereditary cancer. Familial cancer 2009; 8: 457-464.

27. Quinn G, Vadaparampil S, Wilson C et al: Attitudes of high-risk women toward preimplantation genetic diagnosis. Fertility and sterility 2009; 91: 2361-2368.

28. Quinn GP, Vadaparampil ST, Miree CA et al: High risk men's perceptions of preimplantation genetic diagnosis for hereditary breast and ovarian cancer. Human reproduction 2010; 25: 2543-2550.

29. Hui EC, Chan C, Liu A, Chow K: Attitudes of Chinese couples in Hong Kong regarding using preimplantation genetic diagnosis (PGD) and human leukocyte antigens (HLA) typing to conceive a 'Saviour Child'. Prenatal diagnosis 2009; 29: 593-605. 


\section{Addendum}

Interview questions for the study: 'Profiles and motives for PGD:

a prospective cohort study of couples referred for PGD in the Netherlands'

1. Which partner is carrier of the disease (male/female/both) (Table 3)

2. Describe the experience with the disease? (affected family member, presentation of the disease) (Tables 1 and 3 )

3. Were alternative reproductive options available or seriously considered? (Alternative reproductive option, Table 4)

4. Which of both partners had the strongest wish for PGD? (male, female, both) (Disagreement reproductive choice, Table 4)

5. With which persons in their social network did the couple discuss their PGD plans? (Openness about PGD plans, Table 4)

6. Did both partners receive sufficient social support? (Social support, Table 4) 

Chapter 6

\title{
Evaluation of exclusion prenatal and exclusion preimplantation genetic diagnosis for Huntington's disease in the Netherlands
}

\author{
M.C. van Rij \\ C.E.M. de Die-Smulders \\ E.K. Bijlsma \\ G.M.W.R. de Wert \\ J.P. Geraedts \\ R.A.C. Roos
}

A. Tibben 


\section{Abstract}

Individuals at $50 \%$ risk of Huntington's disease (HD) who prefer not to know their carrier status, might opt for exclusion prenatal diagnosis (ePND) or exclusion preimplantation genetic diagnosis (ePGD). This study aims to provide a better understanding of couples' motives for choosing ePND or ePND, and surveys couples' experiences in order to make recommendations for the improvement of counselling for exclusion testing.

This qualitative retrospective interview study focussed on couples who underwent ePND or ePGD for Huntington's disease in the period 1996-2010.

Seventeen couples were included: 13 had experienced ePND and six ePGD. Mean time-interval since exclusion-testing was 3.9 years. Couples' moral reservations regarding termination of pregnancy (TOP) or discarding healthy embryos were counterbalanced by the wish to protect their future child against HD. Seven couples had terminated a total of 11 pregnancies with a $50 \%$ HD risk, none showed regret. ePGD was used by couples who wanted to avoid (another) TOP.

ePND and ePGD are acceptable reproductive options for a specific group of counsellees. To guarantee sound standards of care, it is imperative that candidate couples be given in-depth non-directive counselling about all possible scenarios, and adequate professional and psychological support prior to, during and after ePND/ePGD. 


\section{Introduction}

Huntington's disease (HD) is a progressive incurable late-onset neurogenetic disorder with autosomal dominant inheritance ${ }^{1,2}$, caused by CAG trinucleotide repeat expansions in the Huntingtin $(H T T)$ gene $^{3}$. Since the discovery of the gene defect in 1993, the uptake of both presymptomatic testing (PT) and prenatal diagnosis (PND) has remained unexpectedly low ${ }^{4-9}$. Apparently, the majority of individuals at 50\% HD risk prefer not to be informed about their carrier-status. However, to prevent HD in their offspring, exclusion PND (ePND) (usually by chorionic villus sampling) can be considered ${ }^{10}$. Detection of one of either HTT alleles of the affected grandparent is associated with a $50 \%$ HD risk for the foetus, similar to the at-risk parent. Although termination of an at $50 \%$ risk pregnancy (TOP) is initially considered, this remains a moral dilemma. There are reports of couples continuing their pregnancy after receiving a $50 \%$ HD-risk result ${ }^{11,12}$.

Exclusion preimplantation genetic diagnosis (ePGD) has become an alternative since $2002^{13}$. Non-carrier IVF-embryos are selected prior to transfer into the uterus, thus avoiding the chance of TOP of a non-carrier foetus ${ }^{13-15}$. However, in the Netherlands ePGD is prohibited by law because: 1) roughly half of the couples at risk will 'unnecessarily' undergo an invasive IVF/PGD treatment; 2) discarding embryos with a $50 \%$ risk of not being an HD-carrier is considered unethical $^{16,17}$. Dutch couples requesting ePGD are referred to Brussels (Belgium) for treatment.

ePND and ePGD have been applied for more than two decades ${ }^{6,8,13-15,18,19}$. In the Netherlands exclusion-testing is applied in $15 \%$ of prenatal tests for $\mathrm{HD}^{20}$. Other countries showed a variety of $0 \%$ (Germany, Switzerland, Austria, and Greece) to $48 \%(\mathrm{UK})^{7,21-24}$. This qualitative study among couples who have undergone exclusion-testing aims: 1 ) to create a better understanding of the motives of couples opting for ePND or ePGD, 2) to study the acceptability of ePGD among candidates, and 3) to investigate experiences of couples with ePND and ePGD. The findings should enable recommendations to be made for future counselling.

\section{Participants and methods}

Dutch couples who intentionally underwent ePND or ePGD between 1996 and 2010 were approached to participate in this interview study. Persons who were incapable of giving consent or responding to the interview questions were 
excluded. For this study we used the method of 'purposive sampling' ${ }^{25}$. The size of the study group is determined by saturation, i.e. the point at which no new themes are observed, which usually occurs after about 12 interviews ${ }^{26}$. The study protocol was approved by the Medical Ethical Committee of the Maastricht University Medical Centre and the Leiden University Medical Centre.

\section{Recruitment of couples}

Eligible ePND couples were selected from the database of the DNA laboratory in Leiden, where DNA analysis for HD is centrally performed. Couples were informed by the clinical geneticists involved, received written information after a positive response, and were included after returning the informed consent form.

Couples who applied for ePGD in Maastricht University Medical Centre and who had started ePGD in the Free University Hospital in Brussels were approached (by CDS). Further inclusion procedure was identical to the ePND couples.

\section{Procedure}

A semi-structured interview was developed concerning the reproductive decision-making process and explored the following subjects: 1) experiences of the at-risk persons and their partners with affected family members, 2) reasons to opt for exclusion testing, 3) motives contributing to the choice for ePND or ePGD and factors contributing to a possible shift in reproductive behaviour, 4) moral considerations with respect to ePND and ePGD, 5) future prospects connected with the possible impact of HD and the way it affects couples' present life, 6) reflection on reproductive decisions and experiences and on the acceptability of ePGD as a reproductive option.

All interviews were held by the principal investigator (MvR). Psychological follow-up was offered if needed.

\section{Data preparation and analysis}

All interviews were recorded, transcribed verbatim, and anonymised. Interviews were analysed using the phenomenological hermeneutical research approach $^{27}$. By repeatedly listening to the interviews and iterative reading of the transcripts (MvR and AT), the personal and motivational contexts were identified. Reported motives, and aspects contributing to choices were 
categorized until no new key themes were detected. Afterwards, all interviews were reviewed to look for any additional significant statements. To assess reliability of coding, two interviews were independently coded by two other members of the research team (EB and CDS). Differences in coding were minimal.

\section{Results}

Eighteen out of 28 couples consented and were interviewed between February and April 2012. Twelve couples had experienced only ePND with various outcomes (Table 1). Four couples opted for ePGD from the start. Two couples continued with ePGD after one or two TOPs after ePND. Response of ePND couples was $58 \%(14 / 24)$, of ePGD couples $100 \%$. One at-risk female was excluded because she did not meet the inclusion criteria.

Of the 10 couples who did not respond or declined to respond, eight males were at risk and two females. Non-participating couples showed similar outcomes of ePND compared to the participating couples.

At the time of the interview, the at-risk individuals' genetic status was still undisclosed. Three at-risk partners did not attend the interview because they did not want confrontation with HD. Differences in age and time intervals since the last ePND or ePGD between both groups were not statistically significant and may result from the fact that ePGD was only performed in the second half of the inclusion period (Table 1). Reproductive history and outcome per couple are summarized in the Tables 2 and 3 . None of the couples made use of the psychological follow-up.

\section{Experiences with $H D$}

Nine individuals at risk recalled their first experiences with symptomatic HD in a close family member before the age of 13 years, the remaining eight between the ages of 14 and 27 years. Fifteen out of 17 at-risk persons had an affected parent (8 fathers and 7 mothers), one carrier father was still asymptomatic, and one presymptomatic carrier mother had died at the age of 46 years due to cancer. All participants had become aware of their risk of HD in adolescence or early adulthood (14 to 27 years). In two cases, HD symptoms or the loss of an affected family member preceded the awareness of HD and its inheritable nature for more than a decade due to late diagnosis or lack of communication in the respective families. 
Table 1. Couples' characteristics

\begin{tabular}{|c|c|c|c|}
\hline & $\begin{array}{l}e P N D \\
(n=11)\end{array}$ & $\begin{array}{l}e P G D \\
(n=4)\end{array}$ & $\begin{array}{c}e P N D \text { and } e P G D \\
(n=2)\end{array}$ \\
\hline Partner at risk (M/F) & $7 / 4$ & $1 / 3$ & $1 / 1$ \\
\hline Both partners attended interview & 8 & 4 & 2 \\
\hline One of both partners (M/F) & $1 / 2$ & & \\
\hline \multicolumn{4}{|l|}{ Mean age at time of interview (SD) } \\
\hline Male & $38.9(6.2)$ & $34.1(3.7)$ & $38.0(0.5)$ \\
\hline Female & $37.0(6.3)$ & $31.2(3.0)$ & $33.9(2.7)$ \\
\hline \multicolumn{4}{|l|}{ Education } \\
\hline Middle (M/F) & $4 / 6$ & $4 / 3$ & \\
\hline High (M/F) & $7 / 5$ & $0 / 1$ & $2 / 2$ \\
\hline Married/living together & 9 & 4 & 2 \\
\hline Separated & 2 & & \\
\hline \multicolumn{4}{|l|}{ Religious } \\
\hline Yes & $1 R C$ & $1 \mathrm{RC}$ & \\
\hline No & 3 & 1 & \\
\hline Not anymore & 8 & 2 & 2 \\
\hline $\begin{array}{l}\text { Time-interval (years) between interview } \\
\text { and last ePND/ePGD cycle (SD) (range) }\end{array}$ & $\begin{array}{c}5.3(3.3) \\
(0.8-10.3)\end{array}$ & $\begin{array}{l}1.5(1.0) \\
(0.4-2.6)\end{array}$ & $\begin{array}{l}0.3(0.1) \\
(0.3-0.4)\end{array}$ \\
\hline Pregnant at time of interview & & 1 & $2^{1}$ \\
\hline Planning for future pregnancy & 3 & 3 & \\
\hline
\end{tabular}

ePND, exclusion prenatal diagnosis; ePGD, exclusion preimplantation genetic diagnosis; RC, Roman Catholic

1 One spontaneous untested pregnancy

\section{Experiences of partners of at-risk individuals}

Fifteen partners had experienced one or more affected relatives. Two partners had only seen pictures or video recordings of HD patients (see Table 2 for specific information on the couples with corresponding codes: C11, C18). Seven at-risk individuals had informed their partners about their HD-risk immediately or within the first weeks after the beginning of the relationship; one immediately after the diagnosis was made in a relative (C16). Five partners first heard about HD after 3 to 12 months, on the occasion of a family visit or the death of an affected family member. Two female partners heard indirectly (from a third person) about the HD risk of their partners after 6 to 12 months. 
Two at-risk males had first informed their partners incompletely, stating things like "my mother is ill" (C14) or "no children for me" (C06), and their female partners learned in more detail some months later. Early communication of the $H D$ risk was most frequently observed in female at-risk partners ( $M: F=2: 6$ ) versus absent, late or incomplete communication in at-risk males ( $M: F=7: 2$ ) $(p=0.03)$.

\section{Reasons to opt for exclusion-testing}

All at-risk persons insisted on not wanting to know their own HD-carrier status. They feared that HD might control their lives $(n=8)$, deprived them from hope $(n=8)$, or being stigmatized $(n=5)$. The wish 'not to know' was generally respected by their partners. Additionally, all couples intended to prevent the birth of an HD-carrier child $(n=17)$ and cited one or more various underlying motives: to avoid passing HD on to a child $(n=12)$, to eradicate HD (from the family/world) $(n=4)$, the anticipated inability of the partner to cope with a double loss (first the partner then a child) $(n=4)$, the inability to justify having taken the risk of transmitting HD to their future child $(n=4)$.

Table 2. Reproductive history for each couple in specific

\begin{tabular}{|c|c|c|}
\hline Reproductive History & $n=17$ & Couple codes \\
\hline$\geq 1$ child after ePND (HD excluded) & 5 & $04-11-13-16-18$ \\
\hline$\geq 1$ TOP after ePND and $\geq 1$ child after ePND (HD excluded) & $4^{1}$ & 03-06-07-17 \\
\hline$\geq 1$ ePGD child & 4 & 01-02-08-09 \\
\hline 2 TOPs after ePND and ePGD pregnancy ( $2^{\text {nd }}$ trimester) & 1 & 05 \\
\hline $\begin{array}{l}1 \text { TOP after ePND, ePGD unsuccessful, untested child, untested } \\
\text { pregnancy ( } 3^{\text {rd }} \text { trimester) }\end{array}$ & 1 & 15 \\
\hline $\begin{array}{l}\text { Miscarriage } 2 x(e P N D \text { intended), } 1 \text { TOP after ePND, miscarriage } \\
1 x \text { (ePND intended), miscarriage } 1 x \text { (no PND intention) }\end{array}$ & 1 & 14 \\
\hline $\begin{array}{l}\text { Miscarriage after ePND (50\%-risk allele), ongoing pregnancy } \\
\text { after ePND ( } 50 \% \text {-risk allele) }\end{array}$ & 1 & 12 \\
\hline
\end{tabular}

ePND, exclusion prenatal diagnosis; ePGD, exclusion preimplantation genetic diagnosis; TOP, termination of pregnancy

1 Two couples additionally had a miscarriage 
Table 3. Reproductive history of couples attending the interview

\begin{tabular}{lcccc}
\hline & $\begin{array}{c}e P N D \\
(n=11)\end{array}$ & $\begin{array}{c}e P G D \\
(n=4)\end{array}$ & $\begin{array}{c}e P N D \text { and } \\
e P G D(n=2)\end{array}$ & $\begin{array}{c}\text { Total } \\
(n=17)\end{array}$ \\
\hline (couples) & $n$ (couples) & $n$ (couples) & $n$ (couples) \\
\hline Exclusion-PND & $23(11)$ & & $3(2)$ & $26(13)$ \\
TOP 50\%-risk allele & $8(5)$ & $3(2)$ & $11(7)$ \\
Miscarriage (50\%-risk allele) & $1(1)$ & & & $1(1)$ \\
Child HD risk excluded & $13(9)$ & & & $13(9)$ \\
Child (50\%-risk allele) & $1(1)$ & & & $1(1)$ \\
Exclusion-PGD & & $4(4)$ & $2(2)$ & $6(6)$ \\
Cycles started & & $8(4)$ & $6(2)$ & $14(6)$ \\
PGD child & & $4(4)$ & 0 & $4(4)$ \\
$2^{\text {nd }}$ or 3 ${ }^{\text {rd }}$ trimester \\
pregnancy after PGD
\end{tabular}

$\mathrm{n}$, number of prenatal tests or PGD cycles

${ }^{1}$ Untested child and onging pregnancy of the same couple

Motives contributing to the choice for ePND or ePGD

Most couples (13/17) were informed about both options prior to reproductive decision making. Four couples were not aware of ePGD, one of them was counselled in 1997, before the introduction of $\mathrm{ePGD}^{13}$. The remaining three couples were counselled in 2003-2006. The most prominent considerations for either option were the artificial aspect of ePGD versus natural conception in ePND, the objections against TOP (ePND), and the limited success rates (ePGD) (see Table 4). Couples expressed emotional reasons as well as moral objections against TOP. Alternative reproductive options which were considered varied from refraining from having children $(n=6)$, to adoption $(n=6)$, just taking or accepting the risk $(n=2)$, or the use of donor gametes $(n=2)$. Five ePND couples had considered ePGD as an alternative. Two ePGD couples and two ePND couples had considered direct PND without prior PT, but the wish not to know the carrier status of the at-risk parent prevailed. 
Table 4. Advantages and disadvantages of ePND or ePGD considered by couples in their decision-making process

\begin{tabular}{|c|c|c|c|}
\hline$e P N D$ & & $e P G D$ & \\
\hline Advantages & Disadvantages & Advantages & Disadvantages \\
\hline $\begin{array}{l}\text { Natural } \\
\text { pregnancy }\end{array}$ & $\begin{array}{l}\text { TOP (late-onset) HD } \\
\text { TOP healthy child (50\%) } \\
\text { Emotional barrier TOP }\end{array}$ & No need for TOP & $\begin{array}{l}\text { Hormones and } \\
\text { artificial character } \\
\text { PGD }\end{array}$ \\
\hline $\begin{array}{l}\text { High chances } \\
\text { ( } 50 \% \text { favourable } \\
\text { result) }\end{array}$ & $\begin{array}{l}\text { If continued to direct } \\
\text { test, carrier-status } \\
\text { revealed } \rightarrow \text { chance } \\
\text { double bad news }\end{array}$ & $\begin{array}{l}\text { Carrier status at-risk } \\
\text { partner remains } \\
\text { undisclosed }\end{array}$ & $\begin{array}{l}\text { Limited pregnancy } \\
\text { rate }\end{array}$ \\
\hline \multirow[t]{3}{*}{$\begin{array}{l}\text { Easy/no hospital } \\
\text { visits }\end{array}$} & $\begin{array}{l}\text { Having to decide for TOP } \\
\text { or continuation of } \\
\text { pregnancy }\end{array}$ & $\begin{array}{l}\text { Laboratory selects } \\
\text { between embryos; } \\
\text { couple not involved } \\
\text { in selection process }\end{array}$ & $\begin{array}{l}\text { Physical and } \\
\text { practical burden } \\
\text { (duration } \\
\text { PGD/hospital visits) }\end{array}$ \\
\hline & $\begin{array}{l}\text { Chance continuing at-risk } \\
\text { pregnancy }\end{array}$ & & $\begin{array}{l}\text { PGD Belgium: } \\
\text { distance, cultural } \\
\text { and financial } \\
\text { aspects }^{1}\end{array}$ \\
\hline & Stress until PND result & & \\
\hline
\end{tabular}

Factors contributing to a shift in reproductive decisions

The wish to avoid (another) TOP for 50\% HD-risk was the main reason against ePND $(n=6)$. One couple shifted towards exclusion-definitive testing after the birth of an HD-free child, i.e. direct testing of the foetus after identification of a $50 \%$-risk allele ${ }^{9}$. Two couples decided to refrain from having more children after having had one child, because they did not want "to tempt fate anymore" (C11). One couple stopped using ePND for future pregnancies after three miscarriages and one TOP (C14). After the next miscarriage she said: "I knew I would always have the feeling: would the child have it or not? I would have always had that sense of unease "(C14). Two couples shifted from ePND to ePGD, in order to avoid another TOP. After ePGD had failed, one of the latter decided to have children without testing. They thought they could explain to their children that they had done everything in their power to prevent 
transmitting HD (C15). One couple continued their at-risk pregnancy through a combination of circumstances (C12). Their first 50\%-risk allele pregnancy turned out to be a missed abortion at the moment of preparation for TOP. In one phone call the PND-result, again 50\%-risk allele, was reported together with the notification of the gynaecologist that the hospital would not provide another exclusion-test in any future pregnancy. The couple felt they had no choice but to continue their already advanced pregnancy.

\section{Moral considerations}

Protection of the unborn life is one of the moral concerns in ePND and ePGD. Most couples experienced a conflict between the value of the foetus or embryo and the at-risk partner's right not to know. Four female partners explicitly considered the status of the foetus to be of less importance than their at-risk partner's wellbeing. Therefore, violation of his wellbeing due to an unfavourable test result would be unacceptable and TOP acceptable. This can be illustrated by a conflict one couple had after their first ePND showed a highrisk allele. The female partner wanted a direct test to prevent the chance of TOP of a healthy foetus: "At that moment he [the at-risk husband] really showed his fears, really showed his grief. Then we said to each other, we will talk about it tomorrow...". Subsequently, the husband offered to do a direct test, but the woman decided to terminate the pregnancy without further testing, because she finally understood her husband's profound fears and she didn't want to risk a "double loss" of her husband being an HD-carrier, and terminating an affected pregnancy at the same time (CO7).

Moral objections against TOP for a late-onset disease like HD, and the 50\% chance of terminating a healthy foetus, formed an obstacle for two couples $(\mathrm{C} 01, \mathrm{C} 02)$. Another two described an emotional resistance to TOP (C08,C09). Twelve couples showed difficulty accepting the possibility that a healthy foetus is terminated, but after careful consideration they found it morally acceptable given the circumstances: "It was absolutely clear that we wanted to prevent the birth of a child who could get Huntington's ... As much as possible we realised that this could mean that we would do something really bad, but we were determined to do it" (C16). Only one couple expressed neither moral objection nor emotional resistance against TOP after exclusion testing (C03).

When asked, eight couples specifically commented on the moral status of the 5-day embryo (ePGD). Two couples had difficulty to accept discarding healthy embryos: one considered ePGD "the least bad of two options" (C02), the other 
couple would have preferred non-disclosure PGD to prevent discarding healthy embryos (CO5).

Five couples (including C02) considered the PGD embryo to be of less value than a foetus at 12-16 weeks' pregnancy, whereas two couples $(\mathrm{C03}, \mathrm{C} 11)$ valued them equally. One female included the chance of selection in the moral discussion: "PND only involves a chance of TOP while PGD always involves a selection" (C4).

All couples had to reconcile their responsibility towards their future child and the strong wish not to know their own genetic status. One at-risk male: "The burden you would give to a child if you pass on HD is greater, or we thought it was greater, than the termination of a healthy pregnancy" (C12). One couple felt a duty towards their child to prevent the transmission of HD at any cost. In their opinion discarding healthy embryos outweighed the cost and the health benefits to society by reducing the incidence of HD (C08).

Finally, nine couples objected strongly against the political involvement in their personal reproductive decision-making; they believed that people who have not experienced HD cannot judge whether ePND or ePGD is acceptable or not.

The impact of the HD risk on couples' present life and their future prospects

When asked about the future prospects of the couple/family, and the role of Huntington's disease in their future, the majority of couples $(n=10)$ expressed a preference to live for the moment and not look far ahead. Seven couples also pointed out that the partner without HD-risk could be hit by a car or get cancer.

Two at-risk females planned to have their children early in life (C01, C15). Two couples tried to save money for the future of their child and partner (C01,C16). Three at-risk persons were worried about leaving behind their spouse and child(ren). One male partner mentioned risk avoiding behaviour because he might become a single parent in the future ( $\mathrm{CO2}$ ). Five couples were concerned about the increasing need for care if the at risk partner fell ill. Three men elaborated on the possible impact of HD on their child: "Even if I get ill, the child can also learn a lot from that, as long as the stability remains" (C07). "It [having a father with HD] didn't affect me negatively, I think. I think I just had a different outlook on the world really early because of that, that's true" (C06). 


\section{Reconsidering reproductive choices}

All four couples who had only used ePGD (resulting in an ePGD-child) would use it again if they had to start all over. For one of the two couples who shifted from ePND to ePGD, the latter was less burdensome than expected, and resulted in pregnancy. However, this couple still believed chances were in favour of ePND, and it could have turned out right (C05). The other couple felt more positive about ePGD. For them the disappointment after an ePGD-cycle without pregnancy was much less burdensome than after TOP (C15). They would never use ePND again because of the terrible grief they experienced after TOP. Others also described TOP as an emotional and painful event. Shame and fear of incomprehension prevented one woman from sharing the experience with her best friends (C14). Without exception, all couples (who had experienced $\geq 1$ TOP ( $n=7)$ ) felt they 'did the right thing' at that moment, and expressed no regrets. Six out of seven couples would opt for ePND again, while only four had reached their goal of having a healthy child.

In contrast, only one of six couples who had $\geq 1$ child after ePND (and no TOP) would try ePND again without hesitation. One at-risk female would now prefer to first perform PT herself. If she proved to be an HD-carrier, she would refrain from having children (CO4). Two couples disagreed about opting for ePND again or not having children $(\mathrm{C} 13, \mathrm{C} 18)$. Three couples, who had never heard of ePGD prior to the interview, would have liked to know more about ePGD because it seemed an attractive alternative, avoiding the chance of TOP (C12,C14,C16).

\section{The logistics of the procedure}

A total of six couples experienced major or minor obstacles during their ePND or ePGD treatment owing to miscommunication or insufficient (psychological) support. Two couples reported that the ePND-result was communicated by telephone at an inconvenient time, to the other partner, or before the complete chromosomal results were available, contrary to what was agreed with the counsellor. ePND for one couple was refused by two hospitals. After initial agreement, the first hospital withdrew its offer of ePND shortly before the couples' exclusion test. The second hospital refrained from future ePND after having performed two exclusion tests as mentioned before. Four couples reported lack of psychological support. One partner would have preferred to be fully aware of her at-risk partner's strong wish not to know his genetic status before the high risk ePND-result; exploration with a psychologist might 
have made revealing his considerations easier. Two females would have appreciated having had some kind of psychosocial follow-up about 6 months after their TOP. One couple felt supported inadequately after their second TOP, when their mental coach questioned their parenting abilities since they were at risk for HD. Finally, one ePGD couple was disturbed by receiving contradictory information from two IVF co-workers about the number of suitable embryos and the fact that there was an inconsistent explanation given for their not having an embryo transfer in one of their cycles.

\section{Discussion}

In exclusion-testing couples have to weigh up a number of moral dilemmas concerning the conflicting interests of the future child and the at-risk person. Moreover, in the process of ePND and ePGD, couples are exposed to considerable emotional strain. Nevertheless, this study showed that both options were acceptable for all couples involved.

Feelings of responsibility when planning a family underlie one of the most frequently cited motives for presymptomatic testing, and decision making about PND or PGD for HD ${ }^{28-32}$. However, at-risk individuals in this study had to reconcile this responsibility and their wish not to discover their own genetic status. On the one hand they talk of their responsibility towards future children, and are willing to sacrifice their moral reservations about TOP or discarding healthy embryos. On the other hand they live for the moment, do not look too far ahead, and keep hoping ${ }^{33}$. This observation suggests that, like in other studies at-risk couples avoided, minimized, or denied the potential future impact of HD on themselves and their (future) children ${ }^{34}$. Exposure to an affected parent is difficult for children ${ }^{35,36}$, especially if they are confronted with HD very early in life ${ }^{37}$. Therefore, 'the reasonable welfare principle' or the 'high risk of serious harm standard' stating that it is wrong to expose future children to high risks of serious suffering is widely accepted ${ }^{38,39}$. Consequently, in our opinion it is the counsellor's challenge to carefully draw the couple's attention to this issue so that it can be included in the couples' considerations.

Physicians involved in assisted reproductive technologies like IVF/PGD have a shared responsibility towards the child brought into the world by their actions $^{39,40}$. However, physicians may be too reluctant to offer ePND or ePGD, since there are, after all, many children in HD-families who seem to cope reasonably well. Moreover, adaptive coping skills on the part of the unaffected parent may have protective effects ${ }^{37}$. The chance of a child being exposed to 
HD after exclusion testing is actually limited compared to HD-carrier couples opting for direct PND or PGD. Hence, a case-by-case approach, with special attention to the effects of the symptoms of HD upon the future child's welfare, would be preferable ${ }^{40,41}$.

In this paper, we focussed on the variables most relevant to exclusion testing, other factors contributing to couples' reproductive choices, are described in the literature $\mathrm{5}^{5,15,29,30,42-45}$.

For all couples the wish 'not to know' was the starting point for further decisions regarding family planning. The right not to know is part of the right to self-determination, protecting the at-risk person against potentially harmful information ${ }^{46,47}$. It is of the utmost importance that partners reach a state of mutual understanding and respect for the at-risk partner's right not to know prior to exclusion testing. This is especially true if the male is at risk, because his wife will be exposed to the physical burden and emotional stress of ePND or ePGD to preserve her husband's right not to know.

\section{Study limitations}

The participating couples experiencing ePND seemed a fair reflection of the total ePND group in respect of the odds of ePND results (50:50 distribution). However, a selection bias of another kind (impact of ePND and outcome, or gender of at-risk carrier) cannot be ruled out. In ePGD-couples a successful outcome resulting in the birth of a PGD-child was overrepresented. This skewing was not the result of a response bias (100\% response of ePGDcouples), but was solely the result of chance (individual fortune). The positive outcomes of ePGD couples might have biased their experiences. Differences in response between the ePND and ePGD groups might have been centre specific (ranging from $0-100 \%$ ). The concept of cognitive dissonance might explain the more positive presentation of couples' experiences afterwards ${ }^{48}$.

\section{Implications for clinical practice}

Accurate communication of and honouring agreements are essential issues to be considered. A multidisciplinary team, with a positive attitude towards ePND/ePGD, should be able to guide eligible couples through the moral and emotional complexities. The following topics should be explored during reproductive counselling: the emotional implications of ePND or ePGD regarding the procedures themselves and the possibility of TOP after ePND; the moral status of the embryo or foetus and values in relation to TOP; the 
interests of all those involved (future child, at-risk parent, partner); a discussion of all (reproductive) options available; anticipating the future: the possible impact of HD on the future child, and the strategies to limit the psychological repercussions for future children, e.g. by not postponing procreation $^{41}$. Finally, the mutual agreement of both partners and respect for the at-risk partner's right not to know are conditions for the successful application of ePND or ePGD.

\section{Conclusion}

Both ePND and ePGD for HD are acceptable reproductive options for a specific group of counsellees. Couples carefully consider all moral dilemmas involved, and cope with the considerable emotional strain reasonably well. Candidate couples should receive comprehensive and timely non-directive counselling in respect of all the possible scenarios and adequate professional and psychological support prior to, during and after the test/treatment.

\section{Acknowledgements}

The authors would particularly like to thank all couples who participated in the interviews and to express their gratitude to the following colleagues for approaching their clients and informing them about this study: Dr. I. van der Burgt, MD, PhD; Dr. M.C van Maarle, MD, PhD; Dr. A A. Maat-Kievit, MD, PhD; Mr. R.P. Stulp (Bachelor of sience); Dr. C.C. Verschuuren-Bemelmans, MD; and Prof. dr. I. Liebaers.

\section{References}

1. Bates G, Harper P, Jones L (eds): Huntington's Disease. Oxford University Press, New York., 2002.

2. Novak MJ, Tabrizi SJ: Huntington's disease. Brittish Medical Journal (Clinical research ed) 2010; 340: c3109.

3. HDCRG: A novel gene containing a trinucleotide repeat that is expanded and unstable on Huntington's disease chromosomes. Cell 1993; 72: 971-983.

4. Creighton S, Almqvist EW, MacGregor D et al: Predictive, pre-natal and diagnostic genetic testing for Huntington's disease: the experience in Canada from 1987 to 2000. Clinical genetics 2003; 63: 462-475. 
5. Evers-Kiebooms G, Nys K, Harper $\mathrm{P}$ et al: Predictive DNA-testing for Huntington's disease and reproductive decision making: a European collaborative study. European Journal of human genetics 2002; 10: 167-176.

6. Harper PS, Lim C, Craufurd D: Ten years of presymptomatic testing for Huntington's disease: the experience of the UK Huntington's Disease Prediction Consortium. Journal of medical genetics 2000; 37: 567-571.

7. Simpson SA, Zoeteweij MW, Nys $\mathrm{K}$ et al: Prenatal testing for Huntington's disease: a European collaborative study. European Journal of Human Genetics 2002; 10: 689-693.

8. Tassicker RJ, Marshall PK, Liebeck TA, Keville MA, Singaram BM, Richards FH: Predictive and pre-natal testing for Huntington Disease in Australia: results and challenges encountered during a 10-year period (1994-2003). Clinical genetics 2006; 70: 480-489.

9. Maat-Kievit $\mathrm{A}$, Vegter-van der Vlis $\mathrm{M}$, Zoeteweij $\mathrm{M}$ et al: Experience in prenatal testing for Huntington's disease in The Netherlands: procedures, results and guidelines (19871997). Prenatal diagnosis 1999; 19: 450-457.

10. Harper PS, Sarfarazi M: Genetic prediction and family structure in Huntington's chorea. British Medical Journal (Clinical research ed) 1985; 290: 1929-1931.

11. Adam S, Wiggins $S$, Whyte $P$ et al: Five year study of prenatal testing for Huntington's disease: demand, attitudes, and psychological assessment. Journal of medical genetics 1993; 30: 549-556.

12. Tolmie JL, Davidson HR, May HM, McIntosh K, Paterson JS, Smith B: The prenatal exclusion test for Huntington's disease: experience in the west of Scotland, 1986-1993. Journal of medical genetics 1995; 32: 97-101.

13. Sermon $K$, de Rijcke $M$, Lissens $W$ et al: Preimplantation genetic diagnosis for Huntington's disease with exclusion testing. European Journal of Human Genetics 2002; 10: 591-598.

14. Moutou C, Gardes N, Viville S: New tools for preimplantation genetic diagnosis of Huntington's disease and their clinical applications. European Journal of Human Genetics 2004; 12: 1007-1014.

15. van Rij MC, de Rademaeker M, Moutou C et al: Preimplantation genetic diagnosis (PGD) for Huntington's disease: the experience of three European centres. European Journal of Human Genetics 2012; 20: 368-375.

16. Ross-van Dorp CIJM: Letter of the State Secretary of Public Health and Sport. The Hague: Sdu Uitgevers, 2006, Vol 30300 XVI, nr 36.

17. Bussemaker M: Regeling preïmplantatie genetische diagnostiek van de staatssecretaris van Volksgezondheid, Welzijn en Sport (Regulations of the State Secretary of Health on the rules concerning PGD): Staatscourant: Koninkrijk der Nederlanden, 2009, Vol 42, pp 1-12.

18. Jasper MJ, Hu DG, Liebelt J et al: Singleton births after routine preimplantation genetic diagnosis using exclusion testing (D4S43 and D4S126) for Huntington's disease. Fertility and sterility 2006; 85: 597-602.

19. Lashwood A, Flinter F: Clinical and counselling implications of preimplantation genetic diagnosis for Huntington's disease in the UK. Human fertility 2001; 4: 235-238. 
20. van Rij MC, de Koning Gans PA, Aalfs $\mathrm{CM}$ et al: Prenatal testing for Huntington's disease in The Netherlands from 1998 to 2008. Clinical Genetics 2013; [Epub ahead of print].

21 Simpson SA, Harper PS: Prenatal testing for Huntington's disease: experience within the UK 1994-1998. Journal of medical genetics 2001; 38: 333-335.

22. Yapijakis C, Laccone F, Sorensen SA: Predictive and prenatal testing for Huntington's disease in Greece, Germany, Austria, Switzerland and Denmark; in: Evers-Kiebooms G (ed): Prenatal testing for late-oset neurogenetic diseases. Oxford, UK: BIOS Scientific Publishers Ltd, 2002, pp 69-82.

23. Laccone F, Engel U, Holinski-Feder E et al: DNA analysis of Huntington's disease: five years of experience in Germany, Austria, and Switzerland. Neurology 1999; 53: 801806.

24. Panas M, Karadima G, Vassos E et al: Huntington's disease in Greece: the experience of 14 years. Clinical genetics 2011; 80: 586-590.

25. Pope C, van Royen P, Baker R: Qualitative methods in research on healthcare quality. Quality \& Safety in Healthcare 2002; 11: 148-152.

26. Guest G, Bunce A, Johnson L: How many interviews are enough? An experiment with data saturation and variability. Field Methods 2006; 18: 59-82.

27. Lindseth A, Norberg A: A phenomenological hermeneutical method for researching lived experience. Scandinavian Journal of Caring Sciences 2004; 18: 145-153.

28. Tibben A: Predictive testing for Huntington's disease. Brain research bulletin 2007; 72: 165-171.

29. Decruyenaere M, Evers-Kiebooms G, Boogaerts A et al: The complexity of reproductive decision-making in asymptomatic carriers of the Huntington mutation. European Journal of Human Genetics 2007; 15: 453-462.

30. Downing C: Negotiating responsibility: case studies of reproductive decision-making and prenatal genetic testing in families facing Huntington disease. Journal of genetic counseling 2005; 14: 219-234.

31. Duisterhof M, Trijsburg RW, Niermeijer MF, Roos RA, Tibben A: Psychological studies in Huntington's disease: making up the balance. Journal of medical genetics 2001; 38 : 852-861.

32. Klitzman R, Thorne D, Williamson J, Chung W, Marder K: Decision-making about reproductive choices among individuals at-risk for Huntington's disease. Journal of genetic counseling 2007; 16: 347-362.

33. Quaid KA, Sims SL, Swenson MM et al: Living at risk: concealing risk and preserving hope in Huntington disease. Journal of genetic counseling 2008; 17: 117-128.

34. Richards F: Couples' experiences of predictive testing and living with the risk or reality of Huntington disease: a qualitative study. American journal of medical genetics 2004; 126A: 170-182.

35. Vamos M, Hambridge J, Edwards M, Conaghan J: The impact of Huntington's disease on family life. Psychosomatics 2007; 48: 400-404.

36. van der Meer LB, van Duijn E, Wolterbeek R, Tibben A: Adverse childhood experiences of persons at risk for Huntington's disease or BRCA1/2 hereditary breast/ovarian cancer. Clinical genetics 2012; 81: 18-23. 
37. Forrest Keenan K, Miedzybrodzka Z, van Teijlingen E, McKee L, Simpson SA: Young people's experiences of growing up in a family affected by Huntington's disease. Clinical genetics 2007; 71: 120-129.

38. de Wert GM: Ethics of intracytoplasmic sperm injection: proceed with care. Human reproduction 1998; 13 Suppl 1: 219-227.

39. Pennings G: Measuring the welfare of the child: in search of the appropriate evaluation principle. Human reproduction 1999; 14: 1146-1150.

40. Pennings G, de Wert G, Shenfield F, Cohen J, Tarlatzis B, Devroey P: ESHRE Task Force on Ethics and Law 13: the welfare of the child in medically assisted reproduction. Human reproduction 2007; 22: 2585-2588.

41. Macleod R, Tibben A, Frontali $M$ et al: Recommendations for the Predictive Genetic Test in Huntington's Disease. Clinical genetics 2013; 83(3):221-31.

42. Maat-Kievit A, Vegter-van der Vlis $M$, Zoeteweij $M$, Losekoot $M$, van Haeringen $A$, Roos R: Paradox of a better test for Huntington's disease. Journal of neurology, neurosurgery, and psychiatry 2000; 69: 579-583.

43. Quaid KA, Swenson MM, Sims SL et al: What were you thinking?: individuals at risk for Huntington Disease talk about having children. Journal of genetic counseling 2010; 19 : 606-617.

44. Harper JC, Coonen $\mathrm{E}$, de Rycke $\mathrm{M}$ et al: ESHRE PGD Consortium data collection X: cycles from January to December 2007 with pregnancy follow-up to October 2008. Human reproduction 2010; 25: 2685-2707.

45. Braude PR, de Wert GM, Evers-Kiebooms G, Pettigrew RA, Geraedts JP: Non-disclosure preimplantation genetic diagnosis for Huntington's disease: practical and ethical dilemmas. Prenatal diagnosis 1998; 18: 1422-1426.

46. Asscher $E$, Koops $B J$ : The right not to know and preimplantation genetic diagnosis for Huntington's disease. Journal of medical ethics 2010; 36: 30-33.

47. de Wert G: Predictive testing for Huntington disease and the right not to know. Some ethical reflections. Birth defects original article series 1992; 28: 133-138.

48. Festinger L: Cognitive dissonance. Scientific American 1962; 207: 93-102. 
Chapter 7

\section{General Discussion}




\section{GENERAL DISCUSSION}

For this thesis, several aspects of reproductive decision making (in case of Huntington's disease (HD)) were studied. The following themes related to reproductive decision making of couples at risk of transmitting HD will be discussed in more detail: the moral considerations and other factors contributing to couples' reproductive decision making, the uptake of PND and PGD among expansion carriers and among the $50 \%$ risk population, future prospects and suggestions for future study, and finally conclusions and implications for practice.

\section{Moral considerations}

In this thesis information is presented on couples expressing their responsibility to prevent harm to their future offspring by preventing the birth of a child with HD (chapters $2 \mathrm{t} / \mathrm{m} 6$ ) or with other severe genetic disorders (chapter 5) using PND, PGD, exclusion PND (ePND), or exclusion PGD (ePGD). These couples are confronted with a number of ethical dilemmas concerning conflicting interests between the future child, the at-risk parent, the female partner, and the responsibility of the caretaker.

The assumption that it is wrong to expose future children to high risks of serious suffering is widely accepted ${ }^{1,2}$. In case of HD, the potential harm may include exposure to a parent affected with HD, who may express behavioural disturbances, psychological or psychiatric problems and has a reduced live expectancy ${ }^{3}$. Furthermore, this potential harm comprises exposure of offspring to the genetic risk of HD. Though the time of eugenics and forced sterilisation of HD patients and individuals at-risk has passed many decades ago ${ }^{4-6}$, still, some authors argue that at-risk individuals should be discouraged from having children $^{7,8}$. Moreover, physicians involved in assisted reproductive treatments like IVF/PGD have a shared responsibility towards the child whose very existence is resulting from their actions ${ }^{2,9}$. In contrast to our expectations, couples interviewed in chapter 6 seemed to underestimate or minimize the impact of parental HD symptoms on their future child. The impact of HD symptoms in a parent may, however, be harmful to children ${ }^{10,11}$, though coping skills of the unaffected parent seem to show protective effects ${ }^{12}$. Nevertheless, the onset of HD symptoms in a parent might be long neglected, especially if the at-risk parent does not want to know his/her carrier status, which may increase 
the inflicted harm to a child. Couples should be aware of the risks of exposure to HD, and especially the non-HD risk partner should be capable of taking responsibility to protect the child, and cope with the situation in case the atrisk partner becomes symptomatic. If this is acknowledged, and a couple decides to have children, their wish to prevent transmission of HD to offspring should be respected. Hence, a case by case access, with special attention to the effects of the symptoms of HD upon the future child's welfare, would be preferable $^{9,13}$.

PGD is a widely accepted reproductive technology, applied for quite a number of hereditary disorders in an increasing number of countries ${ }^{14,15}$. The major disadvantage of PGD is the limited pregnancy rate of about $20 \%$ per started cycle $^{15}$. The risks involved with IVF/PGD are generally accepted, when considering the aim of preventing transmission ( $50 \%$ risk in case of HD) of a severe inheritable disease. Furthermore, in some countries including the Netherlands, hereditary disorders which indicate the use of PGD are more or less comparable to the ones for which a prenatal test can be considered ${ }^{16}$.

A majority of people agree that the moral value of an embryo at the preimplantation stage is limited compared to the value of an embryo or a foetus in an established or clinical pregnancy ${ }^{17}$. Therefore, one could argue that discarding PGD embryos with a CAG expansion would be morally less disputable than a pregnancy termination (TOP) for the same CAG expansion ${ }^{18-}$ ${ }^{22}$. Some people morally object to TOP for late-onset disorders like HD, because a future child with the CAG expansion will be asymptomatic for a long time ${ }^{21,23,24}$. Nevertheless, as will be explained later on in this chapter, couples using PND are expected to terminate their pregnancy if the CAG expansion is detected in the foetus.

If a foetus carries a 50\% HD risk allele of his/her affected grandparent in case of ePND, the general policy is that professional and couple agree to TOP, even though in $50 \%$ of cases the foetus will not develop HD. In the Netherlands, it is legally permitted to terminate a pregnancy in case of 'emergency', including emotional or physical danger/obstacles for the pregnant woman concerning the pregnancy itself or the prospect of having an unplanned and unwanted child $^{25}$. This implicates that the protection of unborn life may be overruled by the considerations regarding the future mother's wellbeing.

TOP for an HD expansion in the foetus can be considered somehow altruistic or child-centred, because the parents do put aside or at least postpone their wish 
to have a child for the sake of their future child's wellbeing. When terminating a pregnancy for a 50\% HD risk (after ePND), the altruistic motive of 'saving harm' is counteracted with the at-risk parent's wish not to know. In a way, one can consider the child being sacrificed in order to maintain the at-risk parent's unknown HD-status. On the other hand, one may respect the at-risk person's profound fear of becoming an HD patient ${ }^{26}$. These individuals have invariably witnessed one or more family members passing through different stages of the disease process. By performing an exclusion test, both the interests of the future child and of the at-risk parent are reconciled. ePND has been applied since 1989, and the results presented in chapter 6 show that couples performing this test do thoroughly consider all conflicting interests. Couples with favourable ePND outcomes, resulting in the birth of one or more children (without having experienced TOP) expressed more ambivalence and were more reluctant about opting for ePND if starting over. Those who decided to go through the process of exclusion testing resulting in TOP did not show remorse. The majority would use ePND again if they had the chance to start over. This might be the result of cognitive dissonance. This coping mechanism would enable people to remain at peace with their actions (if they were in conflict with their moral beliefs), by adapting their moral standards according to their behaviour ${ }^{27}$.

Additionally, one could wonder how couples would reflect on their actions on the long term, after disclosure of the HD status of the at-risk parent. What if the couple finds out that the termination was in fact the pregnancy of a healthy child? In the series described, two couples had each terminated two previous pregnancies for a 50\% HD risk (chapter 4). Both couples had performed an exclusion definitive test in their third pregnancy, in which the atrisk parent turned out to be free of HD. Altogether they had 'unnecessarily' terminated four pregnancies. In this study these couples could not be interviewed, which might be related to their histories (chapter 6).

Couples requesting ePGD showed a similar fear of being identified as HD carrier compared with at-risk persons opting for ePND (chapter 6). However, they did express emotional or moral objections against TOP for a 50\% HD risk, stating that they did not want to risk termination of a healthy foetus. For these couples, and even some of the ePND couples, ePGD represents a solution, avoiding the chance of TOP for $50 \%$ HD risk. Nevertheless, contrary to ePND, ePGD is not allowed in the Netherlands ${ }^{16}$. 
The moral objections against ePGD are the unnecessary exposure to IVF/PGD in $50 \%$ of cases, involving health risks and expenses, and the discarding of healthy embryos in $50 \%$ of cases. However, these objections can by no means counterbalance the potential negative impact of the alternatives: 1) being coerced to perform a presymptomatic test with the $50 \%$ risk of getting confronted with an inevitable future of $\mathrm{HD}^{26}, 2$ ) opting for ePND while showing reluctance to terminate a $50 \%$ risk pregnancy (involving a potential chance of continuing the pregnancy after a $50 \%$ risk result), 3) accepting the risk of transmitting HD to offspring, which may lead to feelings of guilt $\left.{ }^{28}, 4\right)$ refraining from biologically own children, while these couples are generally not accepted to adopt children ${ }^{29}$. Moreover, in ePGD for HD the overall prior risk of getting $\mathrm{HD}$ is $25 \%$ per embryo. This is still high or at least comparable to the $25 \%$ risk for couples requesting PGD for X-linked recessive or autosomal recessive inheritable disorders for which PGD is no issue. Furthermore, the argument against discarding healthy embryos may be considered irrelevant, since in PGD for hereditary breast and ovary cancer, male embryos with a $\mathrm{HBOC}$ mutation have a low risk of developing cancer, and for $\mathrm{X}$-linked disorders $50 \%$ of rejected embryos are generally healthy. For these indications PGD is accepted ${ }^{30}$.

More or less unexpectedly, we found that a considerable number of couples decided to continue their pregnancy after PND had shown a CAG expansion or $50 \%$ HD risk allele in the foetus (chapter 2). By continuing an affected pregnancy, the child's right not to know is violated, since the PND result is in fact an early form of presymptomatic testing ${ }^{13,31,32}$. Given the low uptake of presymptomatic testing, most adult individuals at risk for HD prefer not know their HD status ${ }^{33}$, which underscores that a child's right not to know should be safeguarded. When continuing a $50 \% \mathrm{HD}$ risk allele pregnancy after ePND, the HD status of the child is directly connected to the at-risk parent's HD status. The onset of HD symptoms in the parent immediately results in a $100 \%$ HD risk for the child with the same HD allele ${ }^{34}$.

The long term (psychological) consequences of the continuation of an affected pregnancy and thus the birth of a child who is known to be a carrier of an expansion from birth on, for the child itself and for his/her parents, are still unknown. The dilemma on whether or when to inform the child about its HD carrier status and feelings of guilt might affect the family as a whole. 


\section{Other factors contributing to couples' reproductive decision making}

\section{Gender of at-risk individual}

In nearly every study reported in this thesis, differences were observed correlated to the gender of the at-risk partners. First, the at-risk males opting for PND or PGD had significantly less frequently performed PT compared to atrisk females (chapters 2 and 4). If the couple had an untested child prior to PND or PGD, the at-risk partner was predominantly male (71\%) (chapter 4$)$. Atrisk men interviewed in chapter 6 more frequently had informed their partners about their HD risk indirectly, incompletely or late after the onset of their relationship, while at-risk women had told their partners about $H D$ at a relatively early stage in the relationship. A similar tendency may be concluded from the preponderance of at-risk females opting for PT (M/F ratio: ranges from $45 / 55$ to $33 / 67 \%$ ) reported in many countries ${ }^{33,35-45}$. Apparently, males show a relatively stronger tendency to avoid facing their personal HD risk compared to females. In the heterogeneous group of referrals for PGD, described in chapter 5, females were significantly more often carriers than males among referrals for autosomal dominant disorders (27 males versus 48 females) and chromosomal abnormalities (36 males versus 47 females). The predominance of female carriers for autosomal dominant disorders was the result of skewing among PGD referrals for HD (female versus male partner: 18 versus 7) and for myotonic dystrophy type 1 (15 versus 5). A selection bias may have caused this skewing since the numbers are rather small. However, in the case of myotonic dystrophy type 1, male infertility may have caused an ascertainment bias, and the risk of congenital myotonic dystrophy as the result of anticipation may have resulted in a selection bias.

The limited proportion of male carriers of chromosomal abnormalities may be the result of an ascertainment bias. Multiple miscarriages may more easily result in the diagnosis of a chromosomal abnormality in one of the parents, whereas chromosomal abnormalities leading to male infertility may be less likely to be diagnosed.

In chapter 4, more at-risk females used PGD primarily without having experienced a previous pregnancy, while at-risk males were overrepresented in the group which secondarily used PGD after a history of PND. This might be attributed to a different impact of PND with a possible TOP on at-risk males compared to females. Because the female has to go through the physical 
experience of TOP, an at-risk male may develop a sense of guilt for being the cause of such a stressful event. The expected impact of PGD may also differ among male and female HD carriers.

In the majority of continued pregnancies with HD expansion (8/10), the at-risk parent was female. By denying the child's right to live, the at-risk parent with the same HD expansion may have the sense of rejecting his/her own existence $^{46}$. This effect may be even stronger if the at-risk parent is female.

Finally, the lack of alternative reproductive options for the female partner (chapter 5) showed a strong correlation with PGD use, suggesting that the female partner is the most important determinant in reproductive decision making. This is not very surprising, since reproductive decisions all physically affect the female.

\section{Disease characteristics}

The late onset of HD does contribute to moral objections against PND and TOP for HD, because an HD expansion generally involves three to four decades of healthy life expectancy for the expansion carrier ${ }^{21,23,24}$. However, this disregards the fact that this person will inevitably develop a late-onset disorder. The prospect of insidious deterioration involves a severe burden for this person and his/her family, long before the actual start of symptoms. Moreover, the prospect of cognitive impairment, psychiatric symptoms, personality changes, and an increased dependence of care, urges patients and at-risk individuals to prevent HD from being transmitted, even by terminating a pregnancy ${ }^{23,47,48}$. In chapter 6, couples opting for ePGD explicitly expressed specific moral objections against TOP related to the late onset of HD. Most of these couples did not object to TOP in general. This probably applies for most couples primarily opting for PGD (chapters 4 and 5). In a heterogenic group of couples referred for PGD (chapter 5), however, the disease severity and specific characteristics like the late onset did not significantly contribute to the choice to start PGD, compared to e.g. childhood disorders. However, these PGD referrals represented a self-selected group biased towards PGD. Therefore, this group was not suitable to estimate the impact of disease characteristics on reproductive decision making.

The tendency for couples to continue a pregnancy of a foetus with a CAG expansion seemed to be associated with the CAG expansion size. Pregnancies with reduced penetrance alleles were relatively more frequently continued compared to pregnancies with full penetrance alleles (chapter 2 ). The reduced 
penetrance alleles appear to leave some space for the couples to retain hope for their child's future once being pregnant. This might cause hesitation to terminate the pregnancy, once actually confronted with such a test result. Couples may have been informed about the probable later onset and milder presentation of symptoms, which may have induced hesitation regarding prior intentions to TOP. Or they may have had the prior intention only to terminate a full expansion pregnancy. The effect of CAG repeat size in the full penetrance alleles on the severity of the disease remains under debate ${ }^{49-51}$. Nevertheless, some couples did include the exact repeat number (smaller than at-risk parent, or smaller than previous TOP, or only one CAG repeat longer than previously agreed to continue), in their decision to continue a pregnancy after receiving a full penetrance result. This may be another reflection of preventing untoward emotions pre and post TOP and the tendency of keeping up (unrealistic) hopes $^{28,52-54}$.

\section{Reproductive history}

We presume that couples' primary reproductive choice is mainly based on their moral considerations (first paragraph of this chapter). While, in secondary reproductive choices, after having attempted to have a child, regardless of the method used, couples' experiences are likely to be included in their subsequent decision making. In chapter 5 , among heterogeneous referrals for PGD, couples with fertility problems in need of IVF were more likely to use PGD. In this situation, PGD might be considered just a minimal technical addition to the already invasive IVF procedure. This was in line with the literature ${ }^{18,55-58}$. One can also imagine that if achieving a pregnancy had taken a considerable amount of time and effort, such a pregnancy will become even more precious once established. For this reason, it may become emotionally even more difficult to terminate a pregnancy after PND ${ }^{17,53-56}$.

A history of TOP(s) was associated with an increased probability to use PGD (chapters 4 and 5). The negative outcome and experiences of TOP might lead to reluctance to use PND in future pregnancies and may direct couples towards using PGD. In contrast, the presence of a living child with an inheritable childhood disorder or congenital malformations showed a negative effect on PGD use. This may be due to practical difficulties combining the care for a child with special needs with a time consuming and burdensome PGD treatment (chapter 5). One couple (chapter 6) shifted to exclusion-definitive testing in their second pregnancy. The presence of their first child born after ePND, made that they could not terminate pregnancy for $50 \% \mathrm{HD}$ risk anymore. Of 
the couples who experienced both ePND and ePGD, the first couple thought chances were in favour of PND, while for the second couple the disappointment after a failed PGD cycle was much less than the pain and strong feelings of loss after a pregnancy termination.

\section{Availability of options and (comprehensive) information}

Even though ePGD for HD has been available in Belgium since $2002^{59}$, not all couples interviewed in chapter 6 (who underwent ePND) were aware of this option. Some would have liked to be informed about this alternative for ePND. For couples who were aware of the possibility of ePGD, the long distance and financial aspects concerned with treatment abroad did form an obstacle. The political involvement in their personal reproductive decision making was criticized by a considerable number of couples interviewed, as ePGD may have been a serious option if it would have been available in the Netherlands.

The paradoxical discrepancy between the rather limited proportion of $45 \%$ of couples actually starting PGD after intake compared to the high number of atrisk couples showing interest in 'future' PGD in theoretical settings $s^{18,20,60,61}$ (chapter 5)), shows a parallel with the population at-risk for HD and the use of PT. A similar overestimation of interest was observed in a theoretical setting (before the availability of PT) ${ }^{35,62-64}$. Therefore, we suggest that apart from fear of being identified as HD expansion carrier, the incurability of HD and incapability of coping with the test result ${ }^{32,39,40,42,52,55,61-63,66}$, the theoretical setting itself may have contributed to the overestimation of individuals willing to opt for PT. As in theoretical decision making, individuals may not fully consider or overview all disadvantages involved (chapter 5).

Informed consent is one of the basic principles in any decision making process, including reproductive decision making ${ }^{65}$. However, the initial awareness of HD depends on the family dynamics and adequacy of communication of HD risks within the family ${ }^{23,28,48,66}$. The objective information provided by a professional may be differently perceived and recalled by the at-risk person ${ }^{67}$. Especially, the interpretation and perception of risks related to intermediate and reduced penetrance alleles may be subject to psychological stress and misinterpretations, because they do contradict the generally expected 'black and white' test result ${ }^{68}$. More professional attention for the way accurate information on the exact expansion risks of intermediate alleles per CAG repeat size, for both males and females, is processed could facilitate careful individual decision making. The rather complex principle of exclusion testing 
has been misunderstood by a substantial number of couples $(63 \%)$ in the early years of application and even by health professionals themselves ${ }^{52}$. This also occurred in one couple described in chapter 6, who appeared not to have fully grasped the connected fate of the at-risk parent and the child born after continuation of a $50 \%$ HD risk allele pregnancy. Besides personal misinterpretation, keeping up hopes may have contributed to this phenomenon $^{23,28}$.

\section{Uptake of presymptomatic testing, PND and PGD for HD}

Internationally, the actual uptake of presymptomatic testing for HD has been much lower than expected prior to introduction of PT in $1993^{33,41,42,44,64,69-71}$. The need for certainty and the reproductive motive are frequently reported reasons to opt for $\mathrm{PT}$, as well as other motives such as organising practical life matters, or informing existing children about their risk ${ }^{72,73}$. For individuals not opting for a presymptomatic test, fear of being identified as HD carrier, incurability, loss of hope, the fear of stigma and early medicalization, concerns about access to insurance and social services, as well as other financial matters play a role (chapter 6) $33,41,42,44,54,64,69-71,74$.

Uptake calculations presented in the literature as well as in this thesis are rough estimates of difficult to define variables and are therefore of limited value.

Estimations of the uptake of PT among the at 50\% risk population largely depend on the prevalence of HD and on an estimation of the number of $(50 \%)$ at risk individuals. In the UK recent reports suggest that the actual prevalence of HD may be twice as high as the usually assumed $5-10 / 100,000^{75,76}$. One possible cause for this underestimation is the decentralisation of diagnostics, which may lead to incomplete ascertainment. The fear of stigma in patients and family members, leading to reluctance against confirmative DNA analysis in assumed HD patients, may also contribute to underestimation of the prevalence 4 . One could wonder whether these assumptions can be extrapolated to the Dutch situation. First of all, in the Netherlands HD DNA diagnostics of are centralized in Leiden, providing a complete overview of the tested HD population in our country. Secondly, a delay in diagnosis may also lead to underestimation of the prevalence. This delay may be due to lack of a family history, an atypical presentation, and/or late onset of symptoms. The family history may be negative in case of non-paternity (chapter 6), as well as in 'new' cases. These 'new' cases occur due to expansion of a reduced 
penetrance allele or an intermediate allele into a CAG repeat size $\geq 36$. The onset of symptoms may be generally late or even absent, due to the incomplete penetrance of these 'reduced penetrance' alleles. The background prevalence of $4 \%$ of intermediate alleles observed in chapter 2 is in accordance with the frequencies of $2-6 \%$ observed by others ${ }^{77-80}$. New cases are assumed to represent about $1-4 \%$ of all HD patients ${ }^{81,82}$.

Apart from an accurate estimate of the disease prevalence, uptake calculations include assumptions on the number of $50 \%$ at-risk individuals. Former publications assume that the number of at-risk individuals equals 3-5 times the number of $\mathrm{HD}$ patients ${ }^{40,83}$ and more recently an empirically derived ratio of 1 patient to 4.2 at $50 \%$ risk individuals was suggested ${ }^{84}$. The number of children per family, and the distance between generations (the age at which people get children) influence the accuracy of the aforementioned calculation factor ${ }^{84}$. Additionally, the period of the collection of the PT results should be included in an uptake calculation ${ }^{84}$.

The total number of PND tests in the Netherlands in the period under review (1998-2008) has doubled since the period 1987-1997, studied by Maat-Kievit et al. ${ }^{85}$ (chapter 2). The actual increase in use has, however taken place between 1989 (the first PND test) and 1996. Overall, the use of PND has been fairly stable since 1996, even the introduction of PGD in 1998 had no dramatic effect (chapter 3). PGD seems to attract a separate group of individuals, representing about one third of couples opting for reproductive intervention (PND/PGD). One half of these couples exclusively used PGD, while the remaining couples alternated the use of PND and PGD.

From the stability of the use of exclusion testing PND at about 15\% (chapter 2) and the specific underlying motives involved in opting for this method, we conclude that exclusion tests are requested by a very specific subgroup of couples (chapter 6 ).

The uptake of PND or PGD can be calculated by dividing the number of at-risk individuals opting for PND or PGD by the number of CAG expansion carriers. Likewise, the population-based uptake equals the number of at $50 \% \mathrm{HD}$ risk individuals requesting PT, PND or PGD, divided by the estimated number of atrisk individuals in a certain population.

The uptake calculation of HD expansion carriers opting for PND or PGD does also show limitations. For several reasons, we assume that the actual uptake for HD expansion carriers with reproductive motives to perform a PT will be higher than the $32 \%$ mentioned in chapter $4:$ a) About $60-80 \%$ of couples 
choose to perform PT for reproductive reasons ${ }^{86,87}$; b) Around $20-50 \%$ of individuals performing PT for reproductive reasons decide not to have children after testing HD positive ${ }^{37,47,88}$; c) The younger age of HD expansion carriers opting for PND or PGD in chapter 4 ( 2.8 yrs difference for both males $(p=0.02)$ and females $(p=0.0003))$ compared to HD expansion carriers not opting for PND/PGD, might indicate that a substantial number of the latter group did not have reproductive intentions at the moment of PT.

The uptake calculation in the study of Maat-Kievit et al. most probably underestimated the actual uptake of $P N D^{85}$. In our study (chapter 5), we observed that the mean time interval between a PT and a first PND for an atrisk person was about two years. A similar time lapse is observed when comparing the bar charts of presymptomatic test applicants and prenatal tests in the Netherlands between 1987 and 1997. The year of first application of PT was 1987, whereas PND was first performed in 1989. After years of growth, the maximum levels of PT and PND were reached in 1995 and 1996, respectively. After this peak level, both bars charts stabilized. The period of study effectively includes 11 years of PT, and only 9 years of PND. A correction for this time lapse would result in a higher uptake of PND.

\section{Future prospects}

As long as a curative treatment for HD, or modifying measures, are not available, couples will be in search of methods to prevent transmission of HD to their offspring. However, the relatively low uptake of 2 to $4 \%$ of at-risk couples opting for PND and PGD (chapters 2, 3 and 4) and the fact that only $45 \%$ of couples after intake eventually started PGD (chapter 4), and couples' thoroughness of balancing moral dilemmas considering the use of ePND or ePGD (chapter 6) did not provide evidence for the existence of a so feared 'slippery slope'.

Non-invasive PND enables the detection of an HD expansion in foetal DNA circulating in the maternal serum. A blood sample is drawn from the pregnant woman as early as 7-8 weeks gestational age. The method is currently limited to couples where the male is HD expansion carrier ${ }^{52,53}$. Possibly, in the near future, this non-invasive test will become applicable for HD expansion carrier females or for couples requesting exclusion testing. Future application of noninvasive PND resulting in TOP in early pregnancy (8-9 weeks) may somewhat reduce the emotional and physical burden compared with a TOP at 13-14 weeks (after CVS result) ${ }^{89,90}$. Furthermore, non-invasive PND entails zero risk of 
miscarriage for the foetus, compared to the $0.5-1.0 \%$ risk after CVS or amniocentesis ${ }^{91-93}$. We want to stress that, for couples with true objections against TOP (at any time in pregnancy), non-invasive PND is not considered to be a likely and acceptable option.

Not all candidate couples were aware of PGD as a reproductive option (chapter 6). More adequate information on all available reproductive options may improve the awareness of couples and the probability of couples applying for PND or PGD by direct testing or exclusion testing. Future application of ePGD in the Netherlands, and more publicity, may result in a small increase of couples requesting ePGD, because couples who were discouraged by the distance and financial aspects of treatment abroad may then consider ePGD as a more acceptable option.

Additionally, significant improvements of the success rates of IVF treatment may contribute to an increased popularity of PGD as a reproductive option.

\section{Suggestions for future study}

For this thesis, we collected data on relatively large groups of patients at risk for HD. However, we remained uninformed about the major part of the at risk HD population, as at-risk individuals not opting for PT and their reproductive decisions were not a focus in this study. One might wonder whether they refrained from having children, accepted the risk of transmitting HD, or found other alternatives. Moreover, were they aware of their HD risk, and were they aware of the reproductive options? These are questions for future studies.

Other interesting subjects for future studies on reproductive decision making among couples at risk for HD may be: 1) The motives contributing to continuation of an affected pregnancy, 2) Gender differences of HD expansion carriers or at-risk individuals in decision making regarding PT, PND, PGD and other reproductive options, 3) A long term evaluation of exclusion testing, after disclosure of the HD status of the at-risk parent. How do the couples respond if the at-risk parent turns out not to be HD carrier? Some couples in the interview study (chapter 6) mentioned that the relief of the at-risk parent being free form HD would be greater than the regret of unnecessary PGD or PND treatments. But will this also apply for couples who did terminate pregnancies or go through unsuccessful PGD and never succeeded in having a 'healthy' child? For couples who do reach their goal of having a child, the disadvantages of PND and PGD are probably easier to accept. This may force 
couples to keep going until they reach their goal, which was nicely cited by Decruyenaere et al.: "And each time, I thought: better luck next time and I knew that once a child was born, we would forget all pain and sorrow of the last years". 47

The most accurate way to assess the uptake of PND or PGD among HD expansion carriers would be prospectively. A cohort of HD expansion carriers could be followed from the moment of PT until they have reached an age at which childbearing has become less likely (e.g. 40 years for females). Reproductive motives for PT should not be distinguishing factors for inclusion in such a study, for they might not be prominent at the time of PT, but may only become relevant later in life. The time interval observed between the date of PT and couples' first PND or PGD attempt (11.5 years prior to first attempt to 6.0 years after first attempt) (chapter 4 ) illustrates that follow-up periods of 5 to 10 years (usually applied in research) are likely to result in underestimations of the uptake of PND and/or PGD among HD expansion carriers.

\section{Conclusions and implications for clinical practice}

Decision making on PT and reproductive options are very individual matters. The couples involved in our studies were very well capable of making their individual reproductive choices and deciding between either PND or PGD or exclusions testing and dealing with the consequences. Their decision making was shaped by their moral considerations, expectations and experiences, the strength of the wish to have a child, and finally, the information on, or availability of options. People experiencing HD are the only people who are truly entitled to judge acceptability of TOP for HD ${ }^{94}$. Altogether, the benefits and disadvantages, and moral considerations concerning reproductive decisions should be weighed by the future parents themselves, without the limitations of legislation.

The impact of a parent with HD on a future child should be a point of attention in reproductive counselling. Information provided by counsellors should include a complete overview of all possible options and should be updated regularly. Couples should be guided by a multidisciplinary team, including at least a clinical geneticist and/or genetic counsellor, gynaecologist and psychologist, with a positive attitude towards all available options and respect for the at-risk parent's right not to know. 


\section{References}

1. de Wert GM: Ethics of intracytoplasmic sperm injection: proceed with care. Human reproduction 1998; 13 Suppl 1: 219-227.

2. Pennings $G$ : Measuring the welfare of the child: in search of the appropriate evaluation principle. Human reproduction 1999; 14: 1146-1150.

3. Roos RA: Huntington's disease: a clinical review. Orphanet journal of rare diseases 2010; 5: 40.

4. Wexler A: Stigma, history, and Huntington's disease. Lancet 2010; 376: 18-19.

5. Harper PS: Huntington disease and the abuse of genetics. American journal of human genetics 1992; 50: 460-464.

6. Davenport CB: Huntington's Chorea in Relation to Heredity and Eugenics. Proceedings of the National Academy of Sciences of the United States of America 1915; 1: 283-285.

7. van Zuuren FJ: Een risicodrager kan een kind krijgen zonder Huntington. Maar heeft een kind niet óók recht op gezonde ouders? Trouw. Amsterdam: Pergroep Amsterdam, 2010; 22-7-2010

8. Visser ED: Het recht om niet te weten van de dood: Volkskrant. Persgroep Amsterdam, $2011 ; 28-5-2011$

9. Pennings G, de Wert G, Shenfield F, Cohen J, Tarlatzis B, Devroey P: ESHRE Task Force on Ethics and Law 13: The welfare of the child in medically assisted reproduction. Human reproduction 2007; 22: 2585-2588.

10. Vamos M, Hambridge J, Edwards M, Conaghan J: The impact of Huntington's disease on family life. Psychosomatics 2007; 48: 400-404.

11. van der Meer LB, van Duijn E, Wolterbeek R, Tibben A: Adverse childhood experiences of persons at risk for Huntington's disease or BRCA1/2 hereditary breast/ovarian cancer. Clinical genetics 2012; 81: 18-23.

12. Forrest Keenan K, Miedzybrodzka Z, van Teijlingen E, McKee L, Simpson SA: Young people's experiences of growing up in a family affected by Huntington's disease. Clinical genetics 2007; 71: 120-129.

13. Macleod R, Tibben A, Frontali $M$ et al: Recommendations for the predictive genetic test in Huntington's disease. Clinical genetics 2013; 83: 221-231.

14. de Die-Smulders CE, Land JA, Dreesen JC, Coonen E, Evers JL, Geraedts JP: [Results from 10 years of preimplantation-genetic diagnostics in The Netherlands]. Nederlands tijdschrift voor geneeskunde 2004; 148: 2491-2496.

15. Harper JC, Wilton L, Traeger-Synodinos J et al: The ESHRE PGD Consortium: 10 years of data collection. Human reproduction update 2012; 18: 234-247.

16. Bussemaker M: Regeling preïmplantatie genetische diagnostiek van de staatssecretaris van Volksgezondheid, Welzijn en Sport (Regulations of the State Secretary of Health on the rules concerning PGD): Staatscourant: Koninkrijk der Nederlanden, 2009, Vol 42, pp $1-12$.

17. de Wert G: Ethical aspects of prenatal testing and preimplantation genetic diagnosis for late-onset neurogenetic disease: the case of Huntington's disease; in: Evers-Kiebooms 
G, Zoeteweij MW, Harper PS (eds): Prenatal testing for late-onset neurogenetic diseases. Oxford, UK: BIOS Scientific Publishers Ltd, 2002, pp 129-157.

18. Chamayou S, Guglielmino A, Giambona A et al: Attitude of potential users in Sicily towards preimplantation genetic diagnosis for beta-thalassaemia and aneuploidies. Human reproduction 1998; 13: 1936-1944.

19. Katz MG, Fitzgerald L, Bankier A, Savulescu J, Cram DS: Issues and concerns of couples presenting for preimplantation genetic diagnosis (PGD). Prenatal diagnosis 2002; 22: 1117-1122.

20. Alsulaiman A, Hewison J: Attitudes to prenatal and preimplantation diagnosis in Saudi parents at genetic risk. Prenatal diagnosis 2006; 26: 1010-1014.

21. Kalfoglou AL, Scott J, Hudson K: PGD patients' and providers' attitudes to the use and regulation of preimplantation genetic diagnosis. Reproductive biomedicine online 2005; 11: 486-496.

22. Cameron $\mathrm{C}$, Williamson $\mathrm{R}$ : Is there an ethical difference between preimplantation genetic diagnosis and abortion? Journal of medical ethics 2003; 29: 90-92.

23. Klitzman R, Thorne D, Williamson J, Chung W, Marder K: Decision-making about reproductive choices among individuals at-risk for Huntington's disease. Journal of genetic counseling 2007; 16: 347-362.

24. Craufurd D: Counselling aspects of prenatal testing for late-onset neurogenetic diseases; in: Evers-Kiebooms G, Zoeteweij MW, Harper PS (eds): Prenatal testing for late-onset neurogenetic diseases. Oxford, UK: BIOS Scientific Publishers Ltd, 2002, pp 179-190.

25. Ministerie Volksgezondheid WeS: Wet afbreking zwangerschap (Ministry of Health: Law on pregnancy termination), (Wafz) BWBR0003396, 1981.

26. Asscher $E$, Koops $B J$ : The right not to know and preimplantation genetic diagnosis for Huntington's disease. Journal of medical ethics 2010; 36: 30-33.

27. Festinger L: Cognitive dissonance. Scientific American 1962; 207: 93-102.

28. Quaid KA, Swenson MM, Sims SL et al: What were you thinking?: individuals at risk for Huntington Disease talk about having children. Journal of genetic counseling 2010; 19 : 606-617.

29. European Convention on the Adoption of Children (Revised) BWBV0003426. Straatsburg, 2008.

30. Braude PR, de Wert GM, Evers-Kiebooms G, Pettigrew RA, Geraedts JP: Non-disclosure preimplantation genetic diagnosis for Huntington's disease: practical and ethical dilemmas. Prenatal diagnosis 1998; 18: 1422-1426.

31. van Rij MC, de Rademaeker M, Moutou C et al: Preimplantation genetic diagnosis (PGD) for Huntington's disease: the experience of three European centres. European Journal of Human Genetics 2012; 20: 368-375.

32. Toufexis $M$, Gieron-Korthals $M$ : Early testing for Huntington disease in children: pros and cons. Journal of child neurology 2010; 25: 482-484.

33. Creighton S, Almqvist EW, MacGregor D et al: Predictive, pre-natal and diagnostic genetic testing for Huntington's disease: the experience in Canada from 1987 to 2000. Clinical genetics 2003; 63: 462-475. 
34. Tolmie JL, Davidson HR, May HM, McIntosh K, Paterson JS, Smith B: The prenatal exclusion test for Huntington's disease: experience in the west of Scotland, 1986-1993. Journal of medical genetics 1995; 32: 97-101.

35. Craufurd D, Harris R: Predictive testing for Huntington's disease. British Medical Journal (Clinical research ed) 1989; 298: 892.

36. Dufrasne $S$, Roy $M$, Galvez $M$, Rosenblatt DS: Experience over fifteen years with a protocol for predictive testing for Huntington disease. Molecular genetics and metabolism 2011; 102: 494-504.

37. Evers-Kiebooms G, Nys K, Harper $P$ et al: Predictive DNA-testing for Huntington's disease and reproductive decision making: a European collaborative study. European Journal of Human Genetics 2002; 10: 167-176.

38. Goizet C, Lesca G, Durr A: Presymptomatic testing in Huntington's disease and autosomal dominant cerebellar ataxias. Neurology 2002; 59: 1330-1336.

39. Harper PS, Lim C, Craufurd D: Ten years of presymptomatic testing for Huntington's disease: the experience of the UK Huntington's Disease Prediction Consortium. Journal of medical genetics 2000; 37: 567-571.

40. Laccone F, Engel $U$, Holinski-Feder $E$ et al: DNA analysis of Huntington's disease: five years of experience in Germany, Austria, and Switzerland. Neurology 1999; 53: 801806.

41. Maat-Kievit A, Vegter-van der Vlis $M$, Zoeteweij $M$, Losekoot $M$, van Haeringen $A$, Roos R: Paradox of a better test for Huntington's disease. Journal of neurology, neurosurgery, and psychiatry 2000; 69: 579-583.

42. Morrison PJ, Harding-Lester S, Bradley A: Uptake of Huntington disease predictive testing in a complete population. Clinical genetics 2011; 80: 281-286.

43. Nance MA: Predictive and prenatal testing for late-onset neurogenetic diseases in North-America; in: Evers-Kiebooms G, Zoeteweij MW, Harper PS (eds): Prenatal testing for late-onset neurogenetic diseases. Oxford, UK: BIOS Scientific Publishers Ltd, 2002, pp 191-201.

44. Richards FH, Rea G: Reproductive decision making before and after predictive testing for Huntington's disease: an Australian perspective. Clinical genetics 2005; 67: 404-411.

45. Sizer EB, Haw T, Wessels TM, Kromberg JG, Krause A: The utilization and outcome of diagnostic, predictive, and prenatal genetic testing for huntington disease in johannesburg, South Africa. Genetic testing and molecular biomarkers 2012; 16: 58-62.

46. Richards M: Predictive testing for Huntington's disease. Lancet 2001; 357: 883.

47. Decruyenaere M, Evers-Kiebooms G, Boogaerts A et al: The complexity of reproductive decision-making in asymptomatic carriers of the Huntington mutation. European Journal of Human Genetics 2007; 15: 453-462.

48. Downing C: Negotiating responsibility: case studies of reproductive decision-making and prenatal genetic testing in families facing Huntington disease. Journal of genetic counseling 2005; 14: 219-234.

49. Lee JM, Ramos EM, Lee JH et al: CAG repeat expansion in Huntington disease determines age at onset in a fully dominant fashion. Neurology 2012; 78: 690-695. 
50. Aziz NA, Jurgens CK, Landwehrmeyer GB et al: Normal and mutant HTT interact to affect clinical severity and progression in Huntington disease. Neurology 2009; 73: 1280-1285.

51. Aziz NA, Roos RA, Gusella JF, Lee JM, Macdonald ME: CAG repeat expansion in Huntington disease determines age at onset in a fully dominant fashion. Neurology 2012; 79: 952-953.

52. Adam S, Wiggins $S$, Whyte $P$ et al: Five year study of prenatal testing for Huntington's disease: demand, attitudes, and psychological assessment. Journal of medical genetics 1993; 30: 549-556.

53. Downing NR, Williams JK, Leserman AL, Paulsen JS: Couples' Coping in Prodromal Huntington Disease: A Mixed Methods Study. Journal of genetic counseling 2012; 21(5):662-670.

54. Quaid KA, Sims SL, Swenson MM et al: Living at risk: concealing risk and preserving hope in Huntington disease. Journal of genetic counseling 2008; 17: 117-128.

55. Abu-Musa AA, Nassar AH, Usta IM: Attitude of women with IVF and spontaneous pregnancies towards prenatal screening. Human reproduction 2008; 23: 2438-2443.

56. Borkenhagen A, Brahler E, Wisch S, Stobel-Richter Y, Strauss B, Kentenich H: Attitudes of German infertile couples towards preimplantation genetic diagnosis for different uses: a comparison to international studies. Human reproduction 2007; 22: 2051-2057.

57. Hui PW, Lam YH, Chen $M$ et al: Attitude of at-risk subjects towards preimplantation genetic diagnosis of alpha- and beta-thalassaemias in Hong Kong. Prenatal diagnosis 2002; 22: 508-511.

58. Miedzybrodzka Z, Templeton A, Dean J, Haites N, Mollison J, Smith N: Preimplantation diagnosis or chorionic villus biopsy? Women's attitudes and preferences. Human reproduction 1993; 8: 2192-2196.

59. Sermon $\mathrm{K}$, de Rijcke $\mathrm{M}$, Lissens $\mathrm{W}$ et al: Preimplantation genetic diagnosis for Huntington's disease with exclusion testing. European Journal of Human Genetics 2002; 10: 591-598.

60. Alkuraya FS, Kilani RA: Attitude of Saudi families affected with hemoglobinopathies towards prenatal screening and abortion and the influence of religious ruling (Fatwa). Prenatal diagnosis 2001; 21: 448-451.

61. Palomba ML, Monni G, Lai R, Cau G, Olla G, Cao A: Psychological implications and acceptability of preimplantation diagnosis. Human reproduction 1994; 9: 360-362.

62. Kessler S, Field T, Worth L, Mosbarger H: Attitudes of persons at risk for Huntington disease toward predictive testing. American Journal of Medical Genetics 1987; 26: 259270.

63. Meissen GJ, Berchek RL: Intended use of predictive testing by those at risk for Huntington disease. American Journal of Medical Genetics 1987; 26: 283-293.

64. Craufurd D, Dodge A, Kerzin-Storrar L, Harris R: Uptake of presymptomatic predictive testing for Huntington's disease. Lancet 1989; 2: 603-605.

65. Hershberger PE, Pierce PF: Conceptualizing couples' decision making in PGD: emerging cognitive, emotional, and moral dimensions. Patient education and counseling 2010; 81: 53-62. 
66. Klitzman R, Thorne D, Williamson J, Marder K: The roles of family members, health care workers, and others in decision-making processes about genetic testing among individuals at risk for Huntington disease. Genetics in Medicine 2007; 9: 358-371.

67. Scully JL, Porz R, Rehmann-Sutter C: 'You don't make genetic test decisions from one day to the next'--using time to preserve moral space. Bioethics 2007; 21: 208-217.

68. Semaka A, Balneaves LG, Hayden MR: "Grasping the Grey": Patient Understanding and Interpretation of an Intermediate Allele Predictive Test Result for Huntington Disease. Journal of genetic counseling 2013; 22(2):200-217.

69. Evers-Kiebooms G, Decruyenaere M: Predictive testing for Huntington's disease: a challenge for persons at risk and for professionals. Patient education and counseling 1998; 35: 15-26.

70. Slaughter JR, Martens MP, Slaughter KA: Depression and Huntington's disease: prevalence, clinical manifestations, etiology, and treatment. Central nervous system spectrums 2001; 6: 306-326.

71. Tibben A, Niermeijer MF, Roos RA et al: Understanding the low uptake of presymptomatic DNA testing for Huntington's disease. Lancet 1992; 340: 1416.

72. Quaid KA: Presymptomatic testing for Huntington disease in the United States. American journal of human genetics 1993; 53: 785-787.

73. van der Steenstraten IM, Tibben A, Roos RA, van de Kamp JJ, Niermeijer MF: Predictive testing for Huntington disease: nonparticipants compared with participants in the Dutch program. American journal of human genetics 1994; 55: 618-625.

74. Quaid KA, Morris M: Reluctance to undergo predictive testing: the case of Huntington disease. American Journal of Medical Genetics 1993; 45: 41-45.

75. Rawlins M: Huntington's disease out of the closet? Lancet 2010; 376: 1372-1373.

76. Spinney L: Uncovering the true prevalence of Huntington's disease. Lancet neurology 2010; 9: 760-761.

77. Kremer B, Goldberg P, Andrew SE et al: A worldwide study of the Huntington's disease mutation. The sensitivity and specificity of measuring CAG repeats. The New England journal of medicine 1994; 330: 1401-1406.

78. Maat-Kievit $\mathrm{A}$, Losekoot $\mathrm{M}$, van den Boer-van den Berg $\mathrm{H}$ et al: New problems in testing for Huntington's disease: the issue of intermediate and reduced penetrance alleles. Journal of medical genetics 2001; 38: E12.

79. Semaka A, Creighton S, Warby S, Hayden MR: Predictive testing for Huntington disease: interpretation and significance of intermediate alleles. Clinical genetics 2006; 70: 283294.

80. Sequeiros J, Ramos EM, Cerqueira J et al: Large normal and reduced penetrance alleles in Huntington disease: instability in families and frequency at the laboratory, at the clinic and in the population. Clinical genetics 2010; 78: 381-387.

81. Goldberg YP, Kremer B, Andrew SE et al: Molecular analysis of new mutations for Huntington's disease: intermediate alleles and sex of origin effects. Nature genetics 1993; 5: 174-179. 
82. Ramos-Arroyo MA, Moreno S, Valiente A: Incidence and mutation rates of Huntington's disease in Spain: experience of 9 years of direct genetic testing. Journal of neurology, neurosurgery, and psychiatry 2005; 76: 337-342.

83. Conneally PM: Huntington disease: genetics and epidemiology. American journal of human genetics 1984; 36: 506-526.

84. Tassicker RJ, Teltscher B, Trembath MK et al: Problems assessing uptake of Huntington disease predictive testing and a proposed solution. European Journal of Human Genetics 2009; 17: 66-70.

85. Maat-Kievit A, Vegter-van der Vlis $M$, Zoeteweij $M$ et al: Experience in prenatal testing for Huntington's disease in The Netherlands: procedures, results and guidelines (19871997). Prenatal diagnosis 1999; 19: 450-457.

86. Decruyenaere M, Evers-Kiebooms G, Boogaerts A et al: Non-participation in predictive testing for Huntington's disease: individual decision-making, personality and avoidant behaviour in the family. European Journal of Human Genetics 1997; 5: 351-363.

87. Richards F: Couples' experiences of predictive testing and living with the risk or reality of Huntington disease: a qualitative study. American journal of medical genetics 2004; 126A: 170-182.

88. Tibben A, Frets PG, van de Kamp JJ et al: On attitudes and appreciation 6 months after predictive DNA testing for Huntington disease in the Dutch program. American journal of medical genetics 1993; 48: 103-111.

89. Bustamante-Aragones A, Trujillo-Tiebas MJ, Gallego-Merlo J et al: Prenatal diagnosis of Huntington disease in maternal plasma: direct and indirect study. European Journal of Neurology 2008; 15: 1338-1344.

90. Gonzalez-Gonzalez MC, Garcia-Hoyos M, Trujillo-Tiebas MJ et al: Improvement in strategies for the non-invasive prenatal diagnosis of Huntington disease. Journal of assisted reproduction and genetics 2008; 25: 477-481.

91. Alfirevic Z, Tabor A: Pregnancy loss rates after midtrimester amniocentesis. Obstetrics and gynecology 2007; 109: 1203-1204; author reply 1204.

92. Wapner RJ, Evans MI, Platt LD: Pregnancy loss rates after midtrimester amniocentesis. Obstetrics and gynecology 2007; 109: 780; author reply 780-781.

93. Smith L: Pregnancy loss rates after midtrimester amniocentesis. Obstetrics and gynecology 2007; 109: 452; author reply 452-453.

94. Greenberg J: Huntington disease: prenatal screening for late onset disease. Journal of medical ethics 1993; 19: 121. 


\section{Summary}




\section{SUMMARY}

This thesis describes the reproductive options for couples at risk of transmitting Huntington's disease (HD) to their offspring. Carriers of a CAG expansion in the HTT gene, who want to prevent transmission of HD to their biological child, may opt for prenatal diagnosis (PND) or preimplantation genetic diagnosis (PGD). Individuals at 50\% risk of HD, who prefer not to know their HD carrier status, may opt for exclusion prenatal diagnosis (ePND) or exclusion preimplantation genetic diagnosis (ePGD). Exclusion PGD, however, is not allowed in the Netherlands. Dutch couples requesting ePGD may be referred to the PGD centre in Brussels. The focus of this thesis was to evaluate the use of prenatal diagnosis (PND) and preimplantation genetic diagnosis (PGD) for HD in the Netherlands. Additionally, factors contributing to couples reproductive choices, as well as specific motives for couples opting for exclusion testing were studied.

In chapter 2, an overview is given of prenatal diagnostic testing for HD in the Netherlands between 1998 and 2008 and compared with available data from the period 1987-1997. The use of PND in the Netherlands has remained rather stable since 1996 at about 20 PND tests for HD a year. In the majority of PND tests, the CAG repeat length in the foetal DNA was detected directly, whereas in about $15 \%$ exclusion testing was applied. The estimated uptake of PND was $22 \%$ of CAG expansion carriers ( $\geq 36$ repeats) at reproductive age. In $9 \%$ of direct tests, the prior HD risk for the foetus was $25 \%$. In a small subgroup of $4 \%$ of couples requesting PND, the at-risk parent carried an intermediate allele. A remarkable number (13\%) of HD expansion or $50 \%$ risk pregnancies were continued to term. These pregnancies are generally expected to be terminated, as this is the main reason to perform PND. Moreover, continuation of such a pregnancy may be considered a violation of the future child's right not to know. Speculations were made on possible factors contributing to these continuations: a CAG repeat expansion in the reduced penetrance allele, or the female gender of the at-risk parent.

In chapter 3 an overview is provided of 13 years of experience of PGD for HD at three European PGD centres in Maastricht, Brussels and Strasbourg, between 1995 and 2008. About two-thirds of the 331 couples for intake, requested direct testing and one-third requested exclusion testing (with a preponderance of French couples). At the time of PGD intake, 39\% of women had experienced one or more pregnancies. A history of pregnancy termination after PND was 
observed more frequently in the direct testing group than in the exclusion group. Of the couples who started PGD, 70\% used direct testing, while 30\% used exclusion testing. The delivery rates per oocyte retrieval and per embryo transfer ( $20 \%$ and $25 \%$, respectively) were comparable to international data. We concluded that PGD is a valuable and safe reproductive option for HD carriers and couples at risk of transmitting HD.

Reproductive behaviour of a cohort of couples opting for PND and PGD for HD between 1998 and 2008 is described in chapter 4. Considerably more females than males had their HD expansion confirmed by PT prior to procreation. The majority of couples underwent PND, one-third started PGD, whereas a smaller subgroup used both. Gender differences were observed between some subgroups: for example, significantly more at-risk individuals or CAG expansion carriers were female in the group of couples using PGD primarily (without any previous pregnancy), whereas in couples who used PGD after having experienced a previous pregnancy (irrespective of the outcome), the male partner was most frequently at $50 \% \mathrm{HD}$ risk or CAG expansion carrier.

ePND was used by $16 \%$ of PND-couples, whereas a much smaller proportion of PGD-couples used ePGD (mainly in Belgium). The limited use of ePGD may be attributed to the current legislation in the Netherlands, where ePGD is not allowed. Couples opting for PGD after a previous pregnancy, more frequently had a history of a pregnancy termination, compared with couples opting for PND after a previous pregnancy. We concluded that couples reconsider their choices in every subsequent pregnancy, based on their previous experience, personal beliefs, and the gender of the at-risk partner. Overall, the chances of favourable outcome were in favour of PND. However, one should not underestimate the disadvantages of PND: the stressful period until the results are available and the impact of termination of an affected pregnancy. Continued affected or $50 \%$ risk pregnancies may be considered another drawback of PND. More study is needed to identify possible motives for continuing these pregnancies and to elucidate the long-term impact on the child and the parents involved.

Couples' motives and profiles for choosing PGD were subject of the study described in chapter 5. A large prospective cohort of 264 couples referred for PGD (for various indications, not only HD) was interviewed semi-structurally after intake, and follow-up data were collected after 6-8 years. Personal experiences and reproductive history were more important determinants of 
eventual PGD use than the mode of inheritance or the expected clinical impact of the disorder.

The study described in chapter 6 aimed to provide a better understanding of couples' motives for choosing ePND or ePGD. This qualitative retrospective interview study showed that couples' moral reservations regarding termination of pregnancy or discarding healthy embryos were counterbalanced by the wish to protect their future child against HD. Of the couples who had terminated pregnancies with a 50\% HD risk, none showed regret. The wish to avoid (another) TOP was the main reason to start ePGD in the first place, or to shift from ePND to an alternative like ePGD. We conclude that ePND and ePGD are acceptable reproductive options for a specific group of counsellees. To guarantee sound standards of care, it is imperative that candidate couples be given in-depth non-directive counselling about all possible scenarios, and adequate professional and psychological support prior to, during and after ePND/ePGD.

\section{Conclusions}

The couples involved in our studies were very well capable of making their individual reproductive choices and deciding between either PND or PGD or exclusion testing and of dealing with the consequences. Their decision making was shaped by their moral considerations, expectations and experiences, the strength of the wish to have a child, and the information on, or availability of options. Altogether, the benefits and disadvantages, and moral considerations concerning reproductive decisions should be weighed by the future parents themselves, without the limitations of legislation. 


\section{SAMENVATTING}

In dit proefschrift worden de reproductieve mogelijkheden beschreven voor paren die een hoog risico hebben op het krijgen van de ziekte van Huntington (HD) en die deze aandoening bij hun nakomelingen willen voorkomen. Dragers van een CAG-expansie in het HTT-gen die het doorgeven van HD aan een biologisch eigen kind willen voorkomen, kunnen kiezen voor prenatale diagnostiek (PND) of preïmplantatie genetische diagnostiek (PGD). Voor individuen met $50 \%$ risico op HD die niet geïnformeerd willen worden over hun HD dragerschap status, behoort exclusie prenatale diagnostiek (ePND) of exclusie preïmplantatie genetische diagnostiek (ePGD) tot de mogelijkheden. Exclusie PGD is echter (nog) niet toegestaan in Nederland. Nederlandse paren die ePGD overwegen, worden verwezen naar het PGD-centrum in Brussel. Het doel van het onderzoek, waarvan de resultaten in dit proefschrift worden weergegeven, was het inventariseren van het gebruik van PND en PGD in Nederland. Daarnaast was de vraag welke factoren van invloed zijn op reproductieve keuzes en welke motieven bijdragen aan de keuze voor een exclusietest.

In hoofdstuk 2 wordt een overzicht gegeven van het gebruik van PND voor HD in de periode 1998-2008. Deze gegevens worden vergeleken met beschikbare informatie over de periode 1987-1997. Het gebruik van PND in Nederland is redelijk stabiel sinds 1996 met ongeveer twintig PND-testen per jaar. In de meeste gevallen wordt de CAG repeat-lengte direct bepaald in foetaal DNA. In ongeveer $15 \%$ van de gevallen wordt gebruik gemaakt van ePND. De geschatte uptake van PND bedraagt $22 \%$ van de CAG-expansie-dragers ( $\geq 36$ repeats) in de reproductieve leeftijd.

Bij 9\% van de directe prenatale testen was het a priori risico op HD voor de foetus $25 \%$. In een klein deel (4\%) van de paren met een PND-verzoek, was de risico-ouder drager van een intermediate allel. Een opvallend aantal zwangerschappen (13\%) met een aangetoonde HD-expansie of een 50\%-HDrisico-allel bij de foetus werd gecontinueerd. Er werd gespeculeerd over factoren die mogelijk hebben bijgedragen aan het continueren van deze zwangerschappen: een CAG-expansie met een verminderde penetrantie, of het vrouwelijk geslacht van de risico dragende ouder.

Hoofdstuk 3 biedt een overzicht van 13 jaar ervaring met PGD voor HD in drie Europese PGD-centra in Maastricht, Brussel en Straatburg tussen 1995 en 2008. Ongeveer tweederde van de 331 paren voor intake in verband met PGD 
voor HD, vroeg een directe test en een derde verzocht om een exclusietest (met een oververtegenwoordiging van Franse paren). Op het moment van de PGD intake was $39 \%$ van de vrouwen al een of meerdere malen zwanger geweest. In de direct test-groep hadden meer paren een eerdere zwangerschapsafbreking ondergaan dan in de exclusie PGD groep. Van de paren die startten met PGD, maakte $70 \%$ gebruik van een direct test en $30 \%$ van ePGD. Het percentage geboren kinderen per eicelpunctie en per embryo terugplaatsing (respectievelijk $20 \%$ en $25 \%$ ) was vergelijkbaar met internationale gegevens. Wij concludeerden dat PGD een waardevolle en veilige optie is voor paren met een hoog risico op transmissie van HD naar hun kinderen.

De reproductieve keuzes van een cohort van paren die gebruik maakten van PND en/of PGD voor HD tussen 1998 en 2008 werden beschreven in hoofdstuk 4. Aanzienlijk meer vrouwen dan mannen $(85,4 \%$ versus $69,9 \%)$ hadden een presymptomatische test (PT) ondergaan voor de eerste zwangerschap of voor de start van de PGD-behandeling. Het merendeel van de paren $(81,5 \%)$ onderging PND, een derde startte met PGD. Van deze laatste groep maakte de helft gebruik van beide opties. We vonden diverse verschillen tussen mannen en vrouwen in de verschillende subgroepen: in de groep met een blanco reproductieve voorgeschiedenis die primair koos voor PGD, was de at-risk- of CAG-expansiedragende partner significant vaker vrouw, terwijl mannelijke CAG-expansiedragers en at-risk-mannen oververtegenwoordigd waren in de groep die 'secundair' PGD startte, dat wil zeggen na een eerdere zwangerschap (onafhankelijk van de uitkomst).

Zestien procent van de paren in de PND-groep maakte gebruik van exclusiePND, terwijl een veel kleiner deel van de paren in de PGD groep gebruik maakte van exclusie-PGD (voornamelijk in Belgie). Het beperkte gebruik van ePGD door Nederlandse paren is waarschijnlijk (mede) veroorzaakt door de huidige regelgeving in Nederland, waar ePGD niet is toegestaan. Paren die in tweede instantie startten met PGD (na een eerdere zwangerschap), hadden vaker een zwangerschapsafbreking in de voorgeschiedenis vergeleken met paren die in tweede instantie voor PND kozen.

We concludeerden dat paren hun keuze heroverwegen na elke achtereenvolgende zwangerschap op basis van hun voorgaande ervaringen en persoonlijke overtuiging. Ook het geslacht van de $\mathrm{HD}$ (risico)-dragende partner speelde een rol bij de keuzes. Over het algemeen was de kans op een goede uitkomst (dat wil zeggen een levend geboren kind zonder de aanleg voor HD) 
hoger bij PND. Echter, de nadelen van PND: de stress tot de testuitslag bekend is en de impact van het afbreken van een zwangerschap bij een ongunstige uitslag van PND voor HD, moeten niet worden onderschat. Ook het continueren van zwangerschappen van een foetus met een CAG-expansie of een $50 \%$-risisco-allel kan gezien worden als een relatief nadeel van PND, omdat het recht op niet weten (van in dit geval de belastende informatie over dragerschap van een ongeneeslijke ziekte) al voor de geboorte van het kind wordt geschonden. Een presymptomatische test voor HD wordt in de regel alleen uitgevoerd bij volwassenen die zelf een weloverwogen keuze maken om deze test te ondergaan, onafhankelijk van anderen. Meer onderzoek is nodig om de motieven voor het continueren van deze zwangerschappen in kaart te brengen en om een beeld te krijgen van de langetermijnconsequenties voor het kind en de betrokken ouders.

De motieven en profielen van paren die kiezen voor PGD waren het onderwerp van studie in hoofdstuk 5. Bij een cohort van 264 paren, allen verwezen voor PGD (voor verschillende indicaties, niet alleen HD), werd direct na de intake een semigestructureerd interview afgenomen. Zes tot acht jaar later werd vervolg-informatie verzameld. Persoonlijke ervaringen en de reproductieve voorgeschiedenis van de paren waren belangrijkere determinanten voor het eventuele PGD gebruik dan de manier van overerving en de verwachte ernst van het ziektebeeld.

Het onderzoek beschreven in hoofdstuk 6 had als doel de motieven voor exclusie-PND en exclusie-PGD beter te leren begrijpen. Dit kwalitatieve retrospectieve onderzoek liet zien, dat morele bezwaren tegen een zwangerschapsafbreking (van een mogelijk gezond kind) of het afkeuren van (mogelijk) gezonde embryo's in het kader van ePGD, voor de geïnterviewde paren ondergeschikt waren aan de wens om een toekomstig kind te beschermen tegen HD. Geen van de paren die een zwangerschap hadden afgebroken omdat de foetus een $50 \%$-risico-allel had, betuigde spijt achteraf. De wens om (nog) een zwangerschapsafbreking te voorkomen vormde de voornaamste reden om primair te kiezen voor ePGD of om na ePND te kiezen voor ePGD. We concluderen dat zowel ePND als ePGD aanvaardbare reproductieve opties zijn voor een specifieke groep van paren die de geboorte van een kind met HD willen voorkomen, maar tegelijkertijd niet geïnformeerd willen worden over hun eigen CAG-repeat-status. Om hoogwaardige zorg te garanderen, is uitgebreide non-directieve counseling van kandidaat-koppels over alle mogelijke scenario's onontbeerlijk. Daarnaast moet adequate 
professionele en psychologische begeleiding beschikbaar zijn vóór, tijdens en na ePND/ePGD.

\section{Conclusies}

De paren die deelnamen aan de verschillende studies waren zeer goed in staat om zelf weloverwogen reproductieve beslissingen te nemen bij hun keuze tussen PND of PGD of een eventuele exclusie-test, en om de gevolgen te dragen van de gemaakte keuzes. Morele overwegingen, verwachtingen en ervaringen, en de sterkte van de kinderwens waren van invloed op de gemaakte keuzes. Daarnaast speelde de informatie over en beschikbaarheid van de reproductieve opties een belangrijke rol bij het gebruik van de verschillende opties. Al met al moeten de voor- en nadelen en de morele aspecten van de reproductieve keuzes tegen elkaar worden afgewogen door de toekomstige ouders zelf, zonder beperkende regelgeving. 


\section{List of co-authors and contributors and their affiliations}

C.M. Aalfs, Department of Clinical Genetics, Amsterdam Medical Centre

R.D.M. Belfroid, Centre for Human and Clinical Genetics, Leiden University Medical Centre

M.J. van Belzen, Centre for Human and Clinical Genetics, Leiden University Medical Centre

E.K. Bijlsma, Centre for Human and Clinical Genetics, Leiden University Medical Centre

I. van der Burgt, Department of Clinical Genetics, Radboud University Medical Centre, Nijmegen

C.E.M. de Die-Smulders, Department of Clinical Genetics, Maastricht University Medical Centre; GROW, School for Oncology and Developmental Biology, Maastricht University

J.C.F.M. Dreesen, Department of Clinical Genetics, Maastricht University Medical Centre

M. Elting, Department of Clinical Genetics, VU Medical Centre, Amsterdam

J.L.H. Evers, Department of Obstetrics and Gynaecology, Maastricht University Medical Centre; GROW, School for Oncology and Developmental Biology, Maastricht University

J.P.M. Geraedts, Department of Clinical Genetics, Maastricht University Medical Centre; GROW, School for Oncology and Developmental Biology, Maastricht University

M. Gielen, Department of Complex Genetics, Cluster of Genetics and Cell Biology, NUTRIM School for Nutrition and Toxicology Research Institute Maastricht, Maastricht University Medical Centre

P.F. Ippel, Department of Medical Genetics, University Medical Centre Utrecht

P.A.M. de Koning Gans, Centre for Human and Clinical Genetics, Leiden University Medical Centre

M. Losekoot, Centre for Human and Clinical Genetics, Leiden University Medical Centre

R. Lulofs, Department of Primary Health Care, Maastricht University

M.C. van Maarle, Department of Clinical Genetics, Amsterdam Medical Centre 
J.A. Maat-Kievit, Department of Clinical Genetics, Erasmus Medical Centre, Rotterdam

C. Moutou, Service de Biologie de la Reproduction, Centre Hospitalier Universitaire, Strasbourg, France

I. Liebaers, Centre for Medical Genetics, University Hospital Brussels, Belgium

L. van Osch, Department of Clinical Genetics, Maastricht University Medical Centre; Department of Health Promotion, Maastricht University

M. de Rademaeker, Centre for Medical Genetics, University Hospital Brussels, Belgium

M. de Rycke, Centre for Medical Genetics, University Hospital Brussels, Belgium

R.A.C. Roos, Department of Neurology, Leiden University Medical Centre

R.P. Stulp, Department of Genetics, University of Groningen, University Medical Centre Groningen

A. Tibben, Centre for Human and Clinical Genetics, Leiden University Medical Centre; Department of Clinical Genetics, Erasmus Medical Centre Rotterdam

S. Vermeer, Department of Clinical Genetics, Radboud University Medical Centre, Nijmegen

C.C. Verschuuren-Bemelmans, Department of Genetics, University of Groningen, University Medical Centre Groningen

S.Viville, Service de Biologie de la Reproduction, Centre Hospitalier Universitaire, Strasbourg, France; Institut de Génétique et de Biologie Moléculaire et Cellulaire (IGBMC), Institut National de Santé et de Recherche Médicale (INSERM) U964/Centre National de Recherche Scientifique (CNRS), Université de Strasbourg, France

G.M.W.R. de Wert, GROW, Research school for Oncology and Developmental Biology, Maastricht University; Department of Health, Ethics and Society, Faculty of Health, Medicine and Life Sciences, Maastricht University 


\section{LIST OF PUBLICATIONS}

The uptake and outcome of prenatal and preimplantation genetic diagnosis for Huntington's disease in the Netherlands (1998-2008). van Rij MC, de Koning Gans PAM, van Belzen MJ, Roos RAC, Geraedts JPM, de Rademaeker M, Bijlsma EK, de DieSmulders CEM. Clinical Genetics. 2013: Jan 25. doi: 10.1111/cge.12089. [Epub ahead of print]

Prenatal testing for Huntington's disease in The Netherlands from 1998 to 2008. van Rij MC, de Koning Gans PAM, Aalfs CM, Elting M, Ippel PF, Maat- Kievit JA, Vermeer S, Verschuuren- Bemelmans CC, van Belzen MJ, Belfroid RDM, Losekoot M, Geraedts JPM, Roos RAC, Tibben A, de Die-Smulders CEM, Bijlsma EK. Clinical Genetics 2013: Jan 25. doi: 10.1111/cge.12090. [Epub ahead of print]

Evaluation of exclusion prenatal and exclusion preimplantation genetic diagnosis for Huntington's disease in the Netherlands. van Rij MC, de Die-Smulders CE, Bijlsma EK, de Wert GM, Geraedts JP, Roos RA, Tibben A. Clinical Genetics 2013: Feb;83(2):118124.

The experience of three European preimplantation genetic diagnosis centres on PGD for Huntington disease. van Rij MC, de Rademaeker M, Moutou C, Dreesen J, de Rycke M, Liebaers I, Geraedts JPM, de Die CEM, Viville S. European Journal of Human Genetics 2012: Apr;20(4):368-75.

Profiles and motives for preimplantation genetic diagnosis (PGD), A prospective cohort study on couples referred for PGD in the Netherlands. van Rij MC, Gielen M, Lulofs R, Evers JL, van Osch L, Muntjewerff N, Geraedts JP, de Die-Smulders CE. Human Reproduction 2011: Jul;26(7):1826-35.

ESHRE PGD Consortium data collection X: cycles from January to December 2007 with pregnancy follow-up to October 2008. Harper JC, Coonen E, de Rycke M, Harton G, Moutou C, Pehlivan J, Traeger-Synodinos J, van Rij MC, Goossens V. Human Reproduction 2010: Nov;25(11):2685-707.

Clinical aspects of preimplantation genetic diagnosis. Christine de Die-Smulders, Maartje van Rij, Johannes Evers. Uit: Preimplantation Genetic Diagnosis, Edited by J. Harper; Cambridge University Press 2009: 151-165.

ESHRE PGD Consortium data collection IX: cycles from January to December 2006 with pregnancy follow-up to October 2007. Goossens V, Harton G, Moutou C, Traeger-Synodinos J, van Rij MC, Harper JC. Human Reproduction 2009: Aug;24(8):1786-810. 
Preïmplantatie genetische diagnostiek bij erfelijke borstkanker. van Rij MC, de DieSmulders CEM. Oncologica sept 2008.

ESHRE PGD consortium data collection VII: cycles from January to December 2004 with pregnancy follow-up to October 2005. Harper JC, de Die-Smulders CEM, Goossens V, Harton G, Moutou C, Repping S, Scriven PN, SenGupta S, TraegerSynodinos J, van Rij MC, Viville S, Wilton L, Sermon KD. Human Reproduction 2008: Apr;23(4): 741-55.

Posttraumatic stress disorder after pre-eclampsia: an exploratory study. Engelhard IM, van Rij MC, Boullart I, Ekhart TH, Spaanderman ME, van den Hout MA, Peeters LL. General Hospital of Psychiatry 2002: Jul-Aug;24(4): 260-4. 


\section{DANKWOORD}

Graag wil ik iedereen bedanken die op enige wijze heeft bijgedragen aan de totstandkoming van dit proefschrift!

Mijn dank gaat in het bijzonder uit naar alle paren die indirect of direct hebben bijgedragen aan het onderzoek.

Daarnaast wil ik mijn promotoren, copromotor en andere begeleiders danken voor hun bijdragen. Allereerst Christine, veel dank voor je begeleiding en je onvoorwaardelijke steun op carrièregebied. In het laatste jaar ben je van copromotor bevorderd tot promotor. Ik ben bijzonder verheugd jouw eerste promovendus te zijn! En ik hoop in de toekomst nog eens samen te kunnen werken. Joep, het is een grote eer om jouw laatste promovendus te mogen zijn. Ik heb genoten van de brainstormsessies en jouw vaak verrassende input. Veel heb ik geleerd van je praktische benadering en je strategische visie. Professor Roos, zonder uw blijk van vertrouwen had dit proefschrift nog vele jaren op zich moeten laten wachten. De tijd die u mij gunde om in alle vrijheid vanuit Leiden mijn van oorsprong Maastrichtse onderzoek voort te zetten, was onontbeerlijk voor het voltooien van dit werk. Emilia, buitengewoon veel dank voor de prettige begeleiding tijdens de Leidse periode van het onderzoek. Dankzij jouw morele ondersteuning heb ik me niet al te zeer laten ontmoedigen na teleurstellingen en steeds weer kracht gevonden om door te gaan. Aad, jouw rustige stijl van begeleiden gaf me het vertrouwen de voor mij nieuwe kwalitatieve onderzoeksmethode snel uit te voeren en af te ronden, waardoor mijn strakke deadlines haalbaar bleken. Marij, veel dank voor het meedenken aan hoofdstuk 5. Het was een prettige samenwerking. Dankzij jouw inzet en geduld lukte het om mijn niet altijd even gestructureerde gedachtelijnen en redeneringen te concretiseren: de voorwaarde om te komen tot een overzichtelijk geheel.

Pia, veel dank voor het op locatie verzamelen van een groot deel van de prenatale data. Het combineren van onze databases heeft nog meer informatie opgeleverd. En Martine, bedankt voor het beantwoorden van mijn query, zeer nuttig voor mijn berekeningen. Céline, many thanks for cooperating in the "BruMaStra" study. Due to the distance, it took us quite some time, but finally we succeeded. Marjan, dank voor de prettige samenwerking via de mail en telefonisch, en voor de Brusselse input bij het BruMaStra-artikel. Ook alle andere co-auteurs, hartelijk dank. 
Collega's op de afdeling klinische genetica in het LUMC, bedankt dat ik ondanks het ruimtegebrek op de afdeling, toch bijna twee jaar een bureau heb mogen gebruiken om verder te werken aan mijn onderzoek. Zonder deze werkplek en de afleiding tijdens de lunches was het een buitengewoon eenzaam promotietraject geworden. En dank dat ik bij jullie eindelijk mag beginnen aan de volgende stap in mijn carrière: de opleiding tot klinisch geneticus!

Oud-kamergenoten, ik heb er heel wat 'versleten', Nienke, Meyke, Sandra, Jessica, Sethareh, Linda, en - te veel om op te noemen - lunchgenoten, dank voor het gezelschap in de soms toch eenzame tijden van onderzoeker, en voor het geduldig uitzitten van mijn klaagzangen en lofredes met betrekking tot het onderzoek en andere levensperikelen.

Joel, Suzanne, Katrien, Petra, Sander en Fem, dank voor jullie vriendschap en medeleven.

Dietje, mijn paranimf, veel dank voor je onuitputtelijke inzet, de nauwgezetheid waarmee je je door mijn proefschrift hebt gewerkt om de laatste puntjes op de i te zetten, je beschikbaarheid voor mijn vragen, je advies, je medeleven en je vriendschap. Ik zie uit naar onze volgende samenwerking weer als collegae! Kim, veel dank voor je vriendschap, en de mooie ervaring van het samen zwanger zijn van onze eerste. De bijzondere speling van het lot, waardoor jij me precies zeven jaar geleden belde met het slechte nieuws over Beernd ... Ik ben blij dat ook jij mijn paranimf wil zijn. En je hebt gelijk, misschien heb ik gewoon iets met 13 juni ...

Beernd, je enthousiasme, je vertrouwen, je onuitputtelijke nieuwsgierigheid en belezenheid, vormden een belangrijke inspiratiebron voor mijn intellectuele verkenningen. Ik heb heel veel van je geleerd. Het spijt me dat het leven zo heeft moeten lopen. En je ouders en zus: Joop, Marlies en Sara, dank voor de aanstekelijke liefde voor muziek en schoonheid, voor het warme thuis. De juiste voedingsbodem om kracht en enthousiasme uit te putten om door te gaan met het leven en er wat van te maken.

Ivon, ik heb altijd veel bewondering gehad voor de kracht en overtuiging waarmee jij je leven en je moederschap hebt gecomponeerd. We delen eenzelfde fascinatie voor vrouwenlijke oerkrachten, zwangerschap en moederschap. Ik geniet van de beeldende soms plastische manier waarop jij deze liefde uitdraagt. En ik ben blij dat ik je weer heb gevonden en dat je mee wilde werken aan de omslag van mijn boekje. 
Lieve papa en mama, veel dank voor jullie onvoorwaardelijke steun, de betrokkenheid en het medeleven. Dank voor het meelezen bij sommige delen van mijn tekst.

Lieve Ariëtte, Reinier en Annica, uit hetzelfde nest, verschillend als we zijn, hebben we een hele hoop gemeen. Dank voor het delen van ons leven, en voor jullie steun en toeverlaat. En Annica, dank voor je praktische tips bij de afwerking van mijn boekje.

Lieve Evert en Refka, ik hoop dat ik de komende tijd een vrolijker moeder zal zijn, en dat we nog heel veel mooie herinneringen kunnen maken samen als gezin. En Refka, ik hoop dat je me kunt vergeven dat ik jouw vierde verjaardag gebruik voor mijn promotie!

Lieve Hany, jij was het die me eind 2006 wees op de vacature: Artspreimplantatie genetische diagnostiek in Maastricht, met daarin het zinnetje: "het verrichten van promotieonderzoek behoort tot de mogelijkheden".

Halsoverkop verhuisden we van Leiden naar de zolder van mijn ouders in Heerlen, en even later, net zwanger van Evert, naar Maastricht, waar jij (na amper een jaar in Nederland) opnieuw moest inburgeren. Helaas bleek het niet gemakkelijk de patiëntenzorg te combineren met onderzoek. De wil was er in ieder geval wel. Het onderwerp kreeg geleidelijk meer vorm. In 2010 kreeg jij opeens een baan in Leiden, en ik kwam met de kinderen en mijn onderzoek weer achter jou aan. Lieve Hany, je weet dat ik door mijn eigen werkkansen niet altijd even enthousiast was over onze verhuizing terug naar Leiden. Maar gelukkig heeft het uiteindelijk voor ons beiden goed uitgepakt. Nu kunnen we met een gerust hart en een mooi aandenken uit Maastricht (twee prachtkinderen en een promotie) onze Maastrichtse tijd echt afsluiten. Ik ben heel blij dat jij al die tijd naast me hebt gestaan, ook al was ik wel erg veel met mijn eigen dingen bezig.

De komende jaren bouwen we aan ons leven in Leiden! 



\section{CURRICULUM VITAE}

Maartje van Rij werd geboren op 30 oktober 1977 te Heerlen. Ze behaalde haar gymnasiumdiploma aan het Grotiuscollege te Heerlen in 1996. Datzelfde jaar startte zij met haar geneeskundestudie aan de Universiteit Maastricht. Van 1997 tot 2000 deed ze wetenschappelijk onderzoek naar de emotionele gevolgen van pre-eclampsie bij de afdeling gynaecologie van het Maastricht Universitair Medisch Centrum (MUMC+). Haar wetenschapsstage 'Gender differences in myocardial infarction' liep ze aan het Suez Canal University Hospital in Ismailia (Egypte). Aan het eind van haar studie (2003) woonde ze en jaar in Egypte, waar ze haar laatste keuzestage liep op de polikliniek voor gezinsplanning in een gezondheidscentrum in Mustakbal City. Van maart 2004 tot juni 2005 werkte zij als arts-assistent gynaecologie in het Diaconessenhuis te Leiden. Aansluitend werkte zij als arts-assistent klinische genetica in het Leids Universitair Medisch Centrum. In december 2006 begon zij aan een baan als arts preïmplantatie genetische diagnostiek in het MUMC+. Naast deze functie startte zij in het jaar 2009 met het promotieonderzoek 'Reproductive options for couples at risk of Huntington's disease' dat leidde tot dit proefschrift. Eind 2010 verhuisde zij met haar gezin naar Leiden, waar zij het onderzoek voortzette. Vanaf mei 2011 werkte zij gedurende 5 maanden als arts assistent Klinische genetica in het VU Medisch Centrum. Met ingang van december 2011 werd ze in dienst van de afdeling neurologie in het LUMC in de gelegenheid gesteld in een jaar tijd het promotie-onderzoek af te ronden. In april 2013 startte zij met de opleiding tot klinisch geneticus in het LUMC. 
